Concepção de um software de geometria interativa utilizando interfaces gestuais para dispositivos móveis

Helena Macedo Reis 


\title{
Concepção de um software de geometria interativa utilizando interfaces gestuais para dispositivos móveis
}

\author{
Helena Macedo Reis
}

Orientador: Prof. Dr. Seiji Isotani

Dissertação apresentada ao Instituto de Ciências Matemáticas e de Computação - ICMC-USP, como parte dos requisitos para obtenção do título de Mestre em Ciências - Ciências de Computação e Matemática Computacional. VERSÃO REVISADA 
Ficha catalográfica elaborada pela Biblioteca Prof. Achille Bassi e Seção Técnica de Informática, ICMC/USP, com os dados fornecidos pelo(a) autor(a)

Reis, Helena Macedo
Concepça de um software de geometria interativa
utilizando interfaces gestuais para dispositivos
móveis / Helena Macedo Reis; orientador Seiji
Isotani. -- São Carlos, 2014.
129 p.
Dissertação (Mestrado - Programa de Pós-Graduação
em Ciências de Computaço e Matemática
Computacional) -- Instituto de Ciências Matemáticas
e de Computação, Universidade de São Paulo, 2014.
1. Geometria interativa. 2. Interface gestual.
3eiji, orient. II. Título.
Seotouch. Dóveis. I. Isotani,





\section{Agradecimentos}

Ao meu orientador, Prof. Dr. Seiji Isotani, pela valiosa orientação. Agradeço pela oportunidade de pesquisa e confiança depositada em mim para desenvolver este trabalho. Sempre esteve disposto a ajudar em todos os momentos.

Aos meus pais, Ramílio e Auriete, pelo seu amor incondicional e apoio em todos os momentos da minha vida. Agradeço pelo esforço, carinho e todo o sacríficio que fizeram para que eu tivesse esta oportunidade. Ambos são pessoas admiráveis e que, sem dúvida, me tornam uma pessoa cada vez melhor todos os dias.

Aos meus amigos Paul Andrew Griffiths, Simone Borges e Vinicius Durelli, que me ajudaram com artigos, apresentações e gráficos.

Aos meus amigos que participaram dos testes de usabilidade, Alexandre Defelicibus, Luis Fernando Moro, Flor Karina, Draylson Micael, Olibário Neto, Laís Zagatt.

A todas as pessoas que, direta ou indiretamente contribuíram com carinho e atenção durante a construção desse trabalho.

Ao Conselho Nacional de Desenvolvimento Científico e Tecnológico (CNPq) pelo apoio financeiro (processo 133843/2012-2) durante o desenvolvimento desta dissertação. 


\section{Resumo}

Os softwares de Geometria Interativa (GI) foram desenvolvidos com o objetivo de possibilitar aos estudantes explorarem a geometria por meio do computador, permitindo a construção e manipulação de objetos geométricos, como retas, pontos e circunferências. Por meio da interface destes softwares, os estudantes são capazes de compreender e manipular os objetos geométricos, podendo influenciar na aprendizagem da geometria. Para Laborde (2007), os desenvolvedores de softwares de GI deveriam se preocupar com os aspectos pedagógicos e com o design da interface, pois, as interfaces indevidamente projetadas podem causar frustrações aos alunos, fazendo com que sintam dificuldade em utilizar o software e terminando por não direcionar o aprendizado da geometria. Apesar desta importância, há poucos estudos que investigam metodologias que relacionam os conceitos pedagógicos e os recursos computacionais. Além disto, há uma carência de pesquisas sobre diferentes tipos de interações disponíveis para a criação de interfaces para softwares de GI. A fim de preencher esta lacuna, este trabalho de mestrado tem como objetivo investigar metodologias para o desenvolvimento de gestos para interfaces gestuais em softwares de GI. É proposto um novo tipo de interação para estes softwares, com o objetivo de apoiar a aprendizagem da geometria por meio das interfaces gestuais. 


\section{Abstract}

The Interactive Geometry software (IG) were developed with the goal of enabling students to explore geometry through the computer, allowing the construction and manipulation of geometric objects, such as, lines, dots and circles. Through these interfaces software, students are able to understand and manipulate geometric objects, and may influence their learning of geometry. To Laborde (2007) , IG developers should worry about the pedagogic aspects and the design of the interface, because the improperly designed interfaces can make students to become frustrated, making them feel difficult to use the software and not focusing in the learning of geometry itself. Despite this importance, there are few studies investigating the pedagogical methodologies that relate concepts and computational resources. Furthermore, there is a lack of research about different types of interactions available for creating interfaces for IG software. In order to fill this gap, this master thesis aims to investigate methodologies for the development of gestures for gestural interfaces in GI software. It is proposed a new type of interaction for these software, aiming to support the learning of geometry. 


\section{Sumário}

1 Introdução 1

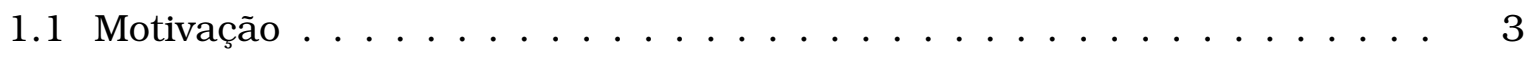

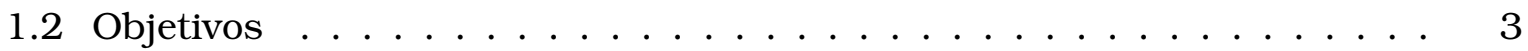

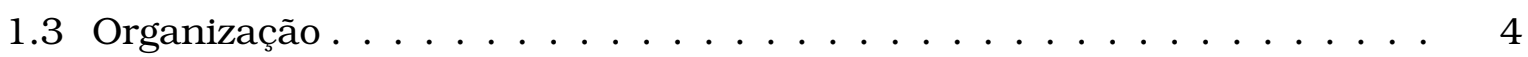

2 Ensino da Geometria e Interfaces Gestuais 5

2.1 Softwares de Geometria Interativa . . . . . . . . . . . . . . . 5

2.2 Ambientes de Geometria Interativa . . . . . . . . . . . 8

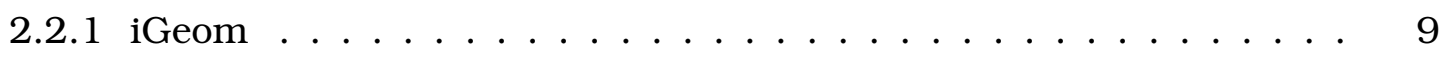

2.2 .2 Cinderella . . . . . . . . . . . . . . . . 10

2.2 .3 C.a.R . . . . . . . . . . . . . . 10

2.2 .4 GeoGebra . . . . . . . . . . . . . . . 10

2.2 .5 Sketchometry . . . . . . . . . . . . . . . . 11

2.2 .6 Geometry Pad . . . . . . . . . . . . . . . . . 12

2.3 Interfaces dos Softwares de GI . . . . . . . . . . . . . . . . 13

2.4 Interfaces de Toque . . . . . . . . . . . . . . . . . 14

2.4.1 Categorias de Interações com Interfaces de Toque $\quad \ldots . .16$

2.4 .2 Tipos de Conjunto de Gestos . . . . . . . . . . . . . . . . 16

2.4.3 Interfaces de Toque em Dispositivos Móveis para Educação . . . . 17

2.5 Avaliação de Interfaces . . . . . . . . . . . . . . . . . . . . 20

2.5.1 Definição de Usabilidade . . . . . . . . . . . . . . . . 21

2.6 Considerações finais . . . . . . . . . . . . . . . . 25

3 Mapeamento Sistemático $\quad 27$

3.1 Processo para Condução de Mapeamento Sistemáticos . . . . . . . . . 28

3.2 Definição de Questões de Pesquisa do Mapeamento Sistemático . . . . . 28

3.3 Busca por Estudos Primários . . . . . . . . . . . . . . 29 
3.4 Triagem dos Estudos Primários . . . . . . . . . . . . . . 30

3.4.1 Critérios de inclusão e exclusão . . . . . . . . . . . . . . . 30

3.4 .2 Processo de triagem . . . . . . . . . . . . . . 31

3.5 Classificação dos artigos . . . . . . . . . . . . . . . . . 32

3.6 Categorização Resultante . . . . . . . . . . . . . . . . . . . . . 32

3.7 Mapeamento dos Estudos Primários e Análise . . . . . . . . . . . . . . . 35

3.7.1 Mapa . . . . . . . . . . . . . . . . . . 40

3.8 Síntese dos estudos do mapeamento . . . . . . . . . . . . . . . . . 42

3.9 Ameaças à Validade . . . . . . . . . . . . . . . . . . . 43

3.10 Considerações finais . . . . . . . . . . . . . . . . . . . . 44

4 Análise de Usabilidade dos softwares de GI para Tablets 47

4.1 Avaliação Heurística . . . . . . . . . . . . . . . . . . . . . . . . 48

4.1 .1 Metodologia . . . . . . . . . . . . . . . . . 49

4.1 .2 Resultados da Avaliação Heurística . . . . . . . . . . . . . . . 50

4.1 .3 Análise dos Dados . . . . . . . . . . . . . . . . . 53

4.2 Questionários . . . . . . . . . . . . . . . . . . 59

4.3 Discussão . . . . . . . . . . . . . . . . . . . 6 61

4.4 Ameaças à Validade . . . . . . . . . . . . . . . . . . . 62

4.5 Considerações finais . . . . . . . . . . . . . . . . . . . 62

5 Desenvolvimento de um Software de GI com Interface Gestual 65

5.1 Identificação dos Requisitos para um Software de GI . . . . . . . . . . . 66

5.2 Definição dos Gestos de Construção . . . . . . . . . . . . . . . . 69

5.2 .1 Gestos do Núcleo . . . . . . . . . . . . . . . . . . . . . . . . 69

5.2 .2 Gestos de Navegação . . . . . . . . . . . . . . . . . . 71

5.2 .3 Gestos Básicos . . . . . . . . . . . . . . . . . 73

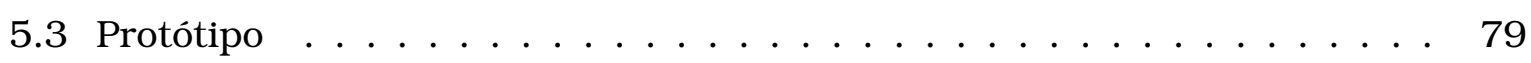

5.3.1 Funcionalidades Disponíveis . . . . . . . . . . . . . 82

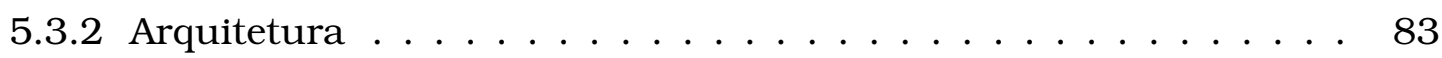

5.3 .3 Implementação . . . . . . . . . . . . . . . . . . . . . 85

5.3 .4 Pontos, Retas e Circunferências . . . . . . . . . . . . . . 88

5.4 Avaliação Heurística . . . . . . . . . . . . . . . . . . . . . . . 89

5.4 .1 Metodologia . . . . . . . . . . . . . . 90

5.4 .2 Resultados da Avaliação Heurística . . . . . . . . . . . . . . . 91

5.4 .3 Análise dos Dados . . . . . . . . . . . . . . . . . . . . 92

5.4 .4 Questionários . . . . . . . . . . . . . . . 93

5.4 .5 Discussão . . . . . . . . . . . . . . . . . . . . 95

5.4 .6 Ameaças à validade . . . . . . . . . . . . . . . . 95

5.5 Considerações finais . . . . . . . . . . . . . . . . . 96 
6 Conclusão $\quad 99$

6.1 Considerações Finais . . . . . . . . . . . . . . . . . . . . 99

6.2 Contribuições . . . . . . . . . . . . . . . . . . . 100

6.3 Limitações do trabalho efetuado . . . . . . . . . . . . . . . . . . . . 102

6.4 Sugestões para trabalhos futuros . . . . . . . . . . . . . . . 102

A Tabelas dos estudos primários classificados e sem classificação $\quad 113$

B Formulário: Análise de usabilidade em softwares de GI para Tablets $\quad 117$

$\begin{array}{ll}\text { C Dicionário de Gestos } & 125\end{array}$ 


\section{Lista de Figuras}

2.1 Criação de um quadrado utilizando um software de GI. . . . . . . . . . . 7

2.2 Modificação do raio da circunferência de 1,16 (esquerda) para 0,808 (di$\begin{array}{ll}\text { reita). Apesar da mudança as propriedades do quadrado são mantidas. } & 7\end{array}$

2.3 Software de GI iGeom . . . . . . . . . . . . . . . . . . . . . 9

2.4 Software de GI Cinderella . . . . . . . . . . . . . . . . . . . . . 10

2.5 Software de GI C.a.R . . . . . . . . . . . . . . . . . 11

2.6 Software de GI Geogebra . . . . . . . . . . . . . . . . . . . . . 12

2.7 Software de GI Geogebra para Tablets . . . . . . . . . . . . . . . . . . . 12

2.8 Software de GI Sketchometry . . . . . . . . . . . . . . . . . . . . 12

2.9 Software de GI Geometry Pad . . . . . . . . . . . . . . . . . . . . 13

2.10 Tipos de interação por toque em telas sensíveis ao toque. . . . . . . . 16

3.1 Distribuição dos estudos primários de acordo com as bases consultadas 35

3.2 Distribuição dos estudos primários pelo tipo da publicação . . . . . . . . 36

3.3 Frequência de estudos em cada categoria . . . . . . . . . . . . 37

3.4 Distribuição das categorias por ano . . . . . . . . . . . . . . 38

3.5 Distribuição dos estudos primários por dispositivos de entrada de dados 38

3.6 Distribuição dos estudos primários por dispositivos de saída de dados . 39

3.7 Distribuição dos estudos primários por tipo de dispositivo . . . . . . . . 39

3.8 Mapa da distribuição dos estudos por categoria . . . . . . . . . . . . . 41

4.1 Distribuição dos estudos primários por tipo de dispositivo $\quad \ldots \ldots$. . . . 49

4.2 Fases da avaliação heurística no softwares propostos pelos avaliadores . 50

4.3 Frequência de problemas encontrados por heurística e por software avaliado . . . . . . . . . . . . . . . . . . . 52

4.4 Menu agrupado do software Geogebra . . . . . . . . . . . . . . 53

4.5 Barra de título do software Geogebra . . . . . . . . . . . . . 53 
4.6 Grau de severidade entre as heurísticas no software Geogebra . . . . . 54

4.7 Menu agrupado do software Geometry Pad . . . . . . . . . . . . . 55

4.8 Função de edição dos objetos geométricos do software Geometry Pad (troca de cor, espessura da reta, rótulo, excluir) . . . . . . . . . . . 56

4.9 Barra de Título do software Geometry Pad . . . . . . . . . . . . . . . 56

4.10 Grau de severidade entre as heurísticas no software Geometry Pad . . . 57

4.11 Caixa de mensagens de tipo de função do software Sketchometry . . . . 58

4.12 Funções de criar e manipular objetos geométricos no software Sketcho-

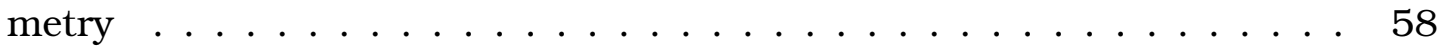

4.13 Grau de severidade entre as heurísticas no software Sketchometry . . . 59

4.14 Pontuação final para cada questão do questionário . . . . . . . . . . . . . 60

5.1 Caso de uso do software GeoTouch . . . . . . . . . . . . . . . . . . 67

5.2 Gesto Toque Breve. . . . . . . . . . . . . . . . . . . . . . . 69

5.3 Gesto Pressionar. . . . . . . . . . . . . . . . . . 70

5.4 Gesto Arrasto. . . . . . . . . . . . . . . . . . . . 70

5.5 Gesto Movimento. . . . . . . . . . . . . . . . . . 70

5.6 Gesto Rotação. . . . . . . . . . . . . . . . . . . . . . . . 71

5.7 Gesto Ajustar. . . . . . . . . . . . . . . . . 71

5.8 Gesto Desfazer. . . . . . . . . . . . . . . . . . . . 71

5.9 Gesto Refazer. . . . . . . . . . . . . . . . . . . . 72

5.10 Gesto Selecionar. . . . . . . . . . . . . . . . . . . . 72

5.11 Gesto Movimentar. . . . . . . . . . . . . . . . . . . 72

5.12 Gesto Editar. . . . . . . . . . . . . . . . . . . 73

5.13 Gesto Ponto. . . . . . . . . . . . . . . . . . 74

5.14 Gesto Ponto Médio. . . . . . . . . . . . . . . . . . . . . 74

5.15 Gesto Circunferência. . . . . . . . . . . . . . . . . . . . 75

5.16 Gesto Circunferência definida por um segmento de reta. . . . . . . . . 76

5.17 Gesto Reta. . . . . . . . . . . . . . . . . . . . . . . 76

5.18 Gesto Semi-reta. . . . . . . . . . . . . . . . . . 77

5.19 Gesto Segmento de reta . . . . . . . . . . . . . . . . 78

5.20 Gesto Perpendicular. . . . . . . . . . . . . . . . 79

5.21 Gesto Paralela. . . . . . . . . . . . . . . . . . . . . . 79

5.22 Tela de apresentação e inicial do software GeoTouch . . . . . . . . . . . . 80

5.23 Telas de apresentação do software GeoTouch . . . . . . . . . . . . . . . 81

5.24 Menu suspenso para criar e remover objetos . . . . . . . . . . . . . 81

5.25 Funcionalidade de Grid . . . . . . . . . . . . . . . . . . . . . 82

5.26 Funcionalidade de Eixo Cartesiano . . . . . . . . . . . . . . . . 82

5.27 Mensagem de saída do software . . . . . . . . . . . . . . 83 
5.28 Arquitetura do software GeoTouch . . . . . . . . . . . . . . 84

5.29Arquitetura do software GeoTouch . . . . . . . . . . . . . . . 86

5.30 Fluxograma das ações ao tocar na tela . . . . . . . . . . . . 88

5.31 Detalhamento do fluxograma da ação de movimento que utiliza algum ponto selecionado . . . . . . . . . . . . . . 89

5.32 Espaço de proximidade para selecionar ou movimentar o ponto . . . . . 89

5.33 Implementação da reta infinita . . . . . . . . . . . . . . . . . 90

5.34 Procura de um ponto ou segmento de reta dentro da circunferência . . . 90

5.35Frequência de problemas encontrados por heurística (vide Tabela 4.1) . 91

5.36 Frequência de problemas encontrados por heurística e por software avaliado . . . . . . . . . . . . . . . . . . . 92

5.37 Grau de severidade entre as heurísticas no software GeoTouch . . . . . 93

5.38 Pontuação final para cada questão do questionário no software GeoTouch 94

5.39 Comparação da pontuação final para cada questão do questionário entre os softwares avaliados neste trabalho . . . . . . . . . . . . . . . . . . 94 


\section{Lista de Tabelas}

2.1 Grau de Severidade das heurísticas . . . . . . . . . . . . . . . 24

3.1 String de pesquisa em inglês . . . . . . . . . . . . . 30

3.2 Guantidade de estudos retornados por cada biblioteca digital, total de estudos candidatos e seleção final. . . . . . . . . . . . . . . . 32

3.3 Categorias resultantes de interações . . . . . . . . . . . . . . 33

3.4 Categorias resultantes de formas de entrada de dados . . . . . . . . . . 34

3.5 Categorias resultantes de saída de dados . . . . . . . . . . . . . . 34

3.6 Categoria resultantes de dispositivos . . . . . . . . . . . . . . . . 34

4.1 Lista de dez heurísticas com suas abreviações . . . . . . . . . . . 51

4.2 Conjunto de funções para aplicação do teste de usabilidade . . . . . . 51

4.3 Lista de problemas encontrados no software Geogebra e a classificação de suas heurísticas ... . . . . . . . . . . . 53

4.4 Lista de problemas encontrados no software Geometry Pad e a classificação de suas heurística . . . . . . . . . . . . . . . . 55

4.5 Lista de problemas encontrados no software Sketchometry e a classifição de suas heurística . . . . . . . . . . . . . . . . . 57

5.1 Funcionalidades para a operação do software . . . . . . . . . . . . . 68

5.2 Funcionalidades para a edição de objetos geométricos . . . . . . . . . . 68

5.3 Funcionalidades básicas para a construção de objetos geométricos . . . 68

5.4 Tabela de operações básicas do software . . . . . . . . . . . . . . . 83

5.5 Tabela de funcionalidades do software . . . . . . . . . . . . . . 84

5.6 Pacotes do softare GeoTouch . . . . . . . . . . . . . . . . . . 85

5.7 Lista de problemas encontrados no software GeoTouch e a classificação de suas heurísticas . . . . . . . . . . . . . . . . . 93 
A.1 Estudos primário selecionados, o tipo do estudo e o tipo de contribuição 113

A.2 Estudos primário selecionados sem categoria, o tipo do estudo e o tipo de contribuição . . . . . . . . . . . . . . . . . . . 115

B.1 Grau de Severidade das heurísticas . . . . . . . . . . . . . 121 


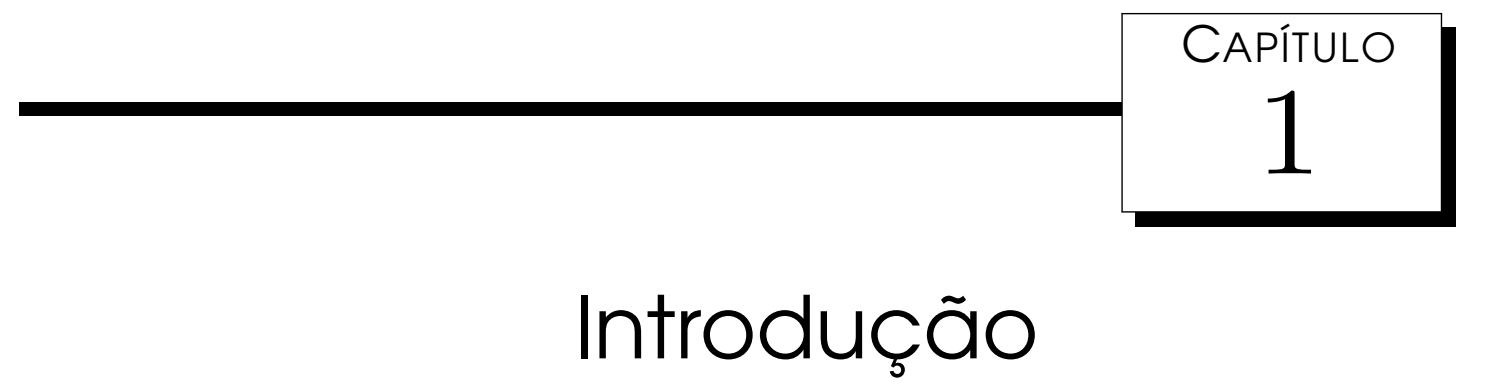

No ensino tradicional da geometria utiliza-se as ferramentas convencionais (régua e compasso) para que os estudantes consigam construir os objetos geométricos no papel. Entretanto, estas ferramentas podem apresentar algumas limitações, como a impossibilidade do aluno manipular dinamicamente o objeto construído ou alterar alguma propriedade do mesmo em tempo real. Isto torna o processo de construção e alteração do objeto demorado e os estudantes levam mais tempo para ver a resposta de suas ações e testar suas hipóteses (Lavy e Shriki, 2010).

Com o propósito de amenizar estes problemas, diversos pesquisadores têm trabalhado no desenvolvimento de softwares para o apoio do ensino da geometria de forma interativa (Jackiw, 1995) (Grothman, 1999) (Kortenkamp, 1999) (Hohenwarter, 2001) (Isotani, 2005), dentre eles, os Softwares de Geometria Interativa (GI), que possibilitam que os estudantes construam e manipulem os objetos geométricos construídos com o uso da tecnologia.

As interfaces destes softwares são importantes, pois é por meio da interface que os estudantes conseguem visualizar as informações e interagir com sistema (Shimomura et al., 2013). Desta forma, ao desenvolver um software de GI, a equipe de desenvolvimento precisa se preocupar com os aspectos pedagógicos e de design da interface (Laborde, 2007), com o objetivo de auxiliar o aluno em seu aprendizado e reduzir a carga cognitiva necessária para lidar com as particularidades da interface do sistema (Schimpf e Spannagel, 2011) (Kortenkamp e Dohrmann, 2010).

Com o propósito de analisar o impacto desta carga cognitiva e a quantidade de ícones apresentados em tela durante o aprendizado da geometria em softwares de GI, dois estudos foram realizados por Schimpf e Spannagel (2011) e Reis et al. (2012). 
Os resultados sugerem que interfaces que possuem grande quantidade ícones podem ser benéficos para os usuários experientes, porém podem causar confusão em usuários iniciantes. Isto acontece devido a dificuldade de localizar o ícone desejado em meio de vários outros ícones, e caso as imagens desses ícones sejam similares, pode gerar mais dúvidas, causar erros de construção e, como consequência, desmotivar e frustrar o aluno durante o processo de aprendizagem.

Para evitar que as interfaces possuam uma quantidade desnecessária de ícones, o uso das interfaces gestuais pode auxiliar na redução de elementos em tela e impedir que sejam visualmente poluídas (Nacenta et al., 2013). Estas interfaces gestuais, também conhecidas como interfaces naturais, necessitam que o usuário utilize gestos para conseguir interagir com o software. Segundo Hanne (1994)), estas interfaces necessitam de menos tempo de treinamento, pois o uso do gestos (se adequadamente desenvolvidos) é mais natural para interagir com o software, se comparado com o uso do mouse.

As interfaces gestuais podem ser encontradas em dispositivos móveis, como tablets e smartphones, que utilizam telas sensiveis ao toque que reconhecem os gestos realizados pelos usuários. Nestas telas sensíveis ao toque, os usuários podem realizar dois tipos de gestos: Toque único ou Multitoque.

Em gestos do tipo "Toque Único"utiliza-se somente um dedo para realizar as ações, enquanto o gesto Multitoque, pode ser utilizado um ou mais dedos. O gesto multitoque é considerado mais natural, pois no mundo real as pessoas utilizam mais de um dedo para interagir com os objetos e ambientes a sua volta (Mathema, 2009). Devido a possibilidade de utilizar mais dedos ao realizar um gesto, isto permite que diferentes gestos sejam desenvolvidos para que os usuários possam interagir com uma interface de software. Esta diversidade de gestos pode ser benéfica, pois permite que diversas funções possam ser acionadas por meio dos gestos, porém, em grande quantidade pode tornar a interface complexa dificultando sua aprendizagem.

Atualmente, apesar da importância e dos benefícios das interfaces multitoque, não há metodologias aproprias para o desenvolvimento destas interfaces que considere a pedagogia, ou seja, em que são relacionados as necessidades do ensino e os recursos tecnológicos (Scharf et al., 2010). Em vista disso, este trabalho investiga quais os critérios que os desenvolvedores devem utilizar ao desenvolver um software de GI para que auxilie no processo do ensino-aprendizagem em interfaces com interação multitoque em dispositivos móveis.

Além disso, existem poucos estudos e ferramentas que exploram e se apropriam adequadamente do uso deste tipo de interface para auxiliar o processo interação em softwares de GI (Scharf et al., 2010) (Reis, 2013). Portanto, este trabalho também investiga quais gestos podem ser utilizados na criação de intefaces de software de GI com interação multitoque em dispositivos móveis. 


\subsection{Motivação}

A principal motivação para realização desta dissertação é a popularização dos dispositivos móveis com tela multitoque principalmente entre os jovens, aliada com a escassez de softwares de GI que podem ser utilizados nestes dispositivos. A interação nestes dispositivos ocorre por meio do toque, sendo que o estudo de Reis (2013) sugere este tipo de interação é pouco explorado nos softwares de GI, tornando-se uma oportunidade de pesquisa.

Acredita-se que o uso da interação por gestos nos softwares de GI pode contribuir para o ensino da geometria se desenvolvido com base em gestos naturais que levam em consideração os conceitos pedagógicos necessários para a construção do saber geométrico. Além disso, as interfaces gestuais podem ser uma estratégia para diminuir a poluição visual, reduzindo a carga cognitiva utilizada pelo estudante (Reis et al., 2012).

Neste contexto, um dos fatores que motivam essa pesquisa é estudar e desenvolver gestos adequados para construção de objetivos geométricos em interface de software de GI para dispositivos móveis com tela multitoque. Estes gestos devem ser desenvolvidos de acordo com as propriedades conceituais do objeto geométrico para que o aluno consiga identificar suas características e aprender a geometria. Isto quer dizer que ao realizar os gestos o aluno estará automaticamente pensando nas propriedades matemáticas do objeto geométrico a ser construído. Por exemplo, ao tentar fazer a construção de uma circunferência, o gesto proposto deve auxiliar o aluno a aplicar a propriedade geométrica envolvida (i.e. todos os pontos da circunferência são equidistante do seu centro).

\subsection{Objetivos}

O objetivo deste projeto é desenvolver um conjunto de gestos para construção de objetos geométricos em um software de GI para dispositivo móvel (como tablet e smartphone) que possua tela sensivel ao toque. Atualmente, a interação por meio de toque é pouco explorada nos softwares de GI (vide Seção 3).

No contexto do aprendizado da geometria, acredita-se que gestos baseados em conceitos geométricos podem trazer benefícios ao aprendizado como a fixação dos conceitos de geometria e a minimização do uso da carga cognitiva. Isso deve-se ao fato de que é mais natural para o estudante aprender e relembrar os conhecimentos de geometria ao aplicá-los na construção e manipulação de objetos geométricos. Neste contexto, este trabalho teve como objetivo investigar três questões de pesquisa:

QP01: É possível propor um conjunto de gestos para a construção de objetos geométricos (e.g. reta e circunferência) em tela multitoque que leva em consideração 
os conceitos geométricos envolvidos?

QP02: É possível desenvolver uma interface de software de GI para dispositivo móvel utilizando o conjunto de gestos propostos?

QP03: É possível comparar e avaliar a usabilidade da interface desenvolvida em relação a outros softwares de GI disponíveis para dispositivos móveis?

\subsection{Organização}

Este trabalho, além deste capítulo, está organizado da seguinte forma. No Capítulo 2, são apresentados os conceitos sobre geometria interativa e de interfaces de GI. Além disso, discute-se também a interação em telas sensiveis ao toque para o ensino. No final do capítulo, apresenta-se a importância da avaliação destas interfaces e quais técnicas podem ser utilizadas.

No Capítulo 3 são apresentados os resultados de um mapeamento sistemático realizado com o objetivo de obter informações sobre quais tipos de interface e de interação estão disponíveis nos softwares de GI. Além disso, apresenta-se uma visão geral das abordagens mais pesquisadas e das estratégias e tecnologias mais empregadas.

No Capítulo 4, são avaliadas as interfaces dos softwares de GI disponíveis em tablets e que possuem interação por toque. Este capítulo apresenta os resultados desta avaliação e quais problemas foram encontrados.

No Capítulo 5, é proposto o desenvolvimento de um software de GI utilizando tanto o conhecimento encontrando no Capítulo 4 sobre os problemas existentes no atuais softwares de GI quanto utilizando conceitos matemáticos relacionados a construção dos objetos geométricos.

Por fim, o Capítulo 6 apresenta as considerações finais, as contribuições do presente trabalho, as suas limitações e sugestões para trabalhos futuros. 


\section{- \\ Ensino da Geometria e Interfaces Gestuais}

Os softwares de Geometria Interativa (GI) são ferramentas que auxiliam no ensino da geometria por meio de computadores. As interfaces desses softwares são importantes, pois são por meio delas que os estudantes conseguem visualizar as informações e interagir com os elementos do sistema. Este capítulo apresenta as características sobre estes softwares de GI, a importância de suas interfaces e um novo conceito de interação, que seria por meio do toque.

Na seção seguinte, Seção 2.1, descreve-se os benefícios da Geometria Interativa e na Seção 2.2 são os ambientes de Geometria Interativa disponíveis. A importância das interfaces de GI é apresentada na Seção 2.3; os conceitos sobre interface de toque e os tipos de avaliações que podem ser realizados nestas interfaces são apresentados nas Seções 2.4 e 2.5. Por fim, as considerações finais são discutidas na Seção 2.6.

\subsection{Softwares de Geometria Interativa}

O termo "geometria"refere-se ao ramo da matemática que estuda as formas, tamanhos e propriedades das figuras (Atiyah, 2003) (Isotani e Brandão, 2006). No ensino clássico, o estudo da geometria ocorre com o uso das ferramentas tradicionais, como a régua e o compasso, para construir e analisar desenhos geométricos. Porém, estas ferramentas apresentam algumas limitações no seu uso em sala de aula, como a dificuldade de manipular os objetos geométricos com facilidade. Por exemplo, para analisar uma construção geométrica em duas posições diferentes (i.e. instâncias da 
construção) é necessário que o estudante faça duas construções com a régua e o compasso. Isso pode dificultar tanto a identificação das relações entre os objetos quanto o desenvolvimento da habilidade de generalização de situações-problema (Lavy e Shriki, 2010).

Outra limitação encontrada no ensino clássico é o tempo gasto pelo professor para verificar as construções geométricas dos alunos. Dependendo do nível de dificuldade e da quantidade de construções, esta verificação pode ser complexa e demorada, o que pode levar os alunos a sentirem frustração, ansiedade e confusão pelo o tempo de espera (Hara e Kling, 2000) (Silva Filho et al., 2008) (Tanbellini e Brandão, 2010). Esta situação pode ser agravada em salas de aula em que há uma quantidade elevada de alunos, onde o professor precisa de mais tempo para responder às necessidades de todos.

A fim de amenizar estes problemas, pesquisadores desenvolveram programas de computador para auxiliar no ensino da geometria. Dentre eles, o que teve maior inserção no ambiente escolar são os softwares de geometria interativa (SGI). O SGI surgiu na década de 1990, com o objetivo de auxiliar os estudantes a explorarem a geometria sem a utilização da régua e do compasso (Roanes-Lozano et al., 2003), permitindo a construção e manipulação de figuras geométricas de forma dinâmica por meio da movimentação do mouse (Escribano et al., 2010). Após o primeiro software Geometria Interativa (GI), o Sketchpad (Jackiw, 1995), vários outros foram desenvolvidos, como, por exemplo, o C.a.R. (Grothman, 1999), o Cinderella (Kortenkamp, 1999), o GeoGebra (Hohenwarter, 2001) e o iGeom (Isotani, 2005).

Os SGI permitem a construção de objetos geométricos como circunferências, retas, semi-retas, ponto, segmentos de retas, entre outros elementos, e a manipulação destes objetos utilizando o mouse (Botana e Valcarce, 2002). Esta manipulação proporcionada pela GI possibilita que o aluno construa objetos geométricos e realize vários testes, enquanto a construção dos objetos geométricos pelas ferramentas tradicionais (i.e. régua e compasso) permite apenas um teste (Isotani e Brandão, 2004).

Um exemplo seria a criação de um quadrado (pontos F, G, H e I) por meio de uma circunferência, tendo o seu raio sendo formado segmento de reta de $1,0 \mathrm{~cm}$, com duas tangentes (pontos $\mathrm{H}$ e G), formando o ponto I na intersecção, resultando ângulos de 90 graus (Figura 2.1 ). Caso o raio desta circunferência ou sua posição seja modificada por meio da movimentação do mouse em tela, as propriedades do objeto não serão modificadas: todos os lados serão iguais e todos os ângulos da figura serão de 90 graus. O tamanho dos lados do quadrado poderão ser diferentes durante a manipulação, assim como a sua rotação (Figura 2.2).

Para Mariotti (2000), a movimentação do mouse pelo aluno ao executar as atividades pode acontecer de forma dedutiva e indutiva. Na dedução chega-se a uma verdade específica a partir de uma mais geral ou abrangente e a conclusão apenas confirma 


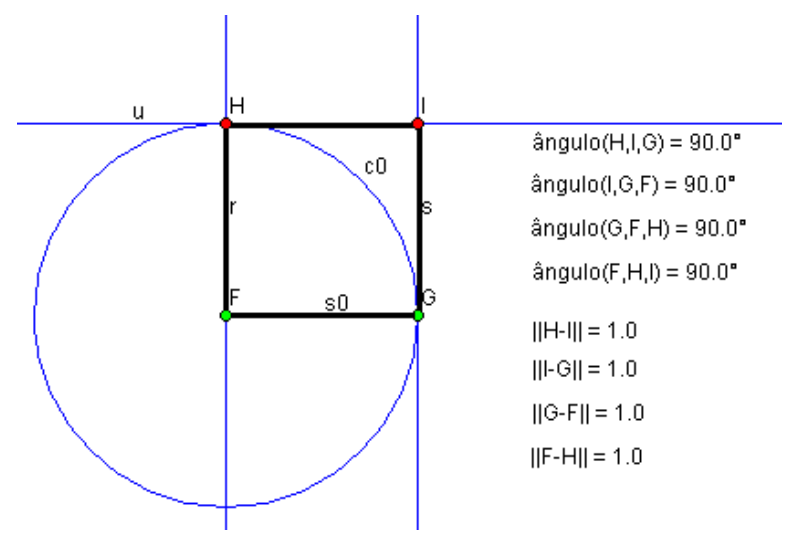

Figura 2.1: Criação de um quadrado utilizando um software de GI.

o que já foi exposto pelas premissas. A indução é o caminho contrário da dedução - ao observar casos particulares são identificados padrões que podem ser aplicados em vários outros casos. Nesta situação, se todas as premissas são verdadeiras é possivelmente (mas não é regra) que a conclusão seja verdadeira.
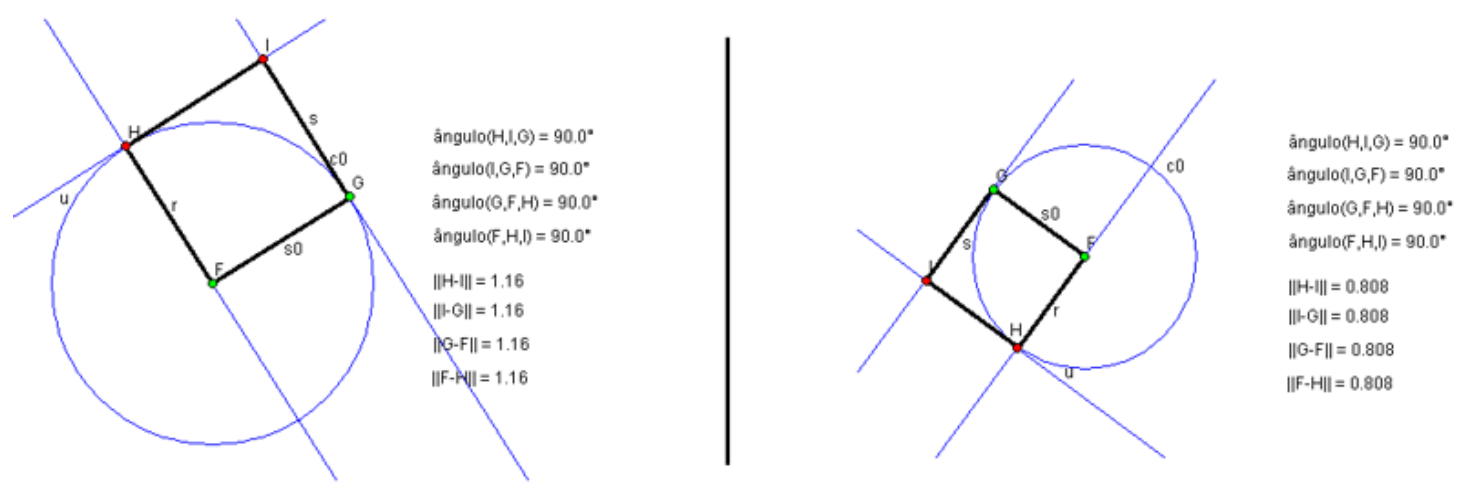

Figura 2.2: Modificação do raio da circunferência de 1,16 (esquerda) para 0,808 (direita). Apesar da mudança as propriedades do quadrado são mantidas.

Ainda, como observado por Hollebrands (2007), os estudantes aplicam dois tipos diferentes de estratégia ao utilizarem um software de GI enquanto aprendem geometria: reativa e proativa. A estratégia reativa é utilizada quando um estudante espera o resultado de uma ação para executar outra ação. Deste modo, o estudante não sabe qual deve ser sua próxima ação sem primeiro compreender a informação/figura que a sua primeira ação gerou na tela do computador. Em contrapartida, os estudantes que usam a ferramenta de forma proativa já sabem quais ações deverão executar antes de fazê-las. Eles já possuem em mente um plano sobre como executar tais ações. Estas duas estratégias estão fortemente ligadas ao nível de conhecimento do aluno em lidar com as tecnologias da informação e comunicação, além da matemática/geometria 
(Hollebrands, 2007). Os estudantes podem, ainda, alterar sua estratégia de proativa para reativa e vice-versa, durante o uso da ferramenta.

Em relação a aprendizagem, Janičić e Quaresma (2007) indicam que os SGI auxiliam no ensino da geometria e o entendimento dos conceitos geométricos. Ao interagir com SGI, os alunos passam a entender quais são as propriedades dos objetos geométricos e como explica-los formalmente. Além disso, eles apresentam maiores níveis de motivação, se comparados a estudantes que utilizam ferramentas tradicionais para aprendizagem de geometria (Erbas e Yenmez, 2011).

Esta motivação em conjunto com os SGI podem afetar o comportamento do estudante ao se deparar com um problema (exercício) a ser resolvido, pois se explorados adequadamente, fazem com que os estudantes tenham a liberdade para elaborar e testar suas próprias hipóteses, tornando-os agentes ativos na construção da solução do problema (Roanes-Lozano et al., 2003). Além disso, a flexibilidade que os softwares de GI proporcionam na execução das atividades, possibilita que os alunos trabalhem de acordo com as suas capacidades $\operatorname{cognitivas}^{1}$, permitindo aos alunos dedicarem o tempo necessário para realizarem as atividades desejadas (Mason, 2010).

Por fim, atividades realizadas num ambiente em que o aluno pode resolver problemas sem o auxilio direto de um professor ajudam a reduzir a dependência do aluno sobre o professor, e incentivam os alunos a construírem o seu próprio conhecimento. Os alunos sentem-se responsáveis pela sua própria educação, além de aumentar a curiosidade e entusiasmo no processo de aprendizagem.

\subsection{Ambientes de Geometria Interativa}

Foi observado anteriormente que todos os ambientes de Geometria Interativa disponíveis possuem as funcionalidades básicas como criação de retas, pontos, circunferências, ferramentas para edição e medida, entre outras. Nestes ambientes, os estudantes podem trabalhar de duas maneiras para realizar as suas atividades: objeto/ação e ação/objeto. Na primeira abordagem, o estudante seleciona um objeto e aplica uma ação sobre este objeto. Na segunda, é o inverso, em que uma ação resulta em um objeto. Há uma discussão sobre qual é a melhor maneira de construção, porém os pesquisadores ainda não possuem ideia de qual solução é a mais adequada. Atualmente, alguns pesquisadores defendem o uso das duas abordagens, na qual o estudante pode pré-selecionar algum objeto e aplicar uma ação e vice-versa (Kortenkamp e Dohrmann, 2010).

Estas duas maneiras de utilizar os recursos do software podem ser vistas na maioria dos softwares de GI, com detaques para os softwares mais conhecidos atual-

\footnotetext{
${ }^{1}$ Capacidade cognitiva é a quantidade de informação que o cérebro é capaz de gerenciar em uma determinada situação (Paas et al., 2003).
} 
mente, o C.a.R. (Grothman, 1999), o Cinderella (Kortenkamp, 1999), o GeoGebra (Hohenwarter, 2001) e o iGeom (Isotani, 2005). Porém, há características diferentes, como a parte de animações nos programas Cinderella e GeoGebra, a de construção de equações algébricas no programa GeoGebra, e a avaliação automática no iGeom. Os detalhes e características destes softwares serão apresentados nas subseções 2.2.1 até 2.2.6.

\subsection{1 iGeom}

O projeto iGeom (Figura $2.3^{2}$ ), coordenado pelo professor Lêonidas de Oliveira Brandão do IME-USP, teve sua primeira versão disponibilizada em 2001. O software é gratuito e foi desenvolvido utilizando a linguagem Java devido à proposta inicial de funcionar em diversas plataformas.

Atualmente, o iGeom possui todas as funcionalidades básicas da GI (e.g. criação de pontos, retas, semi-retas, segmentos, circunferências, polígonos, áreas, medidas dinâmicas e distância, isometrias, perpendiculares e paralelas), além de opções de edição (e.g. esconder/mostrar, remover ou desfazer ação, criar textos, rastrear e modificar características dos objetos) e de gravação e recuperação de arquivos (Isotani, 2005).

Também é possível utilizar recursos avançados, dificilmente encontrados em outros aplicativos do mesmo domínio, como a geração de "scripts" ${ }^{3 ", ~ e x p o r t a c ̧ a ̃ o ~ p a r a ~}$ Web, autoria e validação automática de exercícios e a comunicação com servidores.

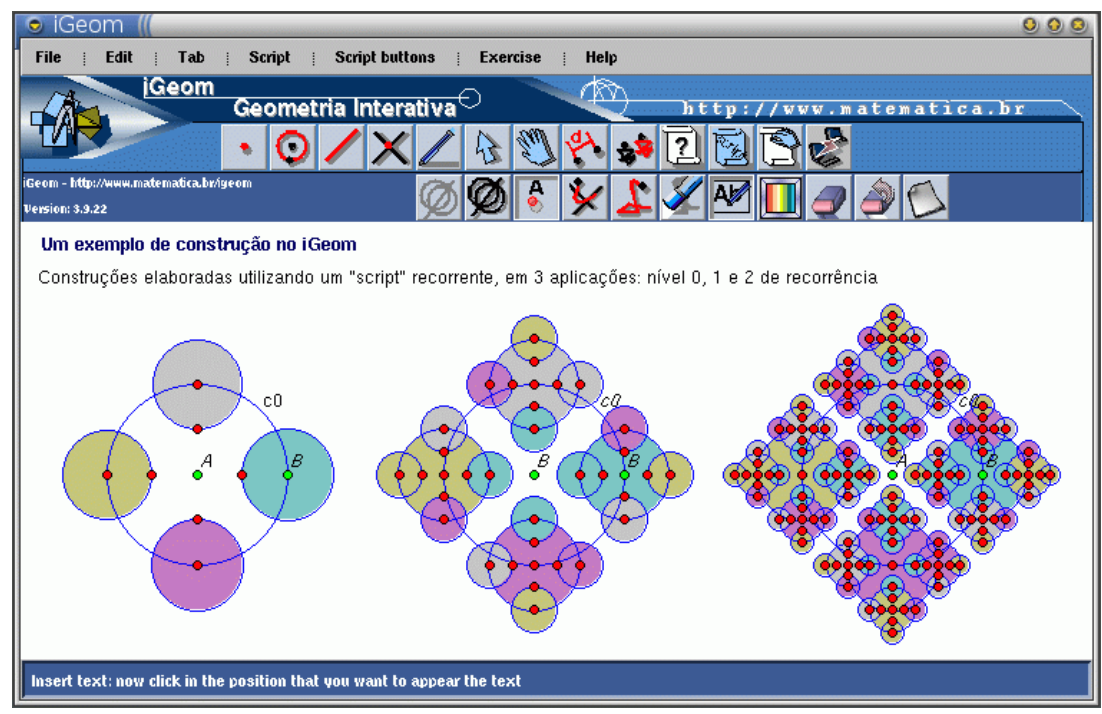

Figura 2.3: Software de GI iGeom .

\footnotetext{
${ }^{2}$ http://www.matematica.br/igeom/frac-tetra-circ-area-color.gif

${ }^{3}$ Script são macros que possuem o algoritmo para realizar uma construção (Isotani, 2005).
} 


\subsubsection{Cinderella}

O Cinderella (Figura 2.44) surgiu em 1992 tendo como os primeiros autores Jürgen Ricther-Gebert e Henry Crapo. Mais tarde, Ulrich Kortenkamp foi integrado à equipe. Primeiramente, o software foi desenvolvido para plataforma NeXT, porém devido a problemas de portabilidade, em 1996 foi reescrito utilizando a linguagem Java e, em 1999, teve sua primeira versão disponibilizada comercialmente. Atualmente, o Cinderella está na versão 1.4 e, devido o seu desenvolvimento atual em Java, é possível usá-lo em qualquer sistema operacional e em navegadores Web.

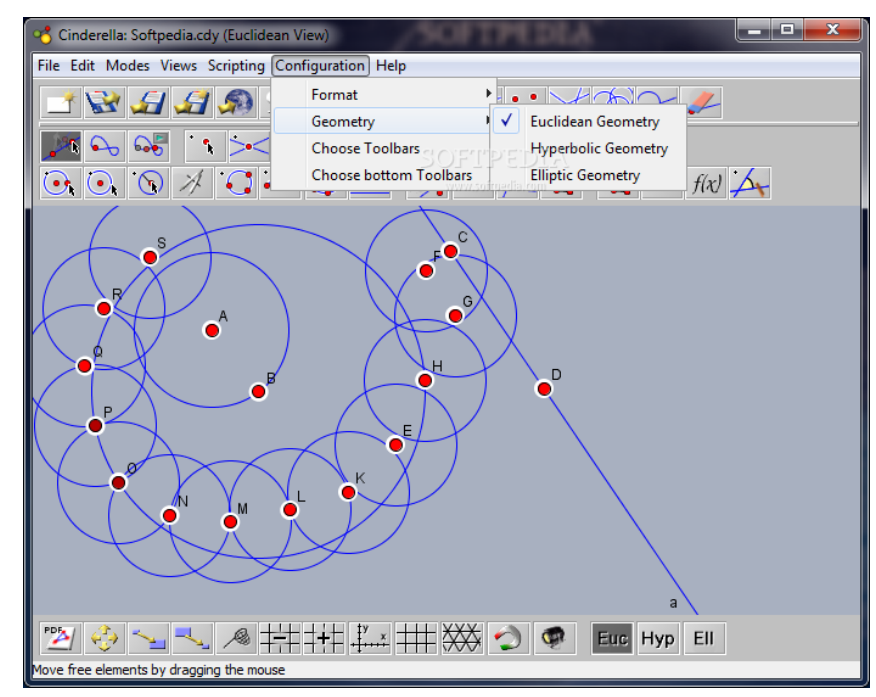

Figura 2.4: Software de GI Cinderella .

\subsubsection{C.a.R}

A primeira versão foi desenvolvida em 1989 por René Grothman, da Universidade Católica de Eichstätt, na linguagem C para o sistema Atari ST. Após descontinuarem este sistema operacional, o programa foi portado para OS/2, depois para DOS e finalmente para Windows em C++. Sua primeira versão Java foi desenvolvida em 1996 (Grothman, 1999). É disponibilizado gratuitamente utilizando a licença GNU General Public License ${ }^{5}$ (Figura $2.5^{6}$ ).

\subsubsection{GeoGebra}

O projeto foi iniciado por Markus Hohenwarter em 2001 na Universität Salzburg, e seu desenvolvimento ainda continua na Florida Atlantic University. O GeoGebra (Fi-

\footnotetext{
${ }^{4}$ http://i1-win.softpedia-static.com/screenshots/Cinderella_8.png

${ }^{5}$ http://www.gnu.org/licenses/licenses.pt-br.html

${ }^{6}$ http://car.rene-grothmann.de/doc_en/images/Vorschaul.jpg
} 


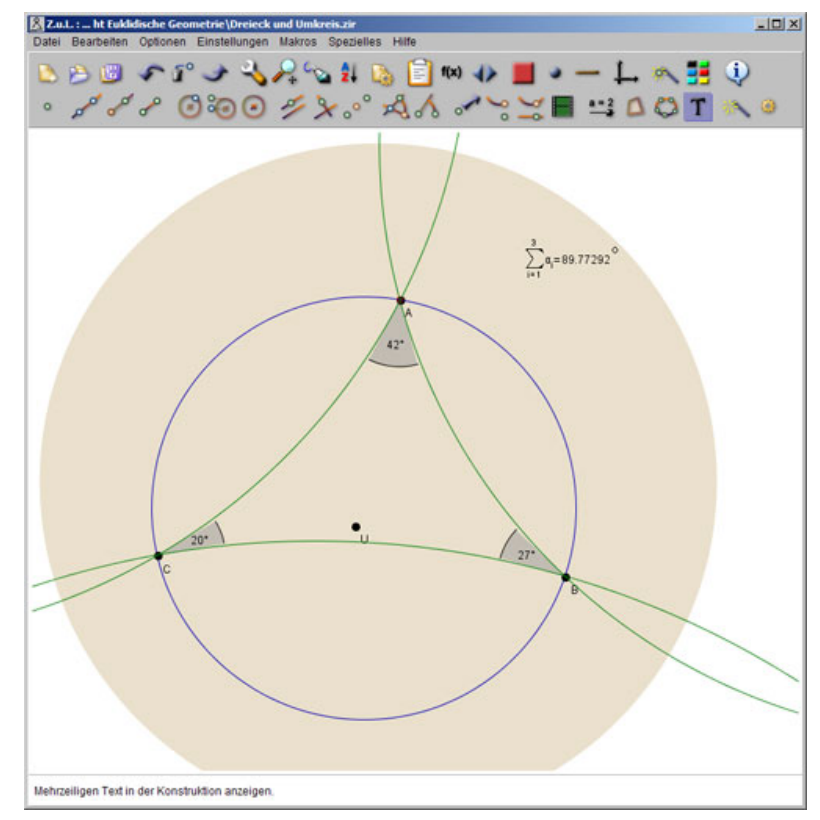

Figura 2.5: Software de GI C.a.R.

gura $2.6^{7}$ ) é um software gratuito que atende do ensino básico ao universitário. Este software está disponivel em diversos idiomas e reúne recursos de geometria, álgebra, tabelas, gráficos, probabilidade, estatística e cálculos simbólicos (Hohenwarter, 2001). Por ser desenvolvido em Java, é multiplataforma o que significa que pode ser instalado em qualquer sistema operacional. Uma versão beta para dispositivos móveis (Figura $2.7^{8}$ ) que possuem o sistema operacional Android e iOS também foi liberada no final do ano de 2013, sendo disponível nas lojas de cada sistema operacional. Em ambos sistemas operacionais, o software pode ser adquirido gratuitamente.

\subsubsection{Sketchometry}

O Skecthometry (Figura $2.8^{9}$ ) foi lançado em julho de 2012 e desenvolvido na University of Bayreuth, na Alemanha. O software foi implementado na tecnologia HTML5 (HTML, JavaScript, CSS, SVG, Canvas) e podendo ser executado em qualquer navegador que suporte esta tecnologia. O objetivo dos pesquisadores era disponibilizar um software de GI que pudesse ser executado tanto em computadores de mesa quanto em dispositivos móveis, como tablets e smartphones. Também é oferecido suporte a cinco línguas: inglês, português, espanhol, alemão e francês e, é gratuito.

\footnotetext{
${ }^{7}$ http://www.geogebra.org/cms//images/stories/screenshots/construction-protocol-circle-tangents. png

${ }^{8}$ https://s3.amazonaws.com/ksr/projects/214315/posts/488589/image-261759-full.jpg? 1369248850

9 http://i2geo.net/static/vignettes/Coll_polx_LamachineamultiplieravecSketchometry. png
} 


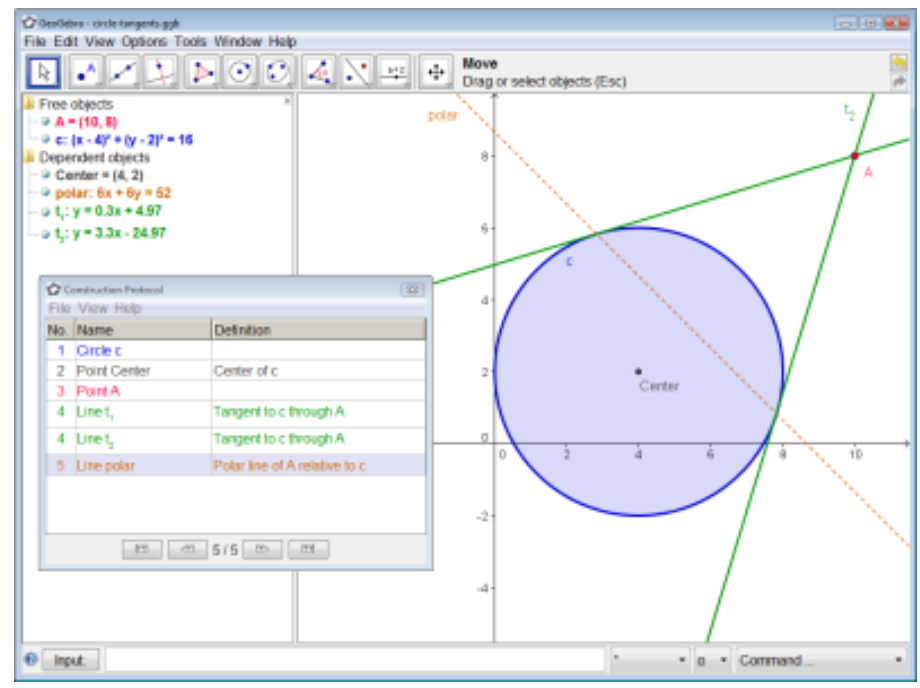

Figura 2.6: Software de GI Geogebra.

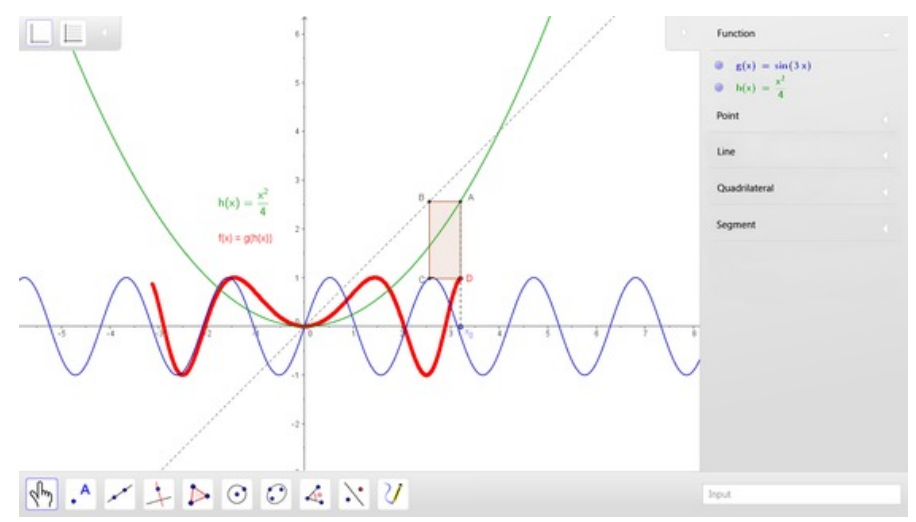

Figura 2.7: Software de GI Geogebra para Tablets.

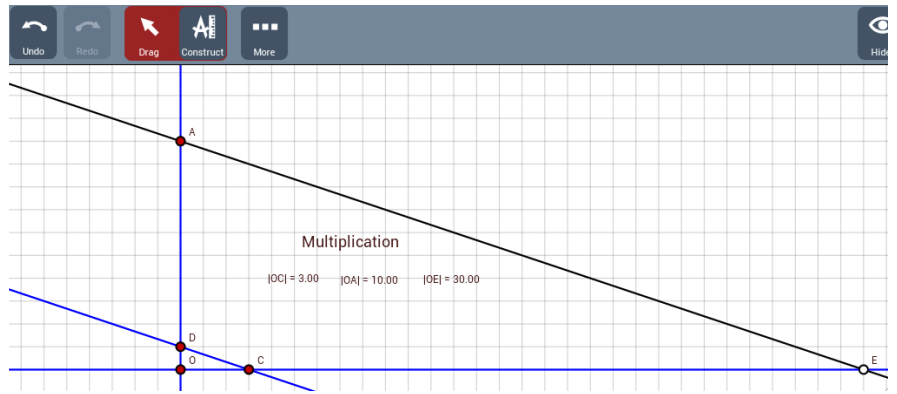

Figura 2.8: Software de GI Sketchometry

\subsubsection{Geometry Pad}

O software Geometry Pad (Figura $2.9^{10}$ ) foi desenvolvido pela empresa Byte Arithmetic LLC e está disponivel para os sistemas operacionais Android e iOS. Algumas 
funcionalidades, como construções de tangente ou objetos geométricos por meio de equações algébricas só podem ser realizadas após o usuário comprar o software.

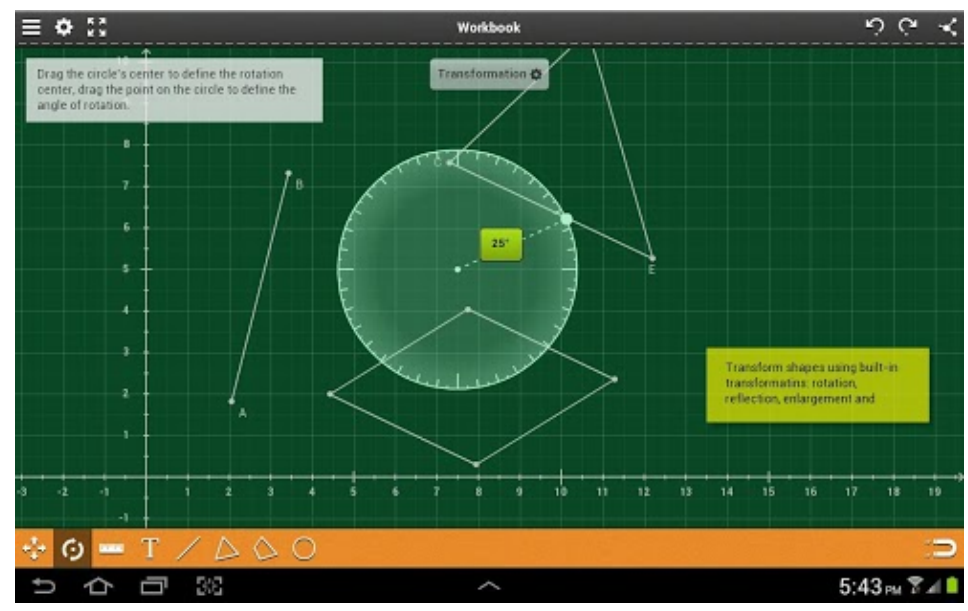

Figura 2.9: Software de GI Geometry Pad

\subsection{Interfaces dos Softwares de GI}

A interface é um importante meio para que os alunos visualizem as informações e interajam com o software (Shimomura et al., 2013). Para Laborde (2007), os desenvolvedores de softwares de GI devem se preocupar tanto com os aspectos pedagógicos quanto com o design da interface. As interfaces indevidamente projetadas podem causar frustrações nos alunos, fazendo com que eles sintam dificuldade em utilizar o software e, como consequência, podem não direcionar a atenção do aluno para o aprendizado da geometria (Schimpf e Spannagel, 2011) (Kortenkamp e Dohrmann, 2010).

O estudo de Reis et al. (2012) e Schimpf e Spannagel (2011) exploraram qual a melhor maneira de projetar e desenvolver uma interface para SGI, reduzindo a carga cognitiva utilizada pelos estudantes durante a aprendizagem. Ambos estudos analisaram como a quantidade e disposição de botões em uma interface pode afetar diretamente no aprendizado do estudante, fazendo com que o uso da sua carga cognitiva pertinente $^{11}$ seja voltado para o aprendizado da interface e não direcionado para o ensino da geometria. Estes dois estudos indicaram que botões exibidos em uma grande quantidade na interface pode ser benéfico para os usuários experientes, mas pode causar frustrações em usuários iniciantes, devido a dificuldade de localizar os ícones desejados.

\footnotetext{
${ }^{11}$ A carga cognitiva pertinente refere-se a construção e automatização de esquemas que auxiliam a assimilação de novas informações (Reis et al., 2012).
} 
Apesar da importância da interfaces no ensino da geometria, estudos sobre as várias formas de interação disponíveis para a criação de interfaces para softwares de GI não tem sido amplamente explorados. Existem poucos estudos na área que exploram as várias formas de interação com os objetos geométricos e em quais dispositivos estes tipo de interação podem ser executados.

Um estudo realizado por Reis (2013) indica que a maioria dos softwares de GI foram desenvolvidos no modelo desktop, exigindo o uso de dispositivos externos, como teclado e mouse, para que o aluno interaja com o software de GI. Reis (2013) aponta também que as interfaces de toque, onde o aluno utiliza gestos para interagir com o software, são pouco exploradas no desenvolvimento de SGI (vide Seção 3. Esta evidência apresenta uma oportunidade de pesquisa para o desenvolvimento de softwares de GI no contexto de interfaces de toque em dispositivos móveis, que será explorado no presente trabalho. Nas próximas subseções serão apresentados os conceitos envolvidos.

As interfaces de toque em que a interação ocorre por meio dos gestos estão cada vez mais disponíveis no mercado, podendo ser encontradas em diversos dispositivos como tablets e smartphones. Estes dispositivos são caracterizados como dispositivos móveis e estão sendo cada vez mais utilizados pelas pessoas no dia-a-dia. Em alguns países a venda e uso de dispositivos móveis superam as de computadores pessoais (Mathema, 2009). Estes dispositivos facilitam o vínculo com as tecnologias informação e comunicação, são portáteis e geralmente possuem algum tipo de conectividade (Castillo e Ayala, 2008). Por serem dispositivos pessoais portáteis, (quase-) sempre estão ao alcance do seu dono.

De acordo com Castillo e Ayala (2008) e Reis et al. (2012), estas características podem ser exploradas no meio educacional para viabilizar a aprendizagem a qualquer lugar e a qualquer hora, pois facilita a distribuição de materiais didáticos e a disseminação da aprendizagem informal. A abordagem de aprendizado em dispositivos móveis é conhecida por Mobile Learning (ou M-Learning) (Castillo e Ayala, 2008).

Neste contexto, este trabalho tem como um dos seus objetivos desenvolver uma interface para SGI que usufrui tanto dos benefícios da interação gestual em telas multitoque quanto do extensivo uso dos dispositivos móveis (em particular tablets) na educação. Assim, nas seções seguintes serão apresentados os conceitos sobre interface, usabilidade e dispositivos móveis na educação, utilizados para execução desta pesquisa.

\subsection{Interfaces de Toque}

Os gestos fazem parte da comunicação entre pessoas e os elementos do seu ambiente. Por meio dos gestos, as pessoas podem cumprimentar os demais, conduzir uma 
orquestra, expressar os seus sentimentos, apresentar ideias, além de outras possibilidades. De forma mais precisa, pode-se definir um gesto como a movimentação do corpo que contém algum tipo de informação que será captada e decodificada por outra pessoa ou agente do ambiente (e.g. um computador com câmera capaz de interpretar os movimentos do corpo humano) (Saffer, 2009). Entretanto, é comum ao interagir com algum tipo de dispositivo tecnológico, como os computadores de mesa atuais, não existir a possibilidade de utilizar o gesto natural (ou interação natural) como meio de comunicação, mas sim a interface de entrada disponivel para o dispositivo.

No caso dos computadores de mesa, toda interação é feita por meio do teclado e mouse, em que o usuário se comunica com o computador por meio de cliques e pressionamento de teclas. Para Kurtenbach e Hulteen (1990), dependendo da situação e necessidade do usuário, este tipo de interação pode ser difícil de usar, não efetiva e pode aumentar os níveis de insatisfação com o uso da interface do software. Para resolver alguns desses problemas, uma das possibilidades seria o desenvolvimento de interfaces que viabilizam a interação por meio de gestos como forma de comunicação humano-máquina. Nacenta et al. (2013) destaca que um dos benefícios das interfaces gestuais em relação ao padrão teclado-mouse é a redução das telas visualmente poluídas com diversos itens e ícones sendo apresentados.

De acordo O'Hara et al. (2013), a possibilidade de interação com a tecnologia por meio dos gestos está se tornando cada vez mais comum no nosso cotidiano. Atualmente, este tipo de interface é normalmente encontrada em dispositivos móveis, como tablets, smartphones, alguns tipos de laptops e em video-games (e.g. a plataforma Kinect e X-Box da Microsoft).

Para Saffer (2009), as melhores interfaces gestuais projetadas seriam as que possibilitam que os humanos utilizem os gestos do seu cotidiano para interagir com o software. Assim, os usuários não teriam que adaptar os seus gestos já conhecidos e utilizados para comunicar com o software, evitando que gestos sejam esquecidos e causem erros, aumentem a frustração e o abandono do uso da interface (Saffer, 2009) (O’Hara et al., 2013) (Nacenta et al., 2013).

Os softwares que necessitam de gestos para que os usuários possam se comunicar criaram um novo paradigma de interação, em que o uso do teclado e do mouse tornaram-se, de certa forma, obsoletos. As telas sensíveis ao toque e outras tecnologias que fazem o uso de gestos vem sendo caracterizados como interfaces naturais (do inglês Natural User Interface - NUI) (O'Hara et al., 2013). As interfaces naturais consistem em um termo de alto nível para a comunicação. Os humanos comunicam-se por meio de gestos corporais e linguagem natural e estes tipos de comunicação vem sendo estudados para que sejam utilizados na comunicação com a tecnologia (Hanne, 1994) (Saffer, 2009). 


\subsubsection{Categorias de Interações com Interfaces de Toque}

Existem vários tipos de categorias de gestos classificados por diversos autores presentes na literatura. Saffer (2009) classifica as interfaces gestuais em duas abrangentes categorias: "Free-form" ou "Touchscreen". Na categoria "Free-form" não é requerido que o usuário toque diretamente ou segure algum dispositivo de entrada com as mãos. Nesta categoria o reconhecimento dos gestos do corpo ocorre por meio de sensores de movimento (e.g. câmera).

Na categoria "Touchscreen" conhecida também no inglês Touch User Interfaces TUIs) é requerido que o usuário toque diretamente em uma tela sensível ao toque e que manipule os objetos por meio desta tela. Este toques (i.e. gestos) nas telas pode ocorrer de três maneiras (Figura 2.10): Single-Touch (Toque único), Multi-Touch (Multitoque) e Multi-Touch All-Point (Multitoque em vários pontos). Nas telas SingleTouch o usuário somente aciona as ações com um dedo. Nas telas Multi-Touch já são utilizados dois dedos para realizar os gestos. Por fim, na tela Multi-Touch All-Point dois ou mais dedos são utilizados.

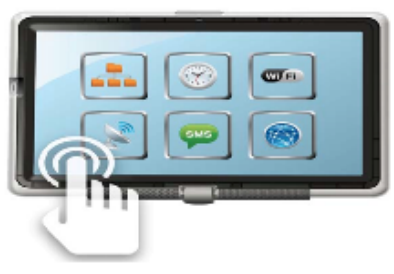

Single-Touch

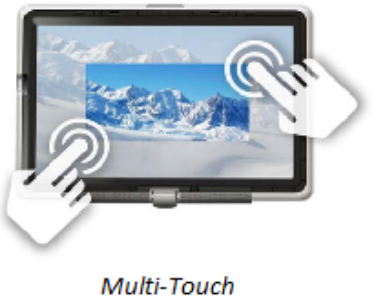

Multi-Touch

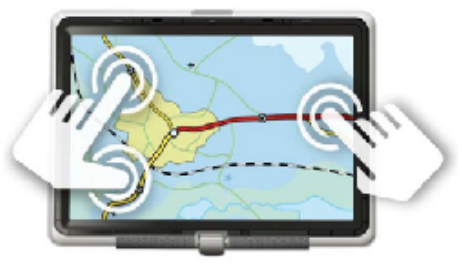

Multi-Touch All

Figura 2.10: Tipos de interação por toque em telas sensiveis ao toque.

No modelo de interação convencional utilizado nos computadores de mesa os usuários interagem com uma interface através de basicamente dois sentidos: visão e toque. Porém, esses dois sentidos são utilizados de forma separada, ou seja, para realizar a entrada dos dados utiliza-se o mouse e o teclado (i.e. toque) e para realizar a saída de dados utiliza-se o monitor (i.e. visão). Diferentemente dos computadores convencionais, os dispositivos com tela sensível ao toque recebem e exibem os dados em uma mesma tela, ou seja, o usuário consegue interagir com o tato e a visão em um único dispositivo (Mathema, 2009).

\subsubsection{Tipos de Conjunto de Gestos}

Os gestos em telas sensíveis ao toque podem ser desenvolvidos e classificados em três conjuntos distintos: gestos pré-definidos, gestos definidos pelos usuários e gestospadrão (Nacenta et al., 2013). Cada conjunto é descrito a seguir: 
- Gestos pré-definidos: São gestos criados a partir dos conhecimentos técnicos e sobre o sistema. Comumente são desenvolvidos pelos designers de interação com o objetivo de criar uma relação forte entre os gestos e os seus significados. Normalmente, os gestos desta categoria são gerados a partir de um estudo feito com usuários reais, que em seguida, são cuidadosamente analisados (e.g. não utilizar gestos semelhantes para várias ações) e selecionados para serem os gestos do produto final.

- Gestos definidos pelos os usuários: São gestos definidos pelos próprios usuários para interagir com a interface do sistema.

- Gestos-padrão: gestos desenvolvidos para realizar a mesma atividade em vários tipos de aplicação (e.g. aumentar uma imagem na tela).

O estudo de Nacenta et al. (2013) demonstra que os gestos definidos pelos usuários apresentam maior nível de satisfação se comparados com os demais gestos (gestospadrão e pré-definidos). Os gestos definidos pelos próprios usuários são considerados mais fáceis de serem memorizados, tendo menos esforço para lembra-los e executálos. Contudo, Nacenta et al. (2013) aconselha que os gestos definidos pelos usuários devem ser utilizados com cautela, não sendo uma solução geral para todos os tipos de software. Por exemplo, ao propor a criação de gestos para interagir com SGI deve-se considerar os conceitos matemáticos e pedagógicos envolvidos no ensino da geometria.

\subsubsection{Interfaces de Toque em Dispositivos Móveis para Educação}

O estudo de Liang et al. (2011) mostra que a maioria dos estudantes e professores acreditam que o uso de dispositivos móveis podem colaborar no ensino e que alguns estudantes já utilizam tablets para realizar as atividades escolares. Naismith et al. (2004) mostra em sua pesquisa que os dispositivos móveis podem fornecer suporte as atividades executadas pelos estudantes, como por exemplo, o trabalho colaborativo por meio de fóruns de discussão que substitui reuniões presenciais, acesso aos materiais e dados a qualquer hora.

Além disso, os estudantes podem realizar as suas atividades em qualquer lugar que desejam, como galerias, museus, bibliotecas, salas de aula e até mesmo em casa, incentivando o aprendizado informal, em que as atividades podem ser executadas também na vida cotidiana. Ainda neste contexto, as atividades dos professores também podem ser beneficiadas com o uso dos dispositivos móveis como, por exemplo, a divulgação e revisão de notas de maneira mais rápida e o gerenciamento de horários de atividades e atendimento direto ao estudante para esclarecer alguma dúvida sem a necessidade de estar em um escritório ou laboratório. 
Apesar dos esforços da comunidade com o intuito de explorar o potencial dos dispositivos móveis como forma de suporte ao processo de ensino-aprendizagem, os estudos sobre o desenvolvimento de interfaces de toque no ambiente educacional aparentemente ainda é limitado (Milrad, 2003).

A maior parte da literatura atual está relacionada apenas com o uso do dispositivo móvel no ambiente educacional, sendo que uma parcela desses estudos são sobre o uso da interface de toque utilizando uma caneta digital (Tootell et al., 2013). Dificilmente encontram-se estudos que trabalham com o desenvolvimento de interfaces de software para dispositivos móveis que tentam solucionar problemas educacionais específicos. Uma das razões para essa lacuna de trabalhos está relacionada com a tarefa de projetar interfaces de software educacional para dispositivo móvel que sejam apropriadas as abordagens pedagógicas, sociais e tecnológicas necessárias no processo de aprendizagem. Está não é uma tarefa trivial e requer conhecimentos multidisciplinar em áreas da computação, educação e design.

\section{Vantagens das Interfaces de Toque e Dispositivos Móveis na Educação}

A mobilidade é uma importante característica dos dispositivos móveis na qual o ambiente de aprendizado pode ser expandido além das salas de aula convencionais, tornando qualquer local um ambiente propício à aprendizagem (Holzinger e Nischelwitzer, A. Meisenberger, 2005) (Parsons et al., 2006). Esta mobilidade pode ser caracterizada pela mobilidade dos serviços, mobilidade do usuário e mobilidade do próprio dispositivo (Parsons et al., 2006). Na mobilidade do usuário, as atividades podem ser realizadas em qualquer lugar e a qualquer hora. A principal vantagem é a não limitação do espaço físico ou de tempo entre professor-aluno e aluno-conteúdo. Desta forma, o aluno não precisa estar no mesmo local e tempo que o seu instrutor para tirar uma dúvida ou solicitar ajuda (Pahwa et al., 2005).

Além disso, o aluno pode acessar o conteúdo (i.e. material didático) quando e onde desejar (Bruno, 2006). No aspecto da mobilidade dos serviços, a informação e os conhecimentos são levados aos alunos no local em que se encontram e nas situações em que as atividades de aprendizagem estão acontecendo (Castillo e Ayala, 2008). $\mathrm{O}$ aluno pode escolher assistir a aula após alguma refeição, compromisso, depois do trabalho ou no final de semana. O estudante possui o controle do seu aprendizado, na qual molda o curso de acordo com suas necessidades e preferências pessoais (Pahwa et al., 2005). A mobilidade do próprio dispositivo se refere ao fato dos dispositivos serem leves e pequenos, facilitando seu uso e transporte.

Diversos trabalhos apontam resultados empíricos dos benefícios dos dispositivos móveis na educação. Por exemplo, o estudo de Sneller (2007) apresenta um experimento utilizando o tablet em sala de aula abordando o ensino da literatura, onde os alunos trabalhavam de forma colaborativa e apresentando a resposta dos exercícios 
de forma rápida. No final deste experimento, o autor realizou uma pesquisa de satisfação entre os estudantes ao utilizar o tablet no ambiente de ensino, tendo como resultado, altos níveis de satisfação na entrega do material, aumento da capacidade de aprender e interesse dos alunos na aprendizagem do conteúdo.

Em um outro estudo, relacionado ao uso dos tablets pelos professores, Lai et al. (2012) demonstrou que a maioria dos professores que utilizaram o dispositivo nas salas de aulas perceberam efeitos positivos no ensino, sendo possivel maior alcance das metas e a redução da carga horaria de trabalho. Além disso, o estudo aponta que os professores consideraram que o uso destes dispositivos podem incentivar os alunos a aprender a matemática e que é adequado o seu uso pós-aula (e.i. uso fora das salas de aula), mas que não é apropriado para todos os assuntos.

\section{Desafios e Limitações das Interfaces de Toque e Dispositivos Móveis na Educação}

Apesar dos dispositivos móveis e as interfaces de toque apresentarem várias vantagens (visto subseção anterior), no aspecto educacional, as abordagens pedagógicas para a aprendizagem com os dispositivos móveis ainda estão sendo pesquisadas, não existindo uma metodologia pedagógica bem formalizada para aplicar o uso dos dispositivos móveis de maneira efetiva no ambiente educacional (Parsons et al., 2006) (Kalloo e Mohan, 2011). No aspecto referente ao dispositivo, os desenvolvedores enfrentam alguns desafios e limitações como: (i) limitação do tamanho da tela, (ii) duração da bateria, (iii) conectividade, (iv) capacidade de processamento e, (v) espaço insuficiente de armazenamento.

A limitação do tamanho da tela dos dispositivos oferecem um grande desafio aos desenvolvedores, e principalmente aos projetistas de interface e interação, pois como a tela é pequena se comparada as telas de desktops (computadores de mesa), é preciso ter um grande cuidado na escolha da posição, forma, estilo e conteúdo que será disposto na tela (Parsons et al., 2006) (Kalloo e Mohan, 2011).

No contexto educacional, se uma interface não for desenvolvida de acordo com critérios de usabilidade ${ }^{12}$ o aprendizado do aluno pode ficar comprometido, pois pode haver uso excessivo da carga cognitiva do aluno para o aprendizado da tela e não para a aprendizagem do conteúdo, gerando confusão e até desmotivação por parte dos alunos (Plass et al., 2003) (Sung e Mayer, 2013).

Além disso, há uma grande variedade de dispositivos à venda no mercado, com características diferentes, dentre elas o tamanho da tela, o que dificulta o desenvolvimento de um software portável para vários tipos de dispositivos.

Outro aspecto relevante é a duração da bateria (Parsons et al., 2006) (Kalloo e Mohan, 2011). Em alguns casos, o tempo de uso limitado das baterias, pode atra-

\footnotetext{
${ }^{12}$ É o desenvolvimento de uma interface de acordo com métodos e técnicas que aumentam a usabilidade para facilitar a utilização da interface pelo usuário.
} 
palhar as atividades dos alunos, principalmente caso a bateria acabe na metade da solução de algum exercício mais complexo ou um vídeo/exposição de média de longa duração.

Alguns aspectos do dispositivo móvel pode afetar na duração da bateria, como por exemplo, a conectividade e o processamento. A conectividade pode ocorrer por WiFi ou 3G, sendo que este último, quando o serviço da operadora está indisponível, consome grande parte da bateria tentando encontrar o sinal. Além disso, se o serviço está indisponível ou a velocidade está muito baixa, impossibilita a realização das tarefas pelos alunos. A capacidade de processamento também consome grande parte da bateria, sendo que os dispositivos com maior velocidade gastam mais energia de processamento.

Ademais, os desenvolvedores devem levar em consideração a capacidade de processamento do dispositivo ao desenvolverem um aplicativo educacional. Alguns softwares requerem muito processamento e podem tornar-se lentos ou até mesmo levar ao encerramento do aplicativo contra a vontade do aluno. Em alguns casos, esta situação compromete totalmente a utilização do software e, consequentemente, o aprendizado.

Ainda neste cenário, alguns softwares podem solicitar que o aluno faça download do conteúdo por meio da internet. Neste caso, pode ocorrer um problema de espaço insuficiente de armazenamento, devido ao tamanho limitando existente nestes dispositivos. Isto significa que o aluno não conseguirá realizar o download do conteúdo até que não libere mais espaço em seu dispositivo.

\subsection{Avaliação de Interfaces}

Como exposto na Seção 2.3 deste trabalho, as interfaces são um importante meio de visualização de informações e interação com o software pelos estudantes. As interfaces de software podem apresentar de diversas maneiras os elementos visuais em tela (e.g, cores e ícones) e os componentes físicos para entrada de dados (e.g. teclado e mouse), fazendo com que algum deles possam ser difíceis de se identificar e manipular.

Além disso, ao projetar uma interface também é necessário considerar que cada usuário trabalha de forma única, fazendo com que a facilidade do uso da interface seja considerado difícil para algumas pessoas, mas fácil para outras. Ou seja, além do processo de design ser importante para eliminar a possibilidade de desenvolver uma interface de maneira inadequada e impedir que os usuários não utilizem ou abandonem o uso do sistema (Bat, 2001), o teste de usabilidade também é necessário para verificar se a interface é adequada para utilização.

De acordo com Rubin e Chisnell (2008) o termo teste de usabilidade refere-se a qualquer técnica usada para avaliar uma interface (ou sistema). O teste de usabili- 
dade é uma ferramenta de pesquisa, que possui raízes na metodologia experimental. Há uma variedade de testes que podem ser conduzidos, desde testes simples aos mais complexos com vários participantes e equipamentos. O principal objetivo do teste de usabilidade é identificar as deficiências existentes nas interfaces, para posteriormente serem corrigidos, garantindo sua utilidade por um grande número de pessoas, facilidade de aprendizagem, ajuda na execução de tarefas de forma eficiente e eficaz, e uma experiência agradável aos usuários que estão utilizando o sistema (Rubin e Chisnell, 2008) (Bat, 2001).

\subsubsection{Definição de Usabilidade}

De acordo com Nielsen (1993), a usabilidade é um dos fatores que pode influenciar em como o usuário aceita um determinado software (i.e. produto). A aceitação do software pelo usuário está conectada com sua capacidade em satisfazer as necessidades dos usuários. Cinco fatores são tradicionalmente associados a usabilidade: (i) capacidade de aprendizado, (ii) eficiência, (iii) capacidade de memorização, (iv) erros e (v) satisfação.

O software deve permitir que o usuário consiga aprender facilmente sobre suas funções e como executá-las rapidamente. O software também deve ser eficiente, permitindo que o usuário seja mais produtivo. Além disso, o software deve ser fácil de ser memorizado, para que quando deixe de ser utilizado por um período, não exija do usuário tempo excessivo de reaprendizagem. Se um usuário cometer algum erro ao utilizar o software, estes erros devem ser fáceis de serem identificados a fim de orientá-lo a remediar o problema e retornar as suas atividades. E por fim, os usuários devem sentir satisfação ao utilizar o software evitando que seja abandonado ou trocado por outro software disponível (Nielsen, 1993) (ISO, 2000).

A usabilidade normalmente é avaliada por testes com a participação de usuários. Estes usuários podem ser usuários reais, que utilizariam o sistema no cotidiano ou especialistas, que possuem conhecimento sobre técnicas e metodologias de avaliação de interfaces. Usualmente, o teste realizado por usuários reais acontece sem tarefas pré-definidas, executando as atividades mais frequentes; diferentemente dos especialistas, que seguem critérios específicos para as suas avaliações.

Outro tipo de teste que também pode ser realizado é em ambiente controlado, como em laboratórios, utilizando participantes reais ou voluntários, que precisam executar tarefas pré-definidas (Nielsen, 1993). Assim, para medir a usabilidade, é extraído um conjunto de dados padrão a partir da experiência de um determinado grupo de usuários. 


\section{Métodos de Avaliação de Usabilidade}

Jeffries e Desurvire (1992) classificam os métodos de avaliação de usabilidade em ensaios de usabilidade (Usability Testing) e inspeção de usabilidade (Usability Inspection). Os ensaios de usabilidade podem envolver (i) observações, (ii) questionários, (iii) entrevistas, (iv) verbalização de procedimentos (Thinking Aloud), (v) interação construtiva, (vi) ensaio retrospectivo, (viii) captura automática a partir da aplicação, e (ix) discussões em grupo.

Usualmente, os ensaios de usabilidade constituem em testes em ambientes reais ou em ambientes controlados, em que os especialistas coletam as informações e problemas relacionados com as interações durante o uso do software por um grupo de usuários (Jeffries et al., 1991) (Nielsen, 1993) (Grice et al., 2013).

Este método de avaliação de usabilidade utiliza preferencialmente usuários reais, visando coletar informações diretamente em ambientes em que os usuários trabalham. Nesta situação, as informações coletadas são consideradas válidas, sendo mais relevantes e mais confiáveis ao serem analisadas. Os resultados também podem ser afetados pela quantidade de vezes que o experimento é realizado. Quanto maior o número de experimentos e de usuários, melhor e mais confiável são os resultados. Contudo, estes resultados também devem ser cautelosamente analisados, pois cada usuário possui um modo específico de trabalhar e experiências pessoais que podem influenciar nos resultados obtidos (Nielsen, 1993).

As inspeções de usabilidade envolvem (i) revisões sistemáticas, (ii) diretrizes de projetos, guias de estilo e padrões, (iii) avaliação heurística, e (iv) inspeção fundamentada na perspectiva. Em geral, as inspeções de usabilidade são realizadas por avaliadores, como ergonomistas, engenheiros de software, engenheiros de usabilidade, que investigam aspectos referentes à usabilidade seguindo critérios ou heurísticas. O uso de avaliadores para realizar inspeções de usabilidade é utilizado principalmente para minimizar custos. Geralmente, o recrutamento de um número suficiente de usuários reais para realizar testes em todas as versões e executar todas as tarefas pode ser difícil e de alto custo (Nielsen, 1995) (Sivaji et al., 2011).

O estudo de Jeffries e Desurvire (1992) comparou ensaios de usabilidade e inspeção de usabilidade para descobrir qual dos dois tipos de avaliação encontrava mais problemas de usabilidade. Como resultado deste estudo verificou-se que os especialistas que utilizaram a avaliação heurística da inspeção de usabilidade encontraram mais problemas de usabilidade se comparado com os usuários comuns que utilizaram os ensaios de usabilidade. Contudo, é importante enfatizar que a avalição heurística deve ser realizada por especialistas (i.e. engenheiros de software ou especialistas em usabilidade), caso contrário os resultados podem não ser confiáveis(Nielsen, 1992).

Neste contexto, este trabalho utilizará a avaliação heurística com apoio de espe- 
cialistas para avaliar a usabilidade da interface proposta para um SGI baseado em gestos com tela multitoque.

\section{Avaliação Heurística}

A avaliação heurística se fundamentou em um conjunto de critérios para identificar problemas de usabilidade em interfaces do usuário (Nielsen, 1992) (Nielsen, 1993) (Baker et al., 2001). Estes critérios são aplicados por especialistas para inspecionar visualmente uma interface e julgar a sua conformidade de acordo com os critérios heurísticos. A heurística são regras gerais usados para avaliar e descrever propriedades comuns das interfaces, ajudando os especialistas a detectarem problemas de usabilidade de maneira mais fácil. Nielsen (1993) propõe uma lista dez heurísticas, a fim de guiar os especialistas na avaliação de usabilidade da interface:

- Visibilidade do status: a interface precisa mostrar ao usuário o que está acontecendo no sistema;

- Relacionamento entre a interface do sistema e o mundo real: a interface deve apresentar elementos reais, que sejam lógicos ou naturais ao usuário, evitando termos técnicos;

- Controle do usuário e liberdade: o sistema deve permitir que o usuário consiga desfazer ou refazer as suas ações, tendo "saídas de emergência"fáceis de serem identificadas pelos os usuários;

- Consistência e padrões: deve-se evitar confundir os usuários com ícones, palavras ou ações similares. O sistema deve apresentar padrões, tratando as ações similares da mesma maneira, a fim de facilitar a identificação pelo o usuário;

- Prevenções de erros: o sistema deve apresentar um bom design para evitar que os erros sejam cometidos pelos os usuários. Além do design, os desenvolvedores devem apresentar caixas de diálogos de confirmação antes de realizar uma ação;

- Reconhecimento em vez de lembrança: deve-se evitar acionar a memória do usuário para lembrar cada elemento do sistema. Para isto, as instruções devem ser visíveis e de fácil recuperação;

- Flexibilidade e eficiência de uso: o sistema deve ser, ao mesmo tempo, fácil para os usuários iniciantes e permitir agilidade aos usuários experientes, que pode ser alcançado por meio de atalhos;

- Estética e design minimalista: a interface não deve conter informações desnecessárias ou raramente usadas pelos usuários; 
- Ajuda para reconhecer, diagnosticar e corrigir erros: as mensagens de erros devem ser em linguagem simples, indicar o problema e sugerir uma solução;

- Ajuda e documentação: as informações de documentação e ajuda devem ser de fácil acesso, que sejam capazes de orientar o usuário em sua tarefa, não ocupando muito o seu tempo.

A cada heurística avaliada, é possível atribuir um grau de severidade entre 0 a 4 Tabela (2.1) à ocorrência do problema, atribuindo um valor aos problemas encontrados e ajudando os desenvolvedores a estimarem o investimento para solucionar o problema de usabilidade. Normalmente são calculados depois da realização das avaliações e executados de forma independente pelos os avaliadores. O grau de severidade combinam quantas vezes um problema ocorre (frequência), o impacto desse problema (quão grave é cada ocorrência) e a persistência do problema (se é isolado, acontecendo somente uma vez ou repetitivo).

Tabela 2.1: Grau de Severidade das heurísticas (Adaptado de Nielsen (1993)).

\begin{tabular}{||c|l||}
\hline \hline Grau de Severidade & \multicolumn{1}{c|}{ Descrição } \\
\hline \hline 0 & Não concordo que seja um problema de usabilidade \\
\hline 1 & $\begin{array}{l}\text { Cosmético: problema superficial, que precisa ser somente } \\
\text { quando houver tempo e dinheiro } \\
\text { Leve: problema de usabilidade pequeno, que possui baixa } \\
\text { prioridade para ser solucionado }\end{array}$ \\
\hline 2 & $\begin{array}{l}\text { Sério: problema de usabilidade severo, que possui priori- } \\
\text { dade e deve ser corrigido assim que possivel }\end{array}$ \\
\hline 3 & $\begin{array}{l}\text { Crítico: possui prioridade máxima e precisa de intervenção } \\
\text { imediata por impedir que os usuários utilizem apropriada- } \\
\text { mente a interface }\end{array}$ \\
\hline
\end{tabular}

A avaliação heurística é frequentemente utilizada por pesquisadores que procuram avaliar a usabilidade de uma interface em um curto período de tempo e que o processo de avaliação tenha um custo baixo. Normalmente é conduzido de 3 a 5 avaliadores, que geralmente conseguem identificar de $75-80 \%$ de todos os problemas de usabilidade e por ser bem documentada, pode ser replicada facilmente (Baker et al., 2001). O processo de avaliação se inicia com a inspeção individual da interface, sendo somente no final das atividades de avaliação que os resultados são integrados e confrontados. Todo o processo de avaliação pode ser registrado por meio de questionários eletrônicos ou em papel e por equipamentos audiovisuais.

Devido aos baixos custos da avaliação heurística e menor tempo para avaliar a usabilidade de um software, esta abordagem foi escolhida para avaliar os softwares de GI com interfaces de toque existentes na área e também o software proposto neste presente trabalho de mestrado. Além dos benefícios de custo e tempo, também foi 
observado que a literatura sugere que a avaliação heurística por especialistas pode encontrar mais problemas comparado com avaliações realizadas por usuários.

\subsection{Considerações finais}

No decorrer deste capítulo apresentou-se os conceitos fundamentais utilizados nesta dissertação. Inicialmente, o conceitos sobre os softwares geometria interativa foram introduzidos. Em seguida, discutiu-se sobre a importância da interface para estes softwares e a possibilidade de desenvolver interfaces de SGI em dispositivos móveis com tela multitoque. Finalmente, foram apresentados os métodos de avaliação de interface, com foco na avaliação heurística que será utilizada como ferramenta para analisar e comparar a usabilidade de diferentes interfaces de SGI.

Os SGI auxiliam no ensino da geometria interativa por meio da tecnologia. Nestes softwares, o estudante consegue realizar a construção dos objetos geométricos e manipulá-los de forma dinâmica. Além da facilidade de construção e manipulação, os softwares de GI possibilitam que os estudantes participem ativamente da construção do seu conhecimento, testando e gerando hipóteses/conjecturas que podem ser verificadas rapidamente. De acordo com a literatura, os estudantes que aprendem geometria com a GI mostram-se mais engajados e motivados com as suas atividades, e também utilizam mais a linguagem matemática para descrever o seu conhecimento (Isotani, 2005). Contudo, para que esse aprendizado ocorra adequadamente, a interface deve ser bem projetada. No contexto de interfaces de GI para dispositivos móveis, existe uma carência de estudos relacionados e, portanto, torna-se uma excelente oportunidade de pesquisa. Assim, este capítulo também apresentou os conceitos relacionados com gestos e interfaces multitoque. Estas interfaces são disponibilizadas principalmente em dispositivos móveis e suas características podem contribuir no processo de ensino-aprendizagem. Por fim, com o intuito de prover os fundamentos básicos relacionados com os métodos de avaliação de interface introduziu de forma sucinta o conceito de teste de usabilidade, com foco na avaliação heurística que será utilizada como ferramenta de análise da interface proposta nesta dissertação. 


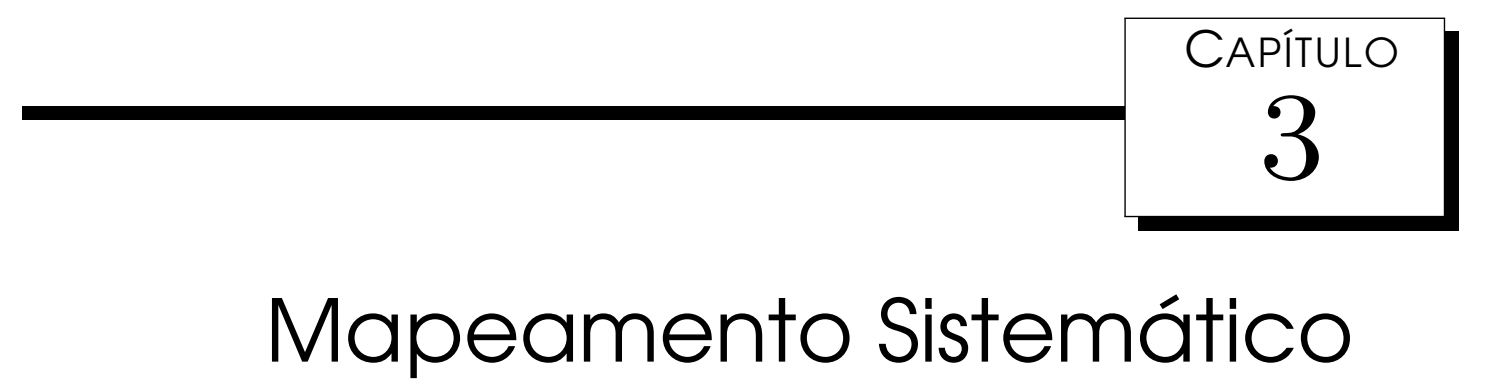

Um mapeamento sistemático foi conduzido e foi utilizado neste trabalho para coletar e categorizar as pesquisas existentes na área de geometria interativa, respondendo algumas questões de pesquisa essenciais para fundamentar esta proposta de mestrado. As questões de pesquisa investigadas neste trabalho procuram identificar nos softwares de GI atuais quais formas de interação são as mais utilizadas (e.g. baseado em toque, clique ou caneta), quais as principais formas de entrada (e.g. mouse ou teclado) e saída (e.g. representação em 2D ou 3D) de dados e para quais tipos de dispositivos estes softwares têm sido comumente desenvolvidos (e.g. computador de mesa ou tablet).

Um mapeamento sistemático é uma forma de sintetizar a informação existente respondendo uma ou mais questões de pesquisa de maneira imparcial. O mapeamento segue uma metodologia que busca a natureza, extensão e quantidade dos estudos publicados (estudos primários ${ }^{1}$ ) em uma determinada área de interesse (Petersen et al., 2008). Estudos secundários, como os mapeamentos sistemáticos, utilizam os estudos primários como base da pesquisa e são recomendados para a identificação de áreas de pesquisa que possuem carência de estudos (Pretorius e Budgen, 2008).

Nas Seções seguintes serão apresentadas as etapas realizadas para condução do mapeamento sistemático. Descreve-se sucintamente o processo conduzido na Seção 3.1; na Seção 3.2 são apresentadas as questões de pesquisa que motivaram a realização do presente mapeamento; a busca dos estudos primários é detalhada na Seção 3.3; a triagem dos estudos primários e a classificação dos artigos são apresentados

\footnotetext{
${ }^{1}$ São estudos individuais que contribuem para uma mapeamento sistemático ou uma revisão sistemática (Kitchenham e Charters, 2007).
} 
nas Seções 3.4 e 3.5, respectivamente; a descrição da categorização resultante é apresentada na Seção 3.6; um mapeamento dos estudos primários e sua análise é oferecida na Seção 3.7. A síntese dos estudos do mapeamento é apresentada na Seção 3.8; e por fim, ameaças à validade e as considerações finais são discutidas nas Seções 3.9 e 3.10 .

\subsection{Processo para Condução de Mapeamento Sistemáticos}

Este estudo baseou-se nas diretrizes propostas por Petersen et al. (2008) e foi conduzido de acordo com os cinco passos a seguir: (i) definição de questões de pesquisa, (ii) busca por estudos primários relevantes, (iii) triagem dos estudos primários, (iv), classificação dos artigos, e (v) mapeamento e extração das informações que atendem as questões de pesquisa previamente estabelecidas. Estes passos podem ser aplicados de forma sequencial e executados diversas vezes de acordo com a necessidade e alteração das informações da pesquisa. Ao final da realização de todos os passos, o resultado final é o mapeamento sistemático.

\subsection{Definição de Questões de Pesquisa do Mapeamento Siste- mático}

A definição das questões de pesquisa é uma atividade importante no planejamento do mapeamento sistemático. As questões devem ser respondidas de acordo com o propósito do mapeamento, sendo que todos os aspectos do mapeamento dependem fortemente das questões de pesquisa (Dybået al., 2007). Até o momento a maioria das ferramentas de GI foram desenvolvidas especialmente para computadores de mesa, com dispositivos de entrada como teclado e mouse. Porém, nos últimos anos surgiram novas formas de interação, como por exemplo, as telas sensíveis ao toque. Por esta razão, este mapeamento tem o objetivo de encontrar quais formas de interação com os dados que os softwares de GI vêm sendo desenvolvidos, quais as formas de entrada e saída e para quais tipos de dispositivos estes softwares vêm sendo mais desenvolvidos. Portanto, as seguintes questões de pesquisa foram formuladas para atender este objetivo:

QP01: Quais são as principais formas de interação ${ }^{2} 3$ investigadas para a utilização destas interfaces nestes softwares de GI?

\footnotetext{
${ }^{2} \hat{\mathrm{E}}$ a forma de como um elemento se relaciona ou interage com outro elemento.

${ }^{3}$ Possíveis formas de interação (e.g interação por toque ou clique) com objetos geométricos construídos.
} 
QP02: Quais são as principais formas ${ }^{4}$ de entrada e saída de dados investigadas para o desenvolvimento de interfaces de softwares de GI?

QP03: Quais são os principais dispositivos para os quais softwares de GI têm sido desenvolvidos?

Além das questões de pesquisa, o escopo do mapeamento sistemático também deve ser definido nesta etapa. O escopo descreve a população a ser considerada, intervenção e resultados esperados, como definidos a seguir:

População : estudos primários sobre softwares de GI.

Intervenção : estudos primários que discutem a interface gráfica dos softwares de GI. É importante mencionar que não é necessário que estes estudos primários apresentem alguma técnica de desenvolvimento ou abordagem prática para a proposta. Deste modo, possibilita que o mapeamento apresente uma visão geral sobre as interfaces gráficas dos softwares de GI existentes.

Resultados esperados : uma visão geral das categorias de quais formas de entrada e saída de dados são utilizados para o aprendizado da geometria. Além disso, identificar quais são as formas de interação e para quais tipos de dispositivos estes softwares vêm sendo desenvolvidos. Com este resultado, pretende-se evidenciar a carência de pesquisas dessas determinadas áreas.

\subsection{Busca por Estudos Primários}

Esta etapa é compreendida pela execução da string de pesquisa nas bibliotecas digitais. A fim de obter um maior número de estudos primários, as seguintes bases foram consultadas, pois, de acordo com Dybået al. (2007), estas bibliotecas estão entre as mais relevantes para a área de Computação ${ }^{5}$ :

- ACM Digital Library (portal.acm.org);

- IEEExplore (ieeexplore.ieee.org);

- Scopus (http://www.scopus.com);

- Elsevier - via Science Direct (www.sciencedirect.com); e

- Springer Link - via Science Direct (www.sciencedirect.com).

\footnotetext{
${ }^{4}$ Possíveis formas de entrada (e.g. mouse ou teclado) e saída (e.g. representação 2D ou 3D) de dados para construir objetivos geométricos.

${ }^{5} \mathrm{Não}$ foram realizadas buscas em artigos português, por não haver um banco de dados para busca avançada disponível para este tipo de pesquisa atualmente.
} 
A string usada nas bibliotecas digitais é formada pelas seguintes palavras-chave e seus sinônimos:

Tabela 3.1: String de pesquisa em inglês.

\begin{tabular}{||c|l||}
\hline \hline Palavra-chave & \multicolumn{1}{c|}{ Termos alternativos e/ou sinônimos } \\
\hline \hline Interactive geometry & $\begin{array}{l}\text { "Dynamic Geometry" OR "Geometry Teaching" OR "Geome- } \\
\text { try Education" }\end{array}$ \\
\hline Interface & $\begin{array}{l}\text { HCI OR "Human-Computer Interaction" OR "Man Computer } \\
\text { Interaction" OR "Human Factors" OR "User Interface" OR } \\
\text { "Computer Interface" OR "Gestural Interface" OR "Human In- } \\
\text { formation Processing" OR gesture OR usability }\end{array}$ \\
\hline
\end{tabular}

A string geral foi construída em duas partes, e formatada de acordo com as regras de cada biblioteca digital, conforme a seguir:

("Dynamic Geometry" OR "Interactive Geometry" OR "Geometry Teaching" OR "Geometry Education") AND (interface OR HCI OR "human-computer interaction" $O R$ "man computer interaction" OR "human factors" OR "user interface" OR "computer interface" OR "gestural interface" $O R$ "human information processing" $O R$ gesture $O R$ usability)

Os autores optaram por utilizar a string de pesquisa somente em língua inglesa devido a preferência por artigos indexados em base de dados consolidadas. A primeira parte da string está relacionada ao ensino da geometria por meio dos softwares de GI e a segunda parte abrange os estudos relacionados com as interfaces destes softwares. O operador boolean OR conecta os os sinônimos da string de pesquisa, enquanto o operador AND conecta as partes. Nenhum campo específico (filtro) foi utilizado para limitar as buscas, como por exemplo, data de publicação.

\subsection{Triagem dos Estudos Primários}

\subsubsection{Critérios de inclusão e exclusão}

Os critérios de inclusão determinam a abrangência e validade dos estudos do mapeamento sistemático, sendo previamente definidos no momento da elaboração do protocolo do mapeamento. Os critérios de inclusão elaborados foram os seguintes:

- Se vários artigos mostram estudos similares sobre o mesmo software, somente o mais recente deverá ser incluído;

- Se houver várias versões do mesmo artigo, e.g. uma resumida e outra completa, a mais completa deverá ser incluída; 
- Artigos que descrevem o desenvolvimento ou análise de interfaces de softwares de Geometria Interativa em qualquer plataforma.

Critérios de exclusão são importantes, pois permitem uma maior precisão na eliminação de artigos considerados não relevantes ao contexto da pesquisa em andamento. Por essa razão, durante a análise dos artigos retornados, todos aqueles que enquadraram-se em ao menos um dos critérios de exclusão abaixo foram descartados.

- Artigos que não apresentam relação com interfaces de softwares de Geometria Interativa serão excluídos;

- Estudos que não estejam na língua portuguesa ou inglesa serão excluídos;

- Relatórios técnicos, documentos que estão disponíveis na forma de resumos ou apresentações/slides e também estudos secundários (ou seja, revisões e mapeamentos sistemáticos da literatura) serão excluídos.

Os estudos encontrados nas bases de dados utilizadas foram analisados a fim de identificar aqueles relevantes ao contexto da pesquisa. Esta análise consistiu na aplicação de critérios de inclusão e exclusão previamente definidos.

\subsubsection{Processo de triagem}

A seleção dos artigos consistiu em duas etapas. Na primeira etapa, houve a leitura do título, resumo e conclusão, sendo por fim aplicado os critérios de inclusão e exclusão. A segunda etapa foi realizada a leitura integral dos artigos selecionado, e novamente foi aplicado os critérios de inclusão e exclusão, a fim de se proceder à categorização dos mesmos.

A pesquisa dos estudos primários foi realizada no período do dia 16/05/2013 ao dia 30/05/2013. Primeiramente foram retornados 998 estudos primários das bibliotecas digitais apresentadas na Tabela 3.2. A autora deste trabalho realizou simultaneamente a leitura dos títulos, resumos e palavras-chave, de todos os artigos e cada um gerou a lista de estudos selecionados. A autora discutiu em conjunto com outro pesquisador sobre quais estudos deveriam ser selecionados, e ao final o conjunto inicial de 998 foi reduzido à somente 45 estudos realmente relacionados ao tópico investigado.

Após este passo, foi realizada novamente a leitura dos resumos, introdução e conclusão e a aplicação dos critérios de inclusão e exclusão, o que resultou em um subconjunto de 21 estudos. Em seguida foi realizada a leitura integral dos estudos selecionados a fim de se proceder a categorização dos mesmos. Esta etapa será discutida mais detalhadamente na próxima seção. 
Tabela 3.2: Quantidade de estudos retornados por cada biblioteca digital, total de estudos candidatos e seleção final.).

\begin{tabular}{||l|r||}
\hline \hline ACM Digital Library & 385 \\
\hline Scopus & 338 \\
\hline Elsevier (via Science Direct) & 243 \\
\hline Springer Link (via Science Direct) & 29 \\
\hline IEEExplore & 12 \\
\hline \hline Total & 998 \\
\hline Candidatos & 45 \\
\hline Seleção Final & 21 \\
\hline
\end{tabular}

\subsection{Classificação dos artigos}

Esta etapa consistiu na classificação dos artigos selecionados anteriormente. Para isto, os resumos foram lidos e as palavras-chave dos estudos foram destacadas para apoiar o processo de classificação. Dessa forma, foi possível padronizar e identificar em qual contexto um determinado estudo se insere.

Entretanto, algumas deficiências foram encontradas na condução deste passo. Uma delas deveu-se ao fato de alguns artigos não apresentarem informações suficientes e/ou concisas em seus resumos. Nestes casos, a omissão de informações tornou o processo de classificação e apuração da relevância dos artigos mais complexo e demorado, uma vez que o artigo necessitou ser analisado ou mesmo lido na íntegra ainda na etapa inicial de seleção. Para a solução deste problema, a utilização da abordagem dos resumos estruturados (struct abstract) poderia melhorar a organização e apresentação das informações (Pretorius e Budgen, 2008).

Outros problemas foram encontrados nesta etapa:

- Em alguns artigos, os resumos apresentaram palavras-chave com sinônimos não usuais. Isto dificultou na identificação destas palavras e na classificação do artigo. Este problema foi resolvido com a leitura das outras seções, como a introdução e a conclusão.

- Poucos artigos não apresentaram a lista palavras-chave. Neste caso, esta lista foi extraída do resumo e das seções de introdução e conclusão.

\subsection{Categorização Resultante}

Cada estudo primário foi categorizado com o seu tipo de contribuição. As seis categorias referentes às formas de interações propostas neste mapeamento são apresentadas na Tabela 3.3 e detalhadas nas próximas seções. 
Tabela 3.3: Categoria resultantes de interações.

\begin{tabular}{||c||}
\hline \hline Categorias \\
\hline \hline Baseado em caneta \\
\hline Baseado em clique \\
\hline Baseado em gestos \\
\hline Baseado em toque \\
\hline Háptica \\
\hline Técnicas Diversas \\
\hline
\end{tabular}

Cada categoria apresentada na Tabela 3.3 pode possuir um ou vários estudos primários classificados. A descrição de cada categoria segue abaixo:

Baseado em caneta : Esta categoria faz o uso da caneta digital para que os alunos realizem a construção e a manipulação dos objetos geométricos. A caneta digital pode ser usada em conjunto com outros tipos de dispositivos, como óculos para realidade aumentada e virtual, lousa digital, mesa digital e tela do PDA;

Baseado em clique : Nesta categoria estão incluídos todos os estudos que apresentem a necessidade o teclado e mouse para que haja interação com o software de GI;

Baseado em gestos : Os estudos incluídos nesta categoria apresenta a interação com os softwares de GI por meio de gestos;

Baseado em toque : Nesta categoria foram incluídos os estudos que exploram as interfaces com interação toque, abrangendo os diversos dispositivos que disponibilizam o multitoque e o toque único;

Háptica : Esta categoria apresenta os artigos relacionados a interfaces táteis, sendo o principal objetivo para interfaces direcionadas aos deficientes visuais;

Técnicas Diversas : Os estudos primários classificados nesta categoria apresentaram diversas técnicas de interação, como, por exemplo, Realidade Aumentada, 2D e 3D. Para poder utilizar estas técnicas propostas por cada estudo primário, a câmera é o principal dispositivo para apoiar na utilização do software, bem como o uso de algumas outras ferramentas, como códigos QR e projetores.

Foram também identificadas as categorias referentes aos dados de entrada (ver Tabela 3.4). Usualmente, os dados de entrada possibilita a interação com o software, realizando uma ação no sistema, que gera uma informação de saída ao usuário.

No campo da computação, a interface gráfica possibilita o usuário a utilizar o software de maneira simples, permitindo a comunicação entre o usuário e o computador. 
Tabela 3.4: Categoria resultantes de formas de entrada de dados.

\begin{tabular}{|c||}
\hline \hline Categorias \\
\hline \hline Tela sensível ao toque \\
\hline Caneta digital \\
\hline Projetor \\
\hline Óculos para realidade virtual e aumentada \\
\hline Mesa digital \\
\hline Luvas \\
\hline Dispositivos hápticos \\
\hline Lousa branca \\
\hline Câmera \\
\hline Teclado e mouse \\
\hline
\end{tabular}

Este tipo de interface pode ser considerada uma forma de saída de dados, em que o usuário consegue identificar visualmente as informações na tela, além de possuir vários tipos. A Tabela 3.5 apresenta as cinco formas de saída de dados encontrados neste mapeamento.

Tabela 3.5: Categoria resultantes de saída de dados.

\begin{tabular}{||c||}
\hline \hline Categorias \\
\hline \hline $2 \mathrm{D}$ \\
\hline 2D/RA \\
\hline $3 \mathrm{D}$ \\
\hline $3 \mathrm{D} / \mathrm{RA}$ \\
\hline $3 \mathrm{D} / \mathrm{RA} / \mathrm{RV}$ \\
\hline
\end{tabular}

Foram também identificados para quais dispositivos os softwares de GI vêm sendo desenvolvidos. A Tabela 3.6 apresenta os quatro dispositivos encontrados neste mapeamento.

Tabela 3.6: Categoria resultantes de dispositivos.

\begin{tabular}{||c||}
\hline \hline Categorias \\
\hline \hline Computador de mesa \\
\hline tablet \\
\hline Tabletop \\
\hline PDA \\
\hline
\end{tabular}

Vale destacar que dentre os 21 estudos que compõem a seleção final, dois estudos foram identificados como estudos que apresentam análise das interfaces de um modo geral. Esses estudos apresentam ideias abstratas ou boas práticas de desenvolvimento sem, no entanto, especificar nenhuma técnica, método, modelo ou abordagem 
de como estas interfaces foram desenvolvidas, e por essa razão nenhuma categoria foi criada para eles.

\subsection{Mapeamento dos Estudos Primários e Análise}

Esta seção apresenta a análise dos estudos primários retornados e classificados de acordo com as formas de interação, as formas de entrada e saída e os dispositivos mais adotados para o uso dos softwares de GI. A maioria dos estudos primários selecionados foram publicados na Scopus e posteriormente na ACM Digital Library, como mostrado na Figura 3.1. As outras bibliotecas digitais como Springer e IEEExplore, tiveram 1 e 1 estudos selecionados, respectivamente. Como descrito anteriormente, na Tabela 3.2 também foi procurado na biblioteca digital Elsevier, entretanto, esta biblioteca foi a última a ser pesquisada e não retornou muitos estudos relevantes a pesquisa. Os poucos estudos retornados não passaram nos critérios de inclusão e exclusão.

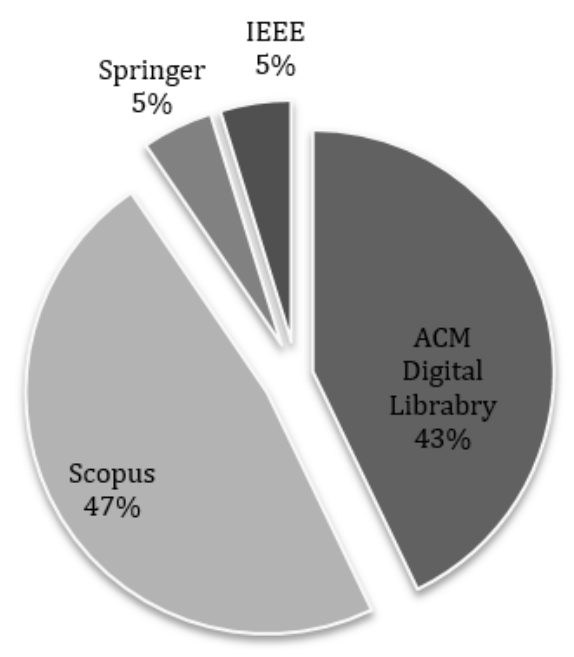

\begin{tabular}{||l|l||}
\hline \hline ACM Digital Library & 9 \\
\hline Scopus & 10 \\
\hline Springer & 1 \\
\hline IEEE & 1 \\
\hline
\end{tabular}

Figura 3.1: Distribuição dos estudos primários de acordo com as bases consultadas.

Em relação aos tipos de publicação, foram analisados os estudos primários publicados em conferências, periódicos, simpósios e como capítulos de livros. A maioria dos estudos selecionados (nove estudos), foram publicados em conferências e periódicos, e em segundo como capítulos de livro com dois estudos. Somente um estudo primário selecionado foi publicado em simpósio. A Figura 3.2 apresenta a quantidade de estudos primários de acordo com o tipo de publicação. É importante mencionar que as áreas de interesse dos estudos selecionados, em sua maioria, apresentam forte relação com diversas subáreas da ciência da computação e com educação. 


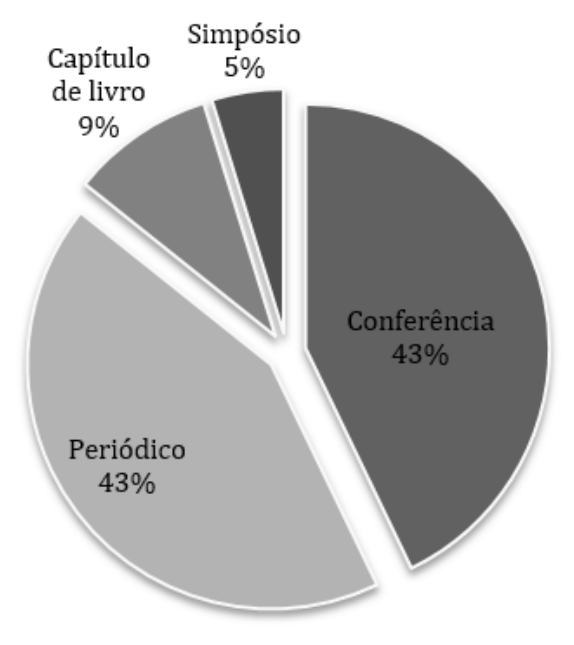

\begin{tabular}{||l|l||}
\hline \hline Conferência & 9 \\
\hline Periódico & 9 \\
\hline Capítulo de livro & 2 \\
\hline IEEE & 1 \\
\hline
\end{tabular}

Figura 3.2: Distribuição dos estudos primários pelo tipo da publicação.

É importante ressaltar que quando dois ou mais estudos primários retornaram reportando a mesma pesquisa, somente a mais recente foi incluída, não considerando o tipo de publicação destes estudos.

A partir da Figura 3.3, pode-se observar que a maioria dos estudos primários selecionados aborda o tipo de interação baseado em clique. Com base nesta evidência, podemos concluir que a resposta à QP1 (Quais são as principais formas ${ }^{6}$ de interação investigadas para a utilização destas interfaces nestes softwares de GI?) é que a maioria dos softwares de GI deve usar a interação baseado em clique. Esta categoria apresentou maior quantidade de números de estudos primários se comparado com as outras categorias, resultando no grupo de evidência (áreas mais enfocadas pelas pesquisas conduzidas). As categorias que a interação ocorre por meio de toque, gestos e háptica podem ser considerados desertos de evidência (do Inglês evidence deserts) (Bailey et al., 2007) devido a carência de pesquisa nessas áreas.

Para verificar as tendências na área, a Figura 3.4 apresenta a relação entre as categorias dos estudos (eixo x) e o ano de publicação (eixo y). Apesar da ocorrência em maior quantidade de estudos primários na categoria baseado em clique, é possível observar que este interesse vêm diminuindo. Nos anos de 2007, 2009 e 2011, esta categoria apresentou três, dois e dois estudos primários respectivamente. Porém, no ano de 2012, esta categoria apresentou somente um estudo primário. Os pesquisadores têm demonstrado interesse nas categoria baseado em toque e técnicas diversas, considerando que estas duas categorias surgiram a partir do ano de 2011 e 2012. Por

\footnotetext{
${ }^{6}$ Possiviveis formas de interação (e.g interação por toque ou clique) com objetos geométricos construídos
} 


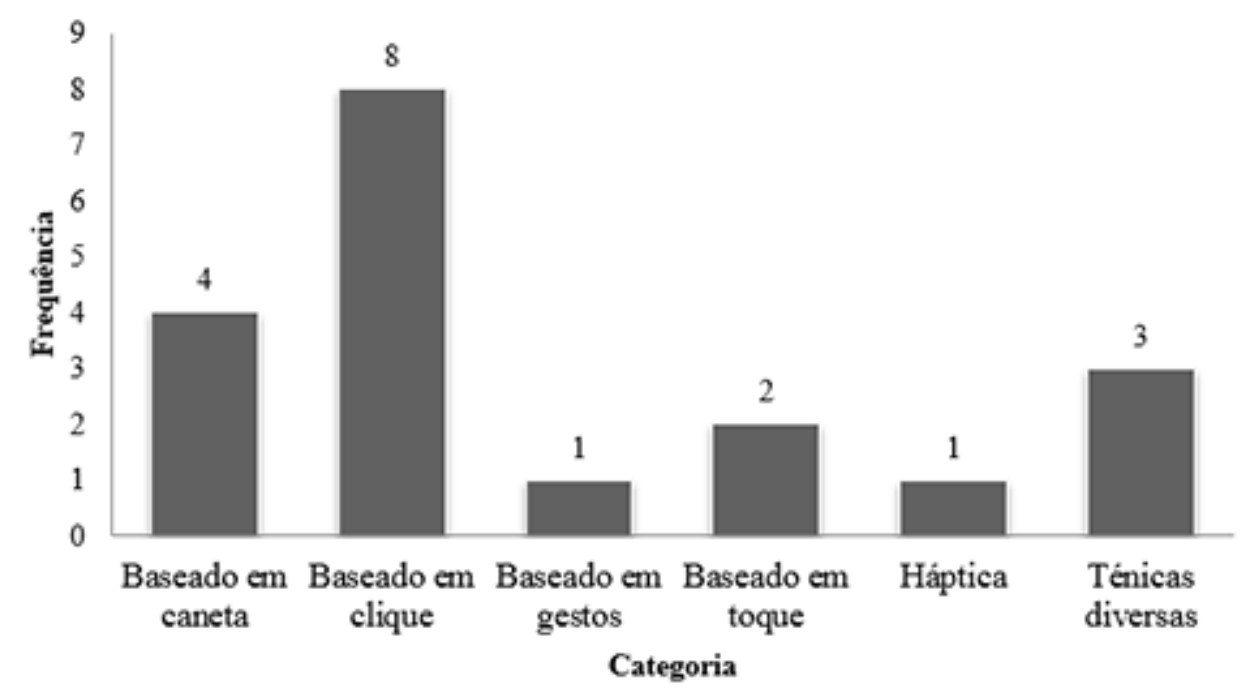

Figura 3.3: Frequência de estudos em cada categoria.

sua vez, as categorias que apresentaram estabilidade no número de estudos primários publicados são baseado em caneta e baseado em gestos, com um estudo cada. Constata-se que a há um estudo a cada três anos para a categoria baseado em caneta. Na categoria baseado em gestos, há somente um estudo no ano de 2006.

Foram identificados também os diferentes tipos de entrada e saída de dados nos quais os softwares de GI utilizam, o que permitiu responder a QP2 (Quais são as principais formas ${ }^{7}$ de entrada e saída de dados investigadas para o desenvolvimento de interfaces de softwares de GI?). Os tipos de entrada são caracterizados por dispositivos que possibilitam a entrada de dados no software de GI. A Figura 3.5 apresenta os tipos de entrada encontrados, que foram classificados em 10 categorias.

Conforme observado, os dispositivos teclado e mouse são os mais utilizados para a entrada de dados, com oito estudos primários. Outros dispositivos utilizados também encontrados foram câmeras, óculos para simular realidade virtual e aumentada e canetas digitais, com três, dois e dois estudos respectivamente. É possivel identificar que outros tipos de dispositivos de entrada são poucos explorados pelos os pesquisadores, como telas sensiveis ao toque, projetores, luvas, mesa digital, lousa branca e por fim, dispositivos hápticos. Em alguns estudos primários, os pesquisadores fizeram a combinação de outras ferramentas com estes dispositivos de entrada, como makers, cartões e ferramentas geométricas tradicionais.

Além dos tipos de entrada, foram identificados os tipos de saída destes softwares de GI. Por meio da Figura 3.6 é possível observar que foram mencionados 5 tipos de saída nos estudos primários analisados. O tipo de saída mais investigado pelos

\footnotetext{
${ }^{7}$ Possíveis formas de entrada (e.g. mouse ou teclado) e saída (e.g. representação 2D ou 3D) de dados para construir objetivos geométricos
} 


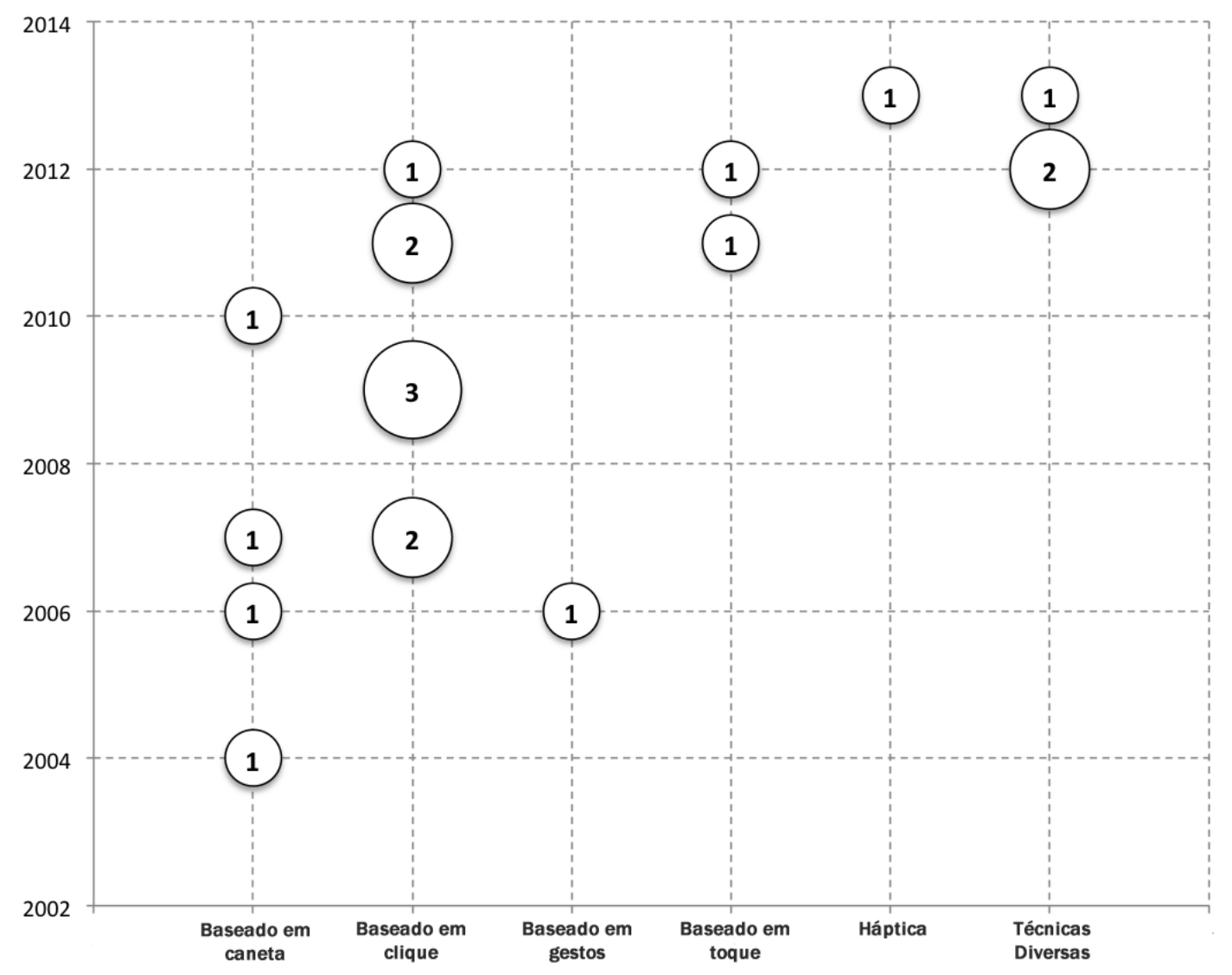

Figura 3.4: Distribuição das categorias por ano.

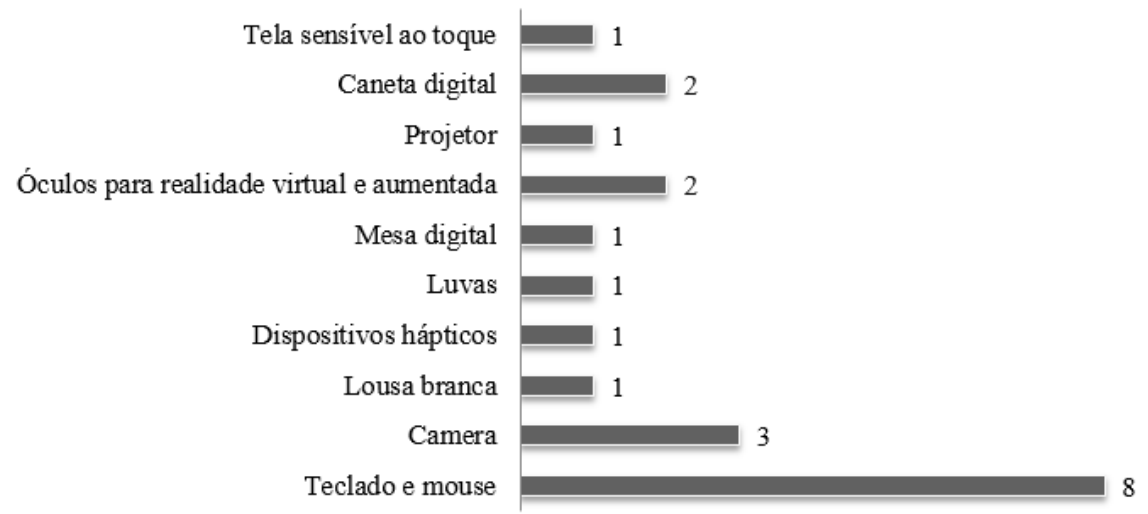

Figura 3.5: Distribuição dos estudos primários por dispositivos de entrada de dados.

pesquisadores é as interfaces $2 \mathrm{D}$ e posteriormente as interfaces $3 \mathrm{D}$. Observa-se que estes tipos de saída são poucos explorados se combinados com outros tipos de saída, como a Realidade Aumentada (RA) e Realidade Virtual (RV).

Na Figura 3.7 é ilustrada a quantidade de estudos primários por tipo de dispositivo, respondendo a QP3 (Quais são os principais dispositivos para os quais softwares 


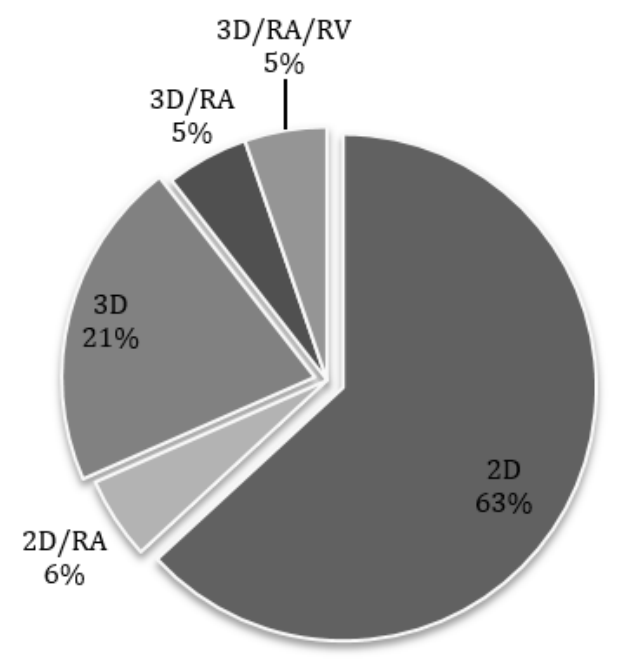

\begin{tabular}{||l|l||}
\hline \hline $2 \mathrm{D}$ & 12 \\
\hline 2D/RA & 1 \\
\hline $3 \mathrm{D}$ & 4 \\
\hline $3 \mathrm{D} / \mathrm{RA}$ & 1 \\
\hline $3 \mathrm{D} / \mathrm{RA} / \mathrm{RV}$ & 1 \\
\hline
\end{tabular}

Figura 3.6: Distribuição dos estudos primários por dispositivos de saída de dados.

de GI tem sido desenvolvidos?). O dispositivo mais investigado pelos os pesquisadores foi o computador de mesa, com 16 estudos primários. Outros dispositivos como tablet, tabletop e PDA apresentaram somente um estudo cada.

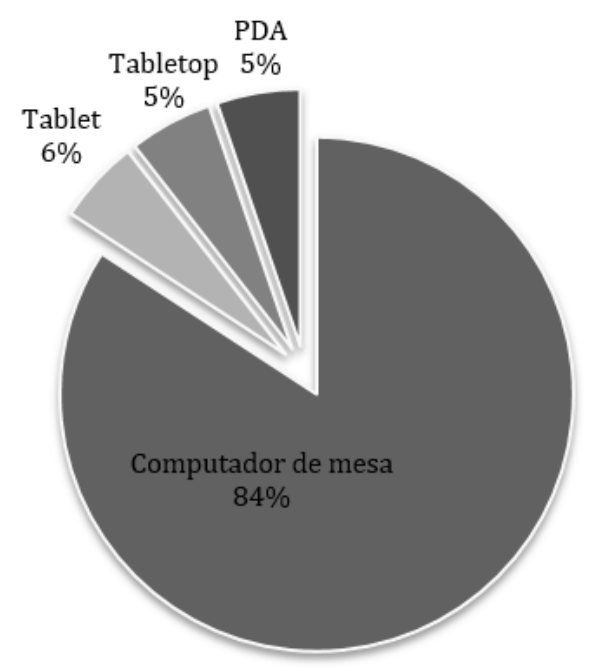

\begin{tabular}{||l|l||}
\hline \hline Computador de mesa & 16 \\
\hline Tablet & 1 \\
\hline Tabletop & 1 \\
\hline PDA & 1 \\
\hline
\end{tabular}

Figura 3.7: Distribuição dos estudos primários por tipo de dispositivo.

No gráfico apresentado na subseção seguinte possibilita uma análise mais detalhada do mapeamento sistemático resultante, evidenciando os grupos de evidência e desertos e a distribuição dos estudos primários de acordo com as categorias. 


\subsubsection{Mapa}

A Figura 3.8 apresenta um diagrama do tipo bubble chart que fornece uma visão mais precisa da frequência das ocorrências dos estudos primários selecionados de acordo com o tipo de contribuição e o tipo de pesquisa realizada de acordo com as definições propostas por Petersen et al. (2008), descritas na Seção 3.1. O eixo y (centro) representa a categoria do estudo; à esquerda estão os tipos de contribuição, e à direita os tipos de pesquisa conduzida. O tamanho de cada bolha é determinada pelo número de estudos primários classificados como pertencentes aos pares correspondentes às coordenadas da bolha. Este resumo fornece uma visão panorâmica que possibilita identificar os estudos já realizados na área, juntamente com lacunas e oportunidades para futuras pesquisas.

No lado da Research Facet (Faceta de pesquisa), é possível observar que não foram encontrados artigos que procuram esboçar novas idéias (Philosophical Papers) ou artigos que relatam como algo deve ser feito na prática pelo autor (Experience Report). A categoria que apresenta mais artigos é a "Evaluation Research", que explora como uma técnica é implementada na área e quais suas consequências. Entretando, a categoria que apresentou menos artigos, foi a "Opinion Paper", que é expressa a opinião pessoal de alguém. No lado da "Contribution Facet" (Faceta de contribuição), nenhum artigo apresentou alguma métrica (Metric), sendo apresentado, na maioria dos artigos, ferramentas (Tool). Outras categorias, como modelo (Model), método (Method) e processo (Process) não foram classificados muitos artigos. 


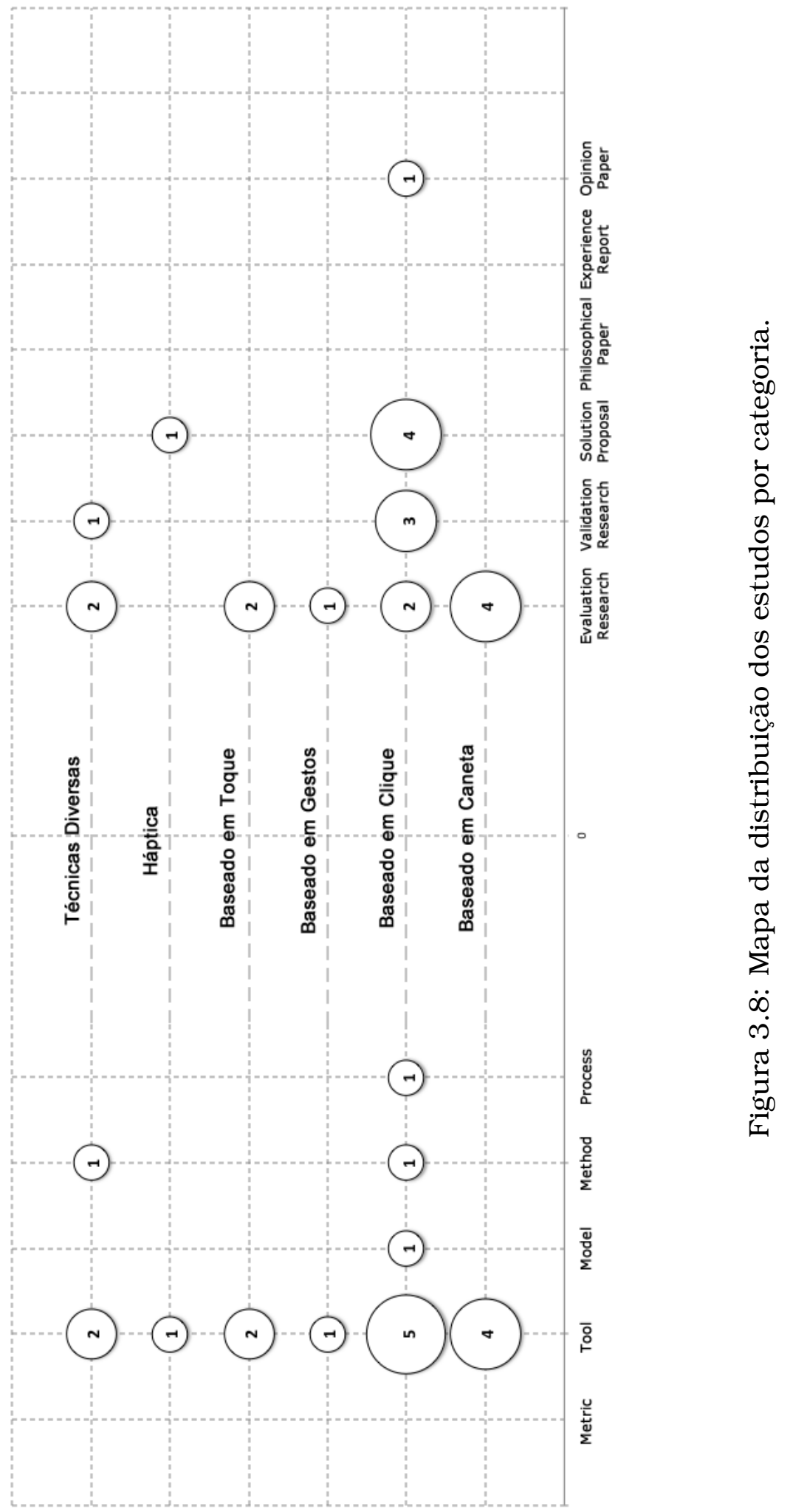


A tabela A.1 disponibilizada no Apêndice A apresenta a lista dos estudos primários selecionados para este mapeamento, com os campos: autor, título do artigo, tipo de pesquisa, e tipo de contribuição. Também está disponibilizada a tabela 2 no Apêndice referente aos estudos que não foram classificados em nenhuma categoria.

\subsection{Síntese dos estudos do mapeamento}

Oito dos estudos encontrados fazem uso de teclado e mouse para prover interatividade ao software de GI. Dentre este oito, dois estudos investigam a relação entre o volume de informações apresentados nas interfaces, o consumo da carga cognitiva dos estudantes e seu impacto no aprendizado dos usuários (Reis et al., 2012) (Schimpf e Spannagel, 2011). Outro estudo com interação por meio do teclado e mouse é apresentado por Kovárová e Sokolsky (2011), que analisaram os problemas encontrados nas interfaces dos softwares Cabri 3D e Archimedes Geo3D, e com os resultados desenvolveram um software com interface em 3D chamado Stereo3D.

Alguns estudos substituíram o uso do mouse pela a caneta digital, como o estudo de Kortenkamp e Materlik (2004), na qual desenvolveram uma versão do software Cinderella para PDA. Além deste estudo, outros três estudos foram classificados na categoria "Baseada em caneta". Tanto o estudo de Liu et al. (2007) quanto o de Song e Zhu (2010) utilizam a caneta digital para reconhecer os objetos geométricos construídos por gestos utilizando a lousa branca. Porém, o estudo de Song e Zhu (2010), ao invés da utilização da lousa branca, os alunos interagem por uma mesa digital substituindo o mouse, nos computadores de mesa. Em ambos softwares, é possível desenhar manualmente os objetos geométricos enquanto o sistema encarrega-se de reconhecer automaticamente o que está sendo desenhado.

Os estudos classificados "Baseado em toque" substitui o uso da caneta digital ou do mouse pelo toque direto na tela sensivel ao toque. Somente dois estudos selecionados foram classificados nesta categoria. No estudo de Blagojevic et al. (2012) são explorados o desenho de objetos geométricos por meio de ferramentas tradicionais como régua, compasso ou transferidor na superfície da tela do textittablet. Apesar deste estudo não ser exclusivamente sobre softwares de GI, os autores enfatizam que esta ferramenta pode também ser utilizada para o ensino da geometria. Além deste estudo, Blanke e Schneider (2011) desenvolveram um software para tabletop em que os alunos podem interagir com os objetos por meio de uma interface multitoque.

Somente um estudo foi classificado como "Baseado em gestos". Neste tipo de interação, cada objeto geométrico possui um tipo diferente de gesto de construção e manipulação. Fabre e Sternberger (2006) acredita que a abordagem de gestos para a construção de objetos geométricos é intuitiva e natural para que os estudantes possam utilizar nos softwares de GI, porém se o software possuir vários tipos de 
gestos e um alto grau de liberdade, pode tornar-se confuso de ser aprendido.

Três estudos primários classificados como "Técnicas Diversas" apresentaram diversas técnicas de interação, como, por exemplo, Realidade Aumentada, 2D e 3D. Para poder utilizar estas técnicas propostas por cada estudo primário, a câmera é o principal dispositivo para apoiar na utilização do software, bem como o uso de algumas outras ferramentas, como códigos QR e projetores. A implementação da abordagem proposta por Banu (2012) explora o uso de câmeras para poder reconhecer os códigos QR (abreviação de Guick Response) e assim projetar os objetos geométricos por meio da Realidade Aumentada em 3D. Como resultado, os alunos aprendem geometria espacial por meio da técnica abordada pelo o autor.

Já o estudo proposto por Starcic et al. (2013) utiliza objetos físicos em formatos de objetos geométricos para que os alunos possam interagir sozinho ou de forma colaborativa. Esta interação é reconhecida por meio de uma câmera posicionada na frente dos alunos no momento das atividades e as instruções são reconhecidas e processadas por meio do computador de mesa. O estudo de Bonnard et al. (2012) também faz o uso da câmera para identificar qual instrução deverá ser executada. Os alunos espalham cartões na mesa, contendo uma descrição sobre o objeto e um código QR. A câmera faz a leitura deste código QR, processa a instrução e projeta o objeto geométrico por meio do projetor por meio da Realidade Aumentada.

$\mathrm{E}$ finalmente, dois estudos não foram classificados em nenhuma categoria em especial, apresentando metodologias de interação nas interfaces para estes softwares. Erez e Yerushalmy (2007) exploraram como a manipulação dos objetos geométricos pelo "arrasto do mouse" em tela pode afetar na percepção dos conceitos geométricos e no aprendizado da geometria. E no estudo de Mackrell (2011) apresenta uma análise como os componentes de uma tela devem ser desenvolvidos, como por exemplo a barra de ferramentas.

\subsection{Ameaças à Validade}

A fim de garantir uma seleção imparcial, as questões de pesquisa e os critérios de inclusão e exclusão foram definidos no início do mapeamento. Porém, não pode ser descartado a ameaça em relação a avaliação da qualidade dos estudos incluídos, em que foram selecionados sem qualquer atribuição de pontuação.

Outra possível ameaça identificada é a possibilidade de alguns artigos relevantes não serem incluídos, devido a utilização de um conjunto limitado de bibliotecas digitais. Além disso, o sistema de classificação e categorias elaborados representam também uma ameaça a validade. Como mostrado por Pretorius e Budgen (2008), a melhor maneira de classificar e categorizar os resultados só é obtido ao final da seleção. Além disso, o agrupamento dos estudos em mais de uma categoria pode re- 
presentar uma ameaça potencial para contagem de frequência e as estatísticas deste estudo de mapeamento.

\subsection{Considerações finais}

No decorrer deste capítulo foi apresentado o mapeamento sistemático conduzido a fim de determinar: (i) quais formas de interação são mais investigadas no desenvolvimento dos softwares de GI, (ii) quais formas de entrada e saída são mais exploradas e; (iii) quais são os dispositivos mais utilizados para executar os softwares de GI. Durante a execução dos procedimentos desse mapeamento, foram retornados 998 artigos, sendo que 45 artigos foram selecionados na primeira etapa e 21 artigos na etapa final. De acordo com os resultado obtidos, as formas de interação, bem como formas de entrada e saída e dispositivos de execução dos softwares de GI ainda são poucos explorados. Contudo, baseado nos dados obtidos em nossa análise, foi possível realizar a categorização das pesquisas na área para responder a questão (QPO1). Esta categorização das formas de interação resultou em seis categorias (Tabela 3.3) que abrangem interação baseada em caneta, baseada em clique, baseada em gestos, baseada em toque, háptica e técnicas diversas. A categoria baseada em clique agrupa mais estudos primários, podendo ser considerada a abordagem mais pesquisada e implementada. Em contraste, entre as categorias com menos estudos estão as baseadas em gestos e em toque, o que motiva a condução desta pesquisa de mestrado.

Além disso, durante a leitura de cada um destes estudos, foram identificadas as formas de interação de entrada e saída dos softwares de GI (Tabela 3.4 e Tabela 3.5), sendo que a forma de interação por teclado e mouse e saída em 2D são as mais investigadas, respondendo a questão QP02. Outras formas de entrada e saída também foram apresentadas, sendo de entrada: câmera, lousa branca, luvas, mesa digital, óculos para realidade de aumentada e virtual, projetor, caneta digital, dispositivos hápticos e telas sensíveis ao toque. Para as formas de saída, além da abordagem em 2D, também foram encontrados softwares que abordam saída em 3D, Realidade Aumentada e Realidade Virtual.

Os tipos de dispositivos que estes softwares são executados também foram investigados neste mapeamento (Tabela 3.6). O dispositivo mais explorado pelos pesquisadores é o computador de mesa, correspondendo 84

Portanto, com este mapeamento é possivel observar que a maioria dos softwares de GI foram desenvolvidos para em modelo desktop, ou seja, baseados em clique e executados em computadores de mesa. Porém, este tipo de interação está tornandose obsoleta com o aumento das vendas de smartphones e tablets, em que apresentam o tipo de interação "Baseado em toque" e "Baseado em gestos". Devido o aumento de vendas desses dispositivos e a facilidade do seu uso, governo de vários países es- 
tão inserindo o uso destes dispositivos em sala de aula para apoiar as atividades de ensino, resultando então, na necessidade dos ambientes de GI sejam desenvolvidos para estes tipos de dispositivos. Em vista aos dados obtidos neste mapeamento, o objetivo deste trabalho é desenvolver uma interface de software de GI para dispositivos móveis e com interação baseada em gestos, a fim de sanar a carência de pesquisas nesta área. 


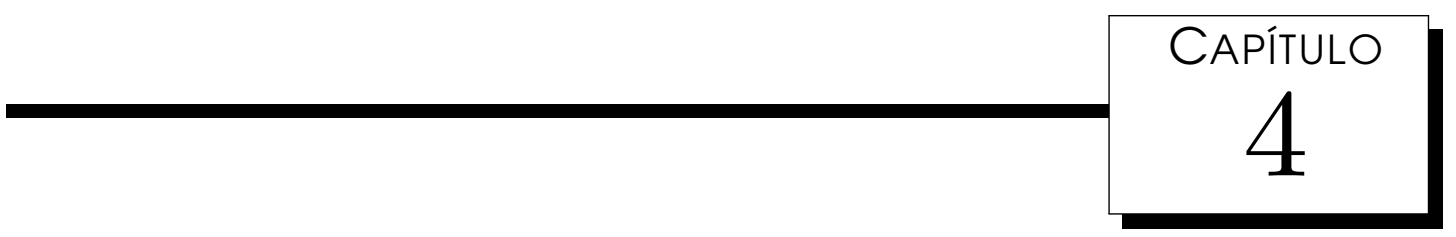

\section{Análise de Usabilidade dos softwares de GI para Tablets}

Como visto no Capítulo 3, a popularização da tecnologia fez com que o uso de dispositivos tecnológicos (e.g. computadores e dispositivos móveis) por pessoas individuais ou em empresas aumentasse consideravelmente nas últimas décadas. Para que as pessoas possam utilizar estes dispositivos, é necessário algum tipo de interface, que promove a comunicação entre o humano e a máquina. Ainda neste Capítulo, foi sugerido que no ambiente educacional, os alunos conseguem aprender o que é ensinado por meio da apresentação do conteúdo em tela nesses dispositivos tecnológicos.

Entretanto, uma das principais razões que os estudantes e professores deixam de utilizar um determinado software é devido a sérios problemas de usabilidade, causado em partes pela falta de metodologias ao desenvolver a interface e avaliá-los de forma adequada (Baker et al., 2001). Sem as metodologias para análise de usabilidade, os desenvolvedores não conseguem desenvolver interfaces capazes de atender os requisitos necessários para que o estudante consiga ter um aprendizado efetivo (Grudin, 1988) (Baker et al., 2001).

Para que os softwares educacionais apoiem o ensino, o design deve ser cuidadosamente desenvolvido de acordo com conceitos pedagógicos e com as diretrizes de usabilidade, para proporcionar os estudantes interações intuitivas e naturais. Caso o software seja desenvolvido com a abordagem pedagógica e de usabilidade separadamente, o software tende a apoiar superficialmente o ensino, fazendo com que as interações possam dar suporte ou não as atividades de ensino. Neste caso, deve haver a união da abordagem pedagógica e usabilidade para que o software permita 
não somente a manipulação eficiente, mas também seja apropriado para atender as atividades de ensino (Baker et al., 2001).

A usabilidade de um software pode ser alcançada por meio de avaliações de usabilidade, utilizando critérios heurísticos. Segundo Dringus (1995) a avaliação heurística pode ser aplicada em interfaces de softwares educacionais, sendo capaz de encontrar vários problemas que afetam o aprendizado. Conforme visto no Capítulo 3, esta avaliação é realizada por especialistas em usabilidade ou engenheiros de software e, é considerada a maneira mais barata e eficiente para encontrar erros em interfaces (Ardito, 2006) (Nielsen, 1993).

Devido a possibilidade de encontrar os problemas que impedem o aprendizado Dringus (1995) e o baixo custo para a sua realização Ardito (2006) Nielsen (1993), a avaliação heurística foi utilizada para avaliar três softwares de GI disponíveis em Tablets. Esta avaliação, que será detalhada neste Capítulo, teve o objetivo de encontrar os problemas nestes três softwares e propor novas diretrizes de desenvolvimento de GI para tablets.

Nas Seções seguintes serão apresentadas as avaliações heurísticas e um questionário aplicado em três softwares de GI para tablets. Descreve-se o objetivo da avaliação heurística na Seção 4.1, bem como a sua metodologia, resultados da avaliação heurística e a análise de dados de cada software avaliado. Na Seção 4.2 é detalhado a aplicação do questionário e os seus resultados. A discussão dos resultados da avaliação e do questionário é apresentada na Seção 4.3; e por fim, ameaças à validade e as considerações finais são discutidas nas Seções 4.4 e 4.5.

\subsection{Avaliação Heurística}

Até o momento é de nosso conhecimento a existência de apenas três softwares de GI que possibilitam o aprendizado da geometria por meio dos dispositivos móveis e gestos/toque. Entretanto, conforme visto no Capítulo 3, até o momento não foi identificado nenhum estudo empírico referente a usabilidade destas interfaces de toque no aprendizado da geometria. Tampouco foram encontrados os critérios técnicopedagógicos utilizados pelos desenvolvedores para desenvolver estas interface de softwares de GI.

Desta forma, este capítulo apresenta uma avaliação de usabilidade realizado com os três softwares de GI identificados, a fim de encontrar problemas de usabilidade que podem afetar a aprendizagem. Os problemas de usabilidade foram identificados e categorizados com o objetivo de propor diretrizes para desenvolvedores de software de GI para dispositivos móveis com interação baseada em gestos multitoque. 


\subsubsection{Metodologia}

Foram selecionados os três softwares de GI disponíveis em dispositivos móveis e que permitem a construção dos objetos geométricos por meio de gestos. Estes softwares são: (a)Geometry Pad $^{1}$, (b)GeoGebra ${ }^{2}$ e (c)Sketchometry ${ }^{3}$.

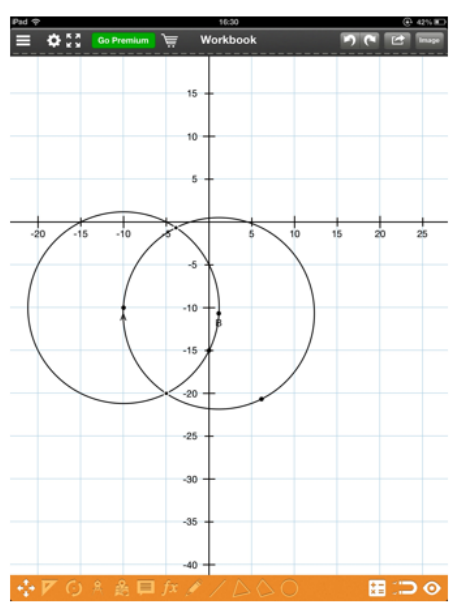

(a)

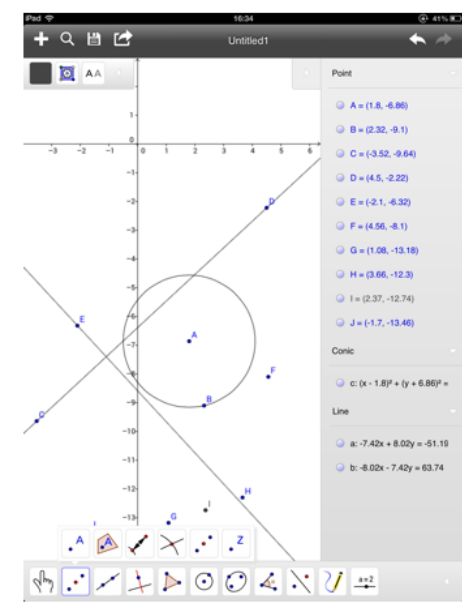

(b)

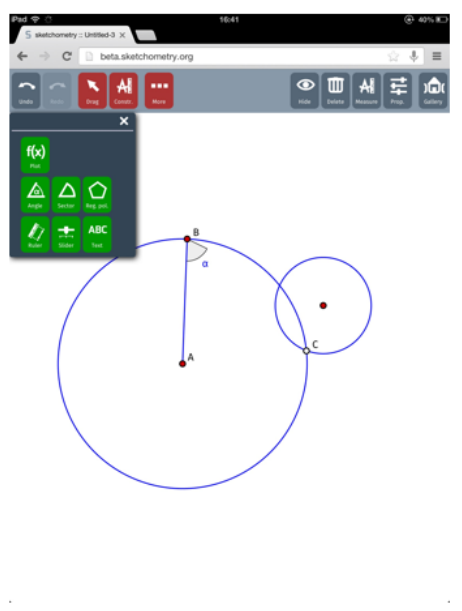

(c)

Figura 4.1: Distribuição dos estudos primários por tipo de dispositivo.

Para realizar a avaliação heurística nos três softwares, foram convidados cinco especialistas, chamados de "avaliadores". Estes especialistas são alunos do programa de pós-graduação em Ciência da Computação e Matemática Computacional do Instituto de Ciências Matemáticas e de Computação da Universidade de São Paulo (ICMCUSP), graduados em Ciência da Computação, com pesquisas realizadas na área de Interação Humano-Computador (principalmente em avaliação de usabilidade utilizando heurísticas) e conhecimentos intermediários em softwares de GI.

A avaliação dos softwares foram realizados utilizando como hardware o tablet iPad de 10 polegadas e com sistema operacional versão iOS 5. Também foi utilizado um computador, para que os avaliadores pudessem responder ao questionário do teste de usabilidade e, um guia impresso contendo uma lista de atividades. O teste foi realizado em três etapas (Figura 4.2).

A primeira etapa consistiu na leitura das dez heurísticas pelos avaliadores. Depois da leitura, os avaliadores realizaram a segunda etapa, que consistiu em executar algumas tarefas do questionário. Neste questionário, cada avaliador teve como tarefa aplicar as dez heurísticas de usabilidade (Tabela 4.1) proposta por Nielsen (1993) para cada item da lista de atividades. Estas atividades foram agrupadas por tipo de

\footnotetext{
${ }^{1}$ http: //www.stemonmobile.com/geometry-pad/

${ }^{2}$ http://www.geogebra.org/cms/pt_BR/download/

$3_{\text {http: / / www. sketchometry.org }}$
} 


\begin{tabular}{|c|c|c|c|}
\hline $\begin{array}{l}\text { Leitura das } \\
\text { heurísticas } \\
\text { O avaliador realizou a } \\
\text { leitura das dez } \\
\text { heurísticas propostas } \\
\text { por Nielsen }\end{array}$ & $\begin{array}{l}\text { Execução das } \\
\text { atividades por } \\
\text { funcionalidades }\end{array}$ & \begin{tabular}{l}
\multicolumn{1}{c}{\begin{tabular}{c}
\multicolumn{1}{c}{ Solução dos } \\
exercícios
\end{tabular}} \\
cinco exercícios de \\
níveis básicos e \\
intermediários, \\
envolvendo as \\
funcionalidades \\
básicas do software \\
avaliado
\end{tabular} & $\begin{array}{l}\text { Preenchimento do } \\
\text { formulário }\end{array}$ \\
\hline
\end{tabular}

Figura 4.2: Fases da avaliação heurística no softwares propostos pelos avaliadores.

funcionalidade que o software disponibiliza (Tabela 4.1).

Por exemplo, a função ponto possuía uma lista tarefas relacionadas a esta funcionalidade, como criação, movimentação e modificação de tamanho do ponto. Para cada funcionalidade, foi solicitado que realizassem atividades que envolveram construção de objetos básicos de geometria (e.g. criação de ponto, ponto médio ou reta), manipulação desses objetos (e.g. mover o ponto) e edição (e.g. modificar o tamanho do ponto). Além disso, foram propostas tarefas básicas padrões de um software, como fazer e desfazer, limpar tela inteira, abrir um documento e salvar um documento.

Na terceira etapa foi solicitado que os avaliadores resolvessem uma lista de exercícios relacionados a construção geométrica de nível básico e intermediário. O objetivo desta etapa foi simular o uso do software em atividades de aprendizagem de geometria. Por fim, na quarta etapa o avaliador preencheu o formulário sobre as heurísticas de usabilidade (Apêndice B - Anexo D), de acordo com o grau de severidade ${ }^{4}$ do problema conforme proposto por Nielsen (1993).

\subsubsection{Resultados da Avaliação Heurística}

Após os softwares serem avaliados, foi criada uma lista para cada software contendo todos os problemas encontrados e classificados nas heurísticas. É importante ressaltar também que devido a complexidade de uma das atividades, os erros/problemas para esta atividade foram classificados em mais de uma heurística, afetando assim a sua frequência.

Inicialmente, para oferecer uma visão geral dos resultados obtidos, apresenta-se a Figura 4.3 que destaca a frequência de problemas encontrados em cada uma das heurística avaliadas e para cada um dos softwares avaliados. No eixo x, é mostrado a

\footnotetext{
${ }^{4}$ Cinco graus de severidade são propostos por Nielsen: grau 0 (não concordo que seja um problema de usabilidade); grau 1 (problema cosmético/superficial); grau 2 (leve); grau 3 (sério) e grau 4 (critico).
} 
Tabela 4.1: Lista de heurística com suas abreviações.

\begin{tabular}{||l|c||}
\hline \hline Heurística & Abreviação \\
\hline \hline Visibilidade do status do sistema & $\mathrm{HO1}$ \\
\hline Correspondência entre o sistema e mundo real & $\mathrm{H} 02$ \\
\hline Controle do usuário e liberdade & $\mathrm{H} 03$ \\
\hline Consistência e padrões & $\mathrm{H} 04$ \\
\hline Prevenção de erros & $\mathrm{H} 05$ \\
\hline Reconhecimento em vez de lembrança & $\mathrm{H} 06$ \\
\hline Flexibilidade e eficiência de uso & $\mathrm{H} 07$ \\
\hline Estética e design minimalista & $\mathrm{H} 08$ \\
\hline Ajuda para identificar, diagnosticar e corrigir erros & $\mathrm{H} 09$ \\
\hline Ajuda e documentação & $\mathrm{H} 10$ \\
\hline
\end{tabular}

Tabela 4.2: Conjunto de funções para aplicação do teste de usabilidade.

\begin{tabular}{||l|}
\hline \hline Heurística \\
\hline \hline Ponto \\
\hline Ponto médio \\
\hline Reta \\
\hline Segmento de reta \\
\hline Semi-reta \\
\hline Perpendicular \\
\hline Paralela \\
\hline Circunferência \\
\hline Medida ângulo \\
\hline Intersecção \\
\hline
\end{tabular}

abreviação das heurísticas, que os seus significados são apresentados na Tabela 4.1. No eixo y, é mostrado a quantidade de vezes que o problema foi encontrado.

Na Figura 4.3, é possivel observar que nenhum dos três softwares apresentaram problemas relacionados a consistência e padrões (H04). Isso mostra uma certa maturidade dos softwares analisados uma vez que todos eles são versões adaptadas de softwares de geometria interativa desenvolvidos para computadores de mesa. Entretanto, um número considerável de problemas na heurística H05 foram encontrados nos três softwares. Ou seja, nenhum deles possui funcionalidades que auxiliam na prevenção de erros durante a criação de uma construção geométrica.

Além disso, o software Geogebra também apresentou uma maior ocorrência de problemas nas heurísticas H02, H06 e H10, se comparado com os outros softwares. Estes problemas estão relacionados a (i) palavras ou elementos em tela que não são familiares aos usuários; (ii) a dificuldade de lembrar como utilizou uma funcionalidade pela última vez; e (iii) a carência de documentação do software. Contudo, este mesmo software foi o único que não apresentou problemas de controle do usuário e 


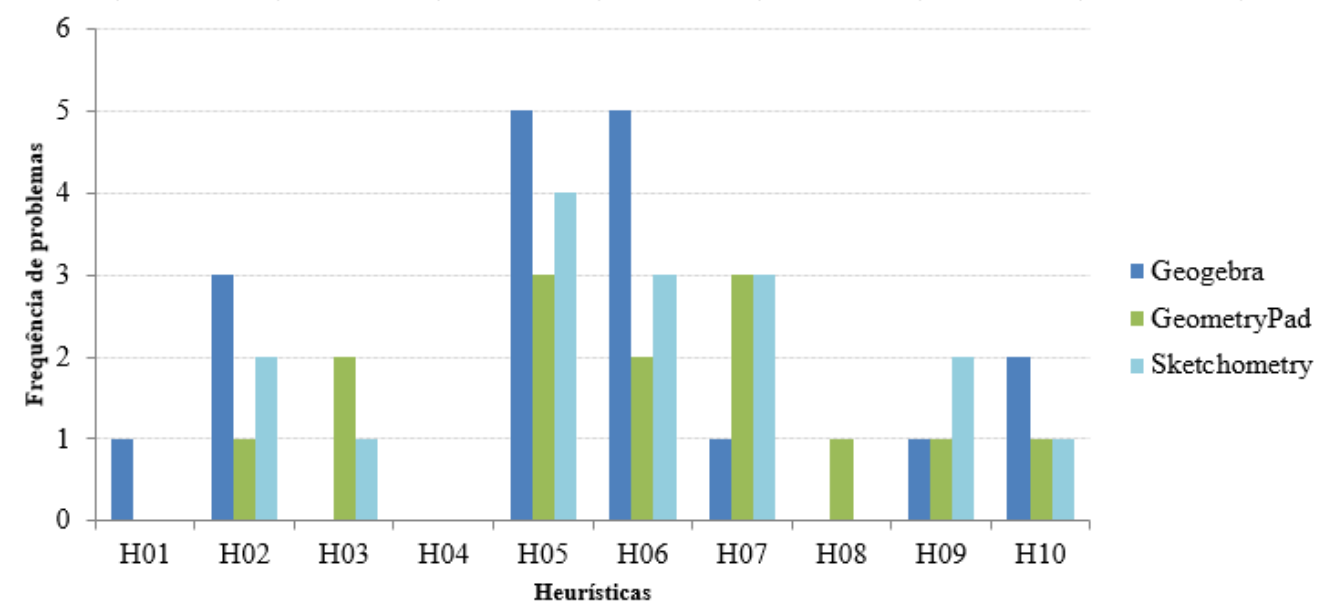

Figura 4.3: Frequência de problemas encontrados por heurística e por software avaliado.

liberdade (H03).

Os softwares Geometry Pad e Sketchometry não apresentaram uma boa prevenção de erros (H05) ao apresentar ícones fora do padrão (i.e. ícones comumente usados), falta de descrição das funções e mensagens de erro ou de passo a passo. Ou seja, o design da interface e como os seus elementos foram expostos não evitaram que os avaliadores cometessem os erros. Estes mesmos erros foram classificados na heurística H06, pois os avaliadores enfrentaram dificuldades em lembrar das funcionalidades durante o uso do software. Os dois softwares também não apresentaram nenhuma tecla de atalho, afetando a flexibilidade e eficiência de uso. O único software que apresentou problemas relacionados a estética e design minimalista (HO8) foi o Geometry Pad, pois apresentou informação irrelevante na interface, como a funcionalidade de exportação localizada na barra de título.

Além disso, este software apresentou um maior número de problemas relacionados a controle e liberdade do usuário (H03), pois não possibilitou que o usuário excluísse vários objetos ao mesmo tempo ${ }^{5}$. Por fim, o software Sketchometry foi o único software que apresentou maior número de problemas de identificação, diagnóstico e correção de erros (H09), pois como é baseado em gestos, o software é incapaz de predizer qual é o gesto que o usuário está tentando realizar para posteriormente apresentar mensagem de erro ou sugerir a sua correção.

\footnotetext{
${ }^{5} \mathrm{~A}$ funcionalidade de exclusão múltipla encontra-se em um local de difícil acesso
} 


\subsubsection{Análise dos Dados}

\section{Geogebra}

Na Tabela 4.3 são apresentados os sete problemas encontrados no software Geogebra e classificados de acordo com as heurísticas propostas por Nielsen (1993).

Tabela 4.3: Lista de problemas encontrados no software Geogebra e a classificação de suas heurísticas.

\begin{tabular}{||l|c||}
\hline \hline Problema & Heurísticas \\
\hline \hline Não tem passos para a construção dos objetos & $1,5,6$ \\
\hline Ícone novo não está no padrão & $2,5,6$ \\
\hline Ícone abrir não está no padrão & $2,5,6$ \\
\hline Ícones similares & $2,5,6$ \\
\hline Não tem teclas de atalho & 7 \\
\hline Falta descrição das funções & $5,6,9,10$ \\
\hline Não tem manual ou ajuda & 10 \\
\hline
\end{tabular}

O principal problema encontrado pelos avaliadores foi a dificuldade de identificação das funções, que estão disponibilizadas em um menu e agrupadas de acordo com funções semelhantes. Estas funções possuem somente ícones, sendo alguns deles semelhantes, o que fez com que os avaliadores apresentassem certa confusão ao escolher qual a função que realmente queria utilizar. Um dos exemplos é apresentado na Figura 4.4, onde os avaliadores tiveram dificuldade em diferenciar a construção de círculo com a construção de eclipse.

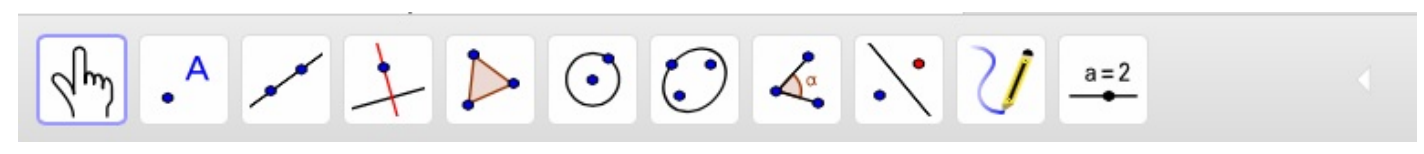

Figura 4.4: Menu agrupado do software Geogebra.

Outros ícones que apresentaram problemas foram os ícones de novo e abrir arquivo (sinal de adição e de lupa na Figura 4.5), que não são semelhantes aos ícones comumente usados em outros aplicativos (i.e. folha em branco e pasta amarela), dificultando o usuário perceber que estas duas funções estão disponíveis e localizadas na interface do software.

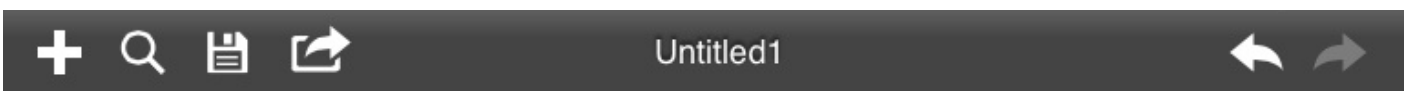

Figura 4.5: Barra de título do software Geogebra.

Os avaliadores consideraram que algumas funcionalidades eram dificeis de serem utilizadas, pois a falta mensagens na tela indicando quais passos deveriam ser reali- 
zados para executar a funcionalidade impossibilitou a construção de alguns objetos, como criar a medida de ângulo ou da paralela. Este problema se agravou pois o software não oferece manual ou qualquer tipo de ajuda dentro do próprio software com a descrição das funcionalidades. Essas informações estão disponíveis somente no website oficial do aplicativo.

Na Figura 4.6 é possivel identificar os problemas encontrados em cada heurística e o seu grau de severidade no software Geogebra. É possível notar que a HO2 (correspondência entre o sistema e o mundo real) tem maior severidade (aproximadamente $75 \%$ ), se comparado com os demais problemas. Isto indica que este problema é crítico e precisa ser analisado em futuras versões do software. As heurísticas H05 (prevenção de erros) e H06 (reconhecimento em vez de lembrança) possuem o segundo maior grau de severidade (aproximadamente 50\%), enquanto não foram encontrados problemas relacionados com as heurísticas HO3 (controle do usuário e liberdade) e HO4 (consistência e padrões).

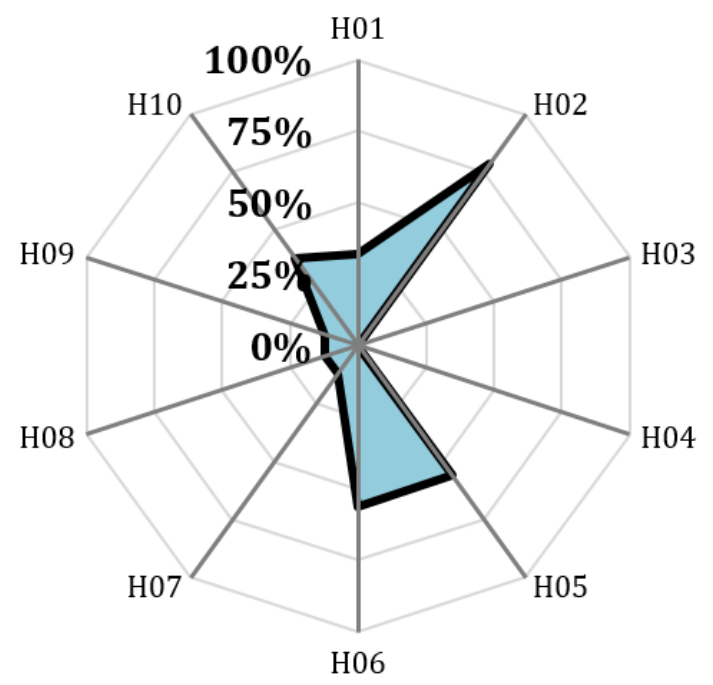

Figura 4.6: Grau de severidade entre as heurísticas no software Geogebra.

\section{Geometry Pad}

Após a avaliação do software Geometry Pad, foram encontrados oito problemas (Tabela 4.4), abrangendo problemas relacionados ao menu, exclusão, teclas de atalhos, falta de mensagem de erro e manual de ajuda.

Um dos problemas substanciais foi a dificuldade de perceber que o menu possui funções agrupadas. Na Figura 4.7, é possivel perceber que os ícones deste menu são apresentados como se fossem desenhos e não botões. Isso fez com que os avaliadores sentissem dificuldades em perceber que os ícones fossem botões com acesso a outras funções. Além disso, ao tentar executar a tarefa para criar um ponto, os avaliado- 
Tabela 4.4: Lista de problemas encontrados no software Geometry Pad e a classificação de suas heurística.

\begin{tabular}{||l|c||}
\hline \hline Problema & Heurísticas \\
\hline \hline Não consegue perceber que o menu possui subopções & 2,5 \\
\hline Não consegue excluir mais de um objeto ao mesmo tempo & 3,7 \\
\hline Difícil de encontrar e lembrar as funções que deseja usar & 5,6 \\
\hline Não tem teclas de atalho para criar ou manipular & 7 \\
\hline Difícil encontrar a função excluir & $3,6,7$ \\
\hline $\begin{array}{l}\text { Botão para exportar em diferentes formatos não precisa } \\
\text { estar na barra de título }\end{array}$ & 8 \\
\hline $\begin{array}{l}\text { Não mostra mensagem de erro quando faz uma construção } \\
\text { errada }\end{array}$ & 5,9 \\
\hline Não tem manual ou ajuda & 10 \\
\hline
\end{tabular}

res apresentaram certo grau de confusão, pois a mesma está disponível no ícone de construção de retas.

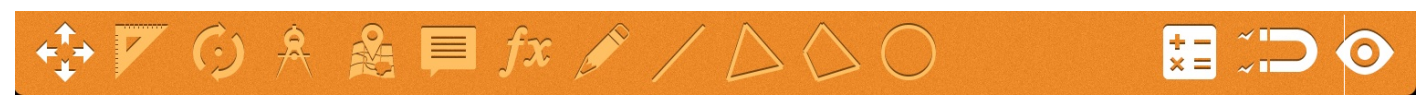

Figura 4.7: Menu agrupado do software Geometry Pad.

Na Figura 4.8 é possível observar a caixa de edição das construções (troca de cor, espessura das linhas, rótulo, excluir) geométricas. O acesso a esta caixa de edição foi considerado complexo pelos avaliadores, pois foi necessário fazer a construção do objeto e posteriormente tocá-lo brevemente para que a caixa aparecesse. Este processo não é explicado em qualquer manual ou ajuda. Dessa forma, o usuário precisa predizer onde esta a funcionalidade e como fazer para acioná-la. Outra função de difícil identificação foi a opção excluir, em que o usuário necessita selecionar o objeto previamente, acessar a caixa de edição, localizar o ícone de exclusão no canto superior direito, para então poder excluir o objeto. Ainda na opção de exclusão, o usuário não consegue excluir mais de uma construção ao mesmo tempo, fazendo com que o usuário leve um longo tempo para poder excluir todos os objetos geométricos construídos.

A Figura 4.9 apresenta outra funcionalidade que está localizada de forma incorreta segundo os avaliadores. É a funcionalidade de exportação em diferentes formados, localizado na barra de título. Normalmente ela não é utilizada frequentemente para justificar sua posição diferenciada e, portanto, poderia estar disponível no menu padrão do sistema onde encontram-se as funcionalidades abrir e salvar.

No aspecto de flexibilidade, o Geometry Pad foi o único que não apresentou teclas de atalhos ou outras maneiras para construir os objetos. Há somente uma maneira de construção acessada por meio do menu. Além disso, apesar de haver um pai- 


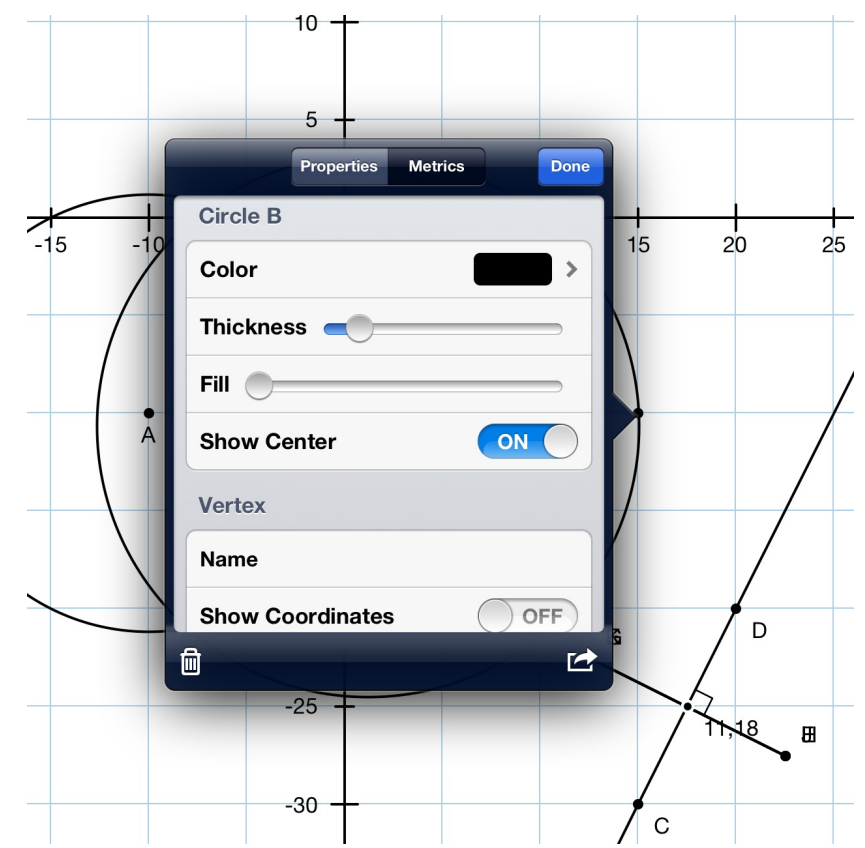

Figura 4.8: Função de edição dos objetos geométricos do software Geometry Pad (troca de cor, espessura da reta, rótulo, excluir).

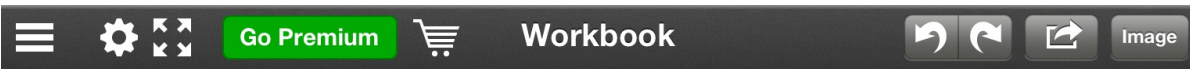

Figura 4.9: Barra de Título do software Geometry Pad.

nel mostrando os passos para realizar a construção de um objeto geométrico, não é apresentada uma mensagem de erro caso o estudante realize a construção de forma incorreta. Este problema é agravado pela a falta de um manual explicando as funcionalidades do aplicativo.

A Figura 4.10 apresenta o grau de severidade dos problemas encontrados de acordo com as heurísticas utilizadas. Observa-se que a heurística relacionada com a ajuda para identificar, diagnosticar e corrigir erros (HO9) possui a maior severidade, apresentando aproximadamente $75 \%$ de gravidade e, portanto, a sua solução é considerada emergencial. As heurísticas relacionadas a controle do usuário e liberdade (H03), prevenção de erros (H05), reconhecimento em vez de lembrança (H06) e flexibilidade e eficiência de uso (H07) apresentaram aproximadamente 50\% de severidade. A heurística $\mathrm{HO8}$ apresentou o menor grau de severidade no sistema, correspondendo aproximadamente a $9 \%$, sendo considerada de baixa prioridade.

\section{Sketchometry}

No software Sketchometry foram encontrados seis problemas (Tabela 4.5), sendo este número o menor dentro os softwares comparados: Geogebra e GeometryPad. 


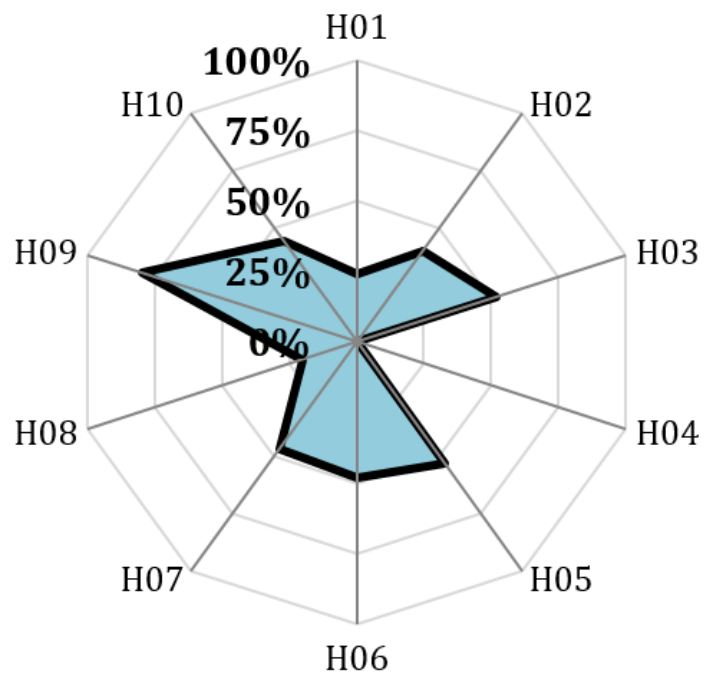

Figura 4.10: Grau de severidade entre as heurísticas no software Geometry Pad.

Tabela 4.5: Lista de problemas encontrados no software Sketchometry e a classifição de suas heurística.

\begin{tabular}{||l|c||}
\hline \hline Problema & Heurísticas \\
\hline \hline Não informa como realizar as construções & $5,6,9$ \\
\hline Não é intuitivo a criação da paralela ou perpendicular & $2,5,6$ \\
\hline Não consegue excluir mais de um objeto ao mesmo tempo & 3,7 \\
\hline Modo de construção e movimentação confunde & $2,5,7,9$ \\
\hline Os gestos são complicados para usuários novatos & $5,6,7$ \\
\hline Não tem manual ou ajuda & 10 \\
\hline
\end{tabular}

Neste software, a interação ocorre de uma maneira diferente dos outros: enquanto os dois software apresentados anteriormente eram fortemente baseados em menu de ícones (i.e. para construir um objeto geométrico é necessário escolher a função adequada no menu), no Sketchometry o estudante utiliza somente gestos para realizar as construções geométricas, sem escolhe-las previamente em um menu. Assim, quando os avaliadores movimentavam os dedos na tela, o aplicativo mostrava no canto superior qual objeto estava sendo construído com o determinado movimento (e.g. circunferência, reta, perpendicular) conforme pode ser visto na Figura 4.11.

Apesar do Sketchometry informar qual objeto está sendo construído, não é mostrado quais passos foram realizados para a construção do objeto. Isto fez com que os avaliadores apresentassem dificuldades de prever quais gestos devem ser realizados para construir o objeto geométrico desejado. Esse problema se agravou quando o gesto não foi desenvolvido de forma intuitiva, como a paralela e a perpendicular. Os avaliadores não conseguiram executar as tarefas relacionadas a estas duas funcionalidades (paralela e perpendicular), pois não estavam intuitivas e o software não 
disponibilizava manual de ajuda descrevendo as funcionalidades. Os objetos simples, como ponto e reta, foram facilmente executados, por terem sido desenvolvidos de forma intuitiva e de acordo com os conceitos matemáticos.

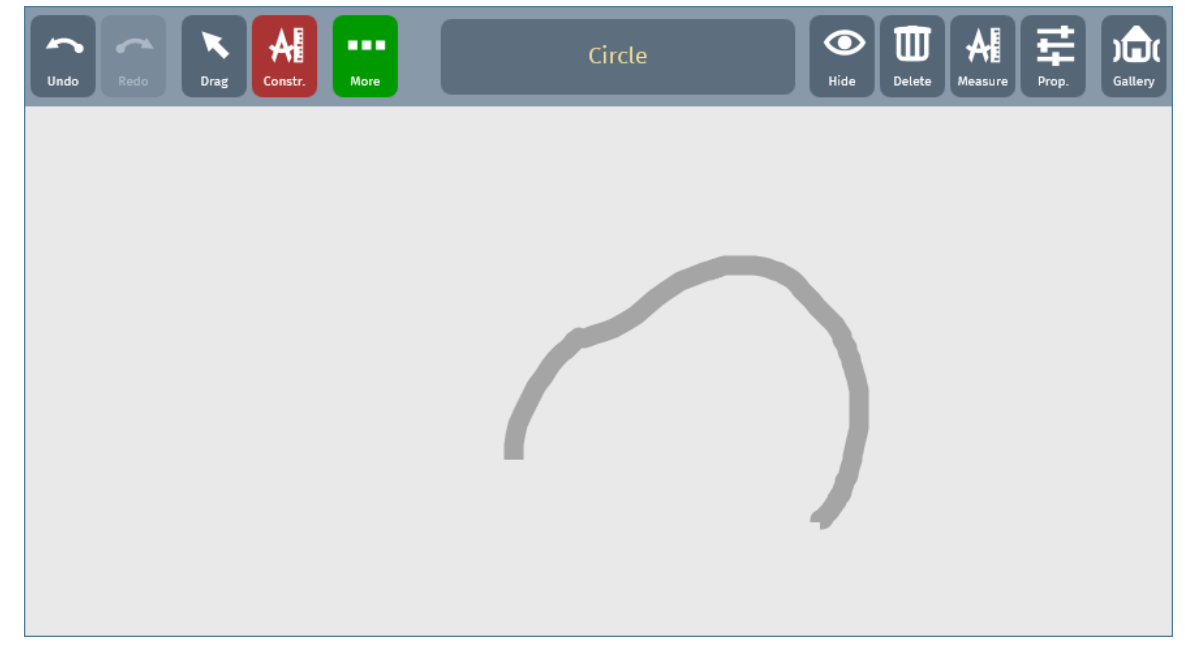

Figura 4.11: Caixa de mensagens de tipo de função do software Sketchometry.

Além de alguns gestos não serem intuitivos, outro agravante é como estes objetos são manipulados ou construídos (Figura 4.12). Para construir um objeto, o avaliador precisou selecionar a opção de construção (botão "Constr"), disponível em um botão no canto superior esquerdo da tela. Para poder manipular este objeto, a opção de manipulação (botão "Drag") deve ser selecionada. Estas duas maneiras confundiram os avaliadores nos primeiros contatos com o software, pois não há manual ou ajuda explicando como proceder.

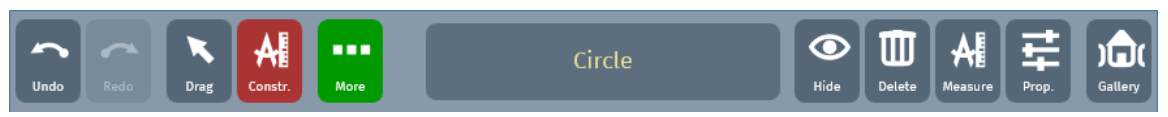

Figura 4.12: Funções de criar e manipular objetos geométricos no software Sketchometry.

Na Figura 4.13 é apresentado o grau de severidade dos problemas encontrados de acordo com as heurísticas. É possível observar que não foram encontrados problemas nas heurísticas relacionadas a consistência e padrões (HO4) e estética e design minimalista (H08). Entretanto, a heurística relacionadas a visibilidade do status do sistema (HO1) e ajuda e documentação (H10) apresentaram alto grau de severidade, correspondendo aproximadamente $75 \%$. Em seguida, as heurísticas relacionadas a correspondência entre o sistema e o mundo real (H02), prevenção de erros (H05), reconhecimento em vez de lembrança (H06), flexibilidade e eficiência de uso (H07) e ajuda para identificar, diagnosticar e corrigir erros (H09) apresentaram grau de severidade aproximadamente 50\%. Apesar deste software apresentar uma menor frequência de 
erros, a maioria deles são considerados com alto grau de severidade e que pode afetar seu uso e adoção por usuários iniciantes.

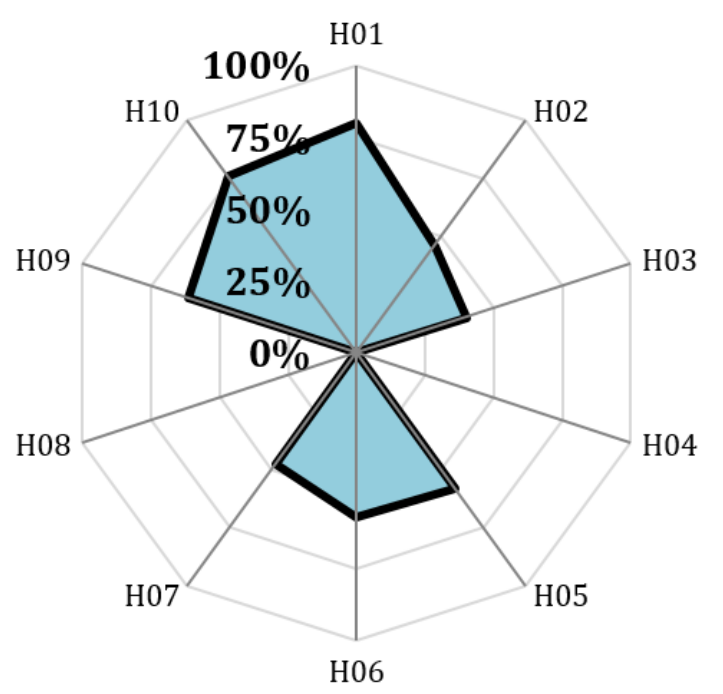

Figura 4.13: Grau de severidade entre as heurísticas no software Sketchometry.

Os avaliadores do software Skecthometry consideraram que a interação por gestos, sem menus, pode ser complexa para os usuários novatos, entretanto possibilita que o usuários mais experientes podem se beneficiarem ao realizarem as tarefas mais rápidas. Além disso, a falta de mensagens que mostram os passos que devem ser realizados para a construção dos objetos geométricos e manual de ajuda, podem fazer com que o aprendizado da interface leve mais tempo. Por fim, os avaliadores não conseguiram excluir mais de um objeto geométrico, fazendo com que levassem um tempo considerável para a exclusão de uma grande quantidade de objetos.

\subsection{Questionários}

Além da avaliação heurística, um questionário para coletar informações sobre o uso dos SGI em tablets foi proposto preenchido pelos avaliadores. Cada avaliador escolheu um número de 1 a 5 para responder as perguntas do questionário, considerando: 1 - Péssimo, 2 - Ruim, 3 - Regular, 4 - Bom e 5 - Excelente. Este questionário foi aplicado para cada software e continha as seguintes perguntas:

901: O tamanho da tela foi adequado para realizar as atividades propostas?

Q02: A utilização dos dedos para interagir com o software foi fácil?

Q03: Os gestos para construir os objetos geométricos são intuitivos/naturais? 
Q04: Os conhecimentos matemáticos previamente conhecidos afetou no modo de construir os objetos geométricos?

Q05: As telas lhe parecem visualmente agradáveis?

Q06: A interface está adequada para ser utilizada em um dispositivo móvel (ou é semelhante a interface de um software de desktop)?

Q07: A interface é fácil de aprender?

Q08: A execução das atividades foi realizada rapidamente?

A Figura 4.14 mostra a pontuação final de cada questão do questionário e a comparação desta pontuação entre os softwares avaliados. A Q1 mostrou que os avaliadores consideraram que o tamanho da tela está menos adequada para realizar as atividades no software Geometry Pad, se comparado com os softwares Geogebra e Sketchometry. O resultado da Q2 mostra que o Sketchometry possui a menor pontuação indicando que a interação por meio de dedos não foi fácil ou intuitiva neste software. Além disso, o mesmo software possui menor pontuação para a Q3, em que os gestos para construir os objetos geométricos não foram intuitivos ou naturais. Já o software Geogebra apresentou uma maior pontuação em relação a Q2, enquanto na Q3 tanto o Geogebra quanto Geometry Pad tiveram a mesma pontuação.

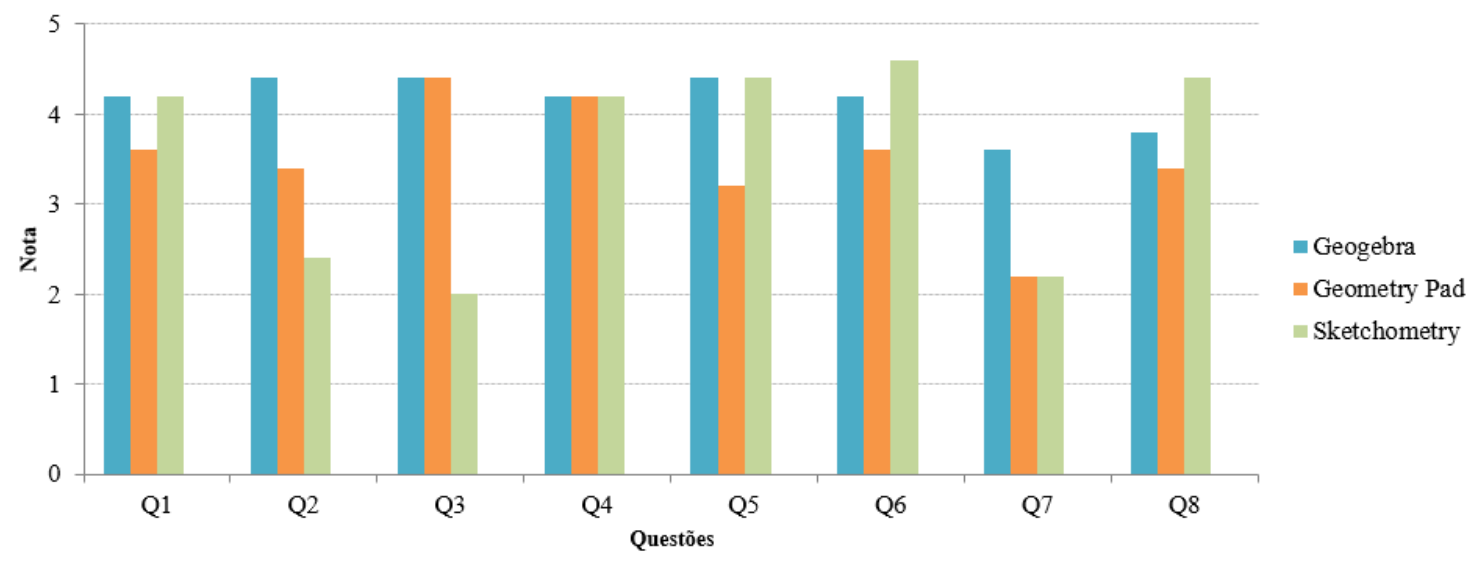

Figura 4.14: Pontuação final para cada questão do questionário.

Todos os avaliadores consideraram que o conhecimento prévio em geometria afetou no modo de interação e de construção dos objetos geométricos em todos os softwares avaliados, respondendo a Q4. Esta questão apresentou a mesma pontuação para os três softwares. Na Q5, que aborda sobre a agradabilidade da tela, somente o Geometry Pad apresentou uma pontuação inferior entre os softwares. Já na Q6, o Sketchometry apresentou uma pontuação maior, mostrando que este software foi desenvolvido 
mais adequadamente para os dispositivos móveis e que explora melhor os seus recursos. Novamente o software Geometry Pad apresentou a menor pontuação entre os softwares avaliados.

No aspecto referente a facilidade de aprendizado da interface abordado na Q7, os softwares Geometry Pad e Sketchometry apresentaram a mesma pontuação, no entanto, menores que a do software Geogebra. Por fim, respondendo a $\mathrm{B} 8$, os avaliadores indicaram que o Sketchometry dá mais velocidade para execução das atividades se comparado com os outros dois softwares.

\subsection{Discussão}

No decorrer deste estudo foi possível observar que na avaliação heurística os três sistemas de GI para tablets apresentaram quatro problemas que foram considerados críticos, sendo eles; (i) correspondência entre o sistema e o mundo real, (ii) prevenção de erros, (iii) reconhecimento em vez de lembrança e (iv) ajuda e documentação. Entretanto, dentre os sistemas avaliados, o Sketchometry apresentou menos problemas associados a usabilidade, indicando que a construção de gestos somente por meio de toque/gestos pode auxiliar na execução das atividades.

Apesar dos avaliadores considerarem que o menu dos sistemas Geogebra e Geometry Pad possa facilitar na localização das funcionalidades e aprendizado da interface pelos os usuários novatos, foi observado que o sistemas Sketchometry pode ser eficiente ao ser utilizado por usuários mais experientes. Também foi considerado pelos avaliadores, que esta experiência e aprendizado das interfaces são afetados pelo conhecimento prévio em geometria, em que a construção dos objetos geométricos estão relacionados com os conceitos da geometria.

Apesar do sistema Sketchometry apresentar problemas mais graves que os outros sistemas, foram listados menos itens que podem prejudicar no momento da interação. O principal problema apresentado foi a falta de informações sobre quais gestos os usuários deveriam fazer, fazendo com que o usuário precise testar o gesto para depois verificar qual objeto foi construído. Por possuir uma interface minimalista, há menos ícones apresentados em tela, e assim reduz a possibilidade do sistema utilizar ícones que não estão no padrão ou que não correspondem ao mundo real. Entretanto, este tipo de interação, redução de ícones e menu, causa problemas na prevenção de erros. Guando o usuário não sinaliza previamente o que deseja fazer em um sistema totalmente gestual, há uma dificuldade maior para que o sistema consiga identificar o gesto que deseja fazer e evitar que o usuário comenta algum tipo de erro. Em vista de todos esses problemas apresentados neste estudo, algumas diretrizes são propostas para o desenvolvimento de sistemas de GI para tablets:

- Guia de ajuda visual (figuras que mostram os gestos e funções que o software 
possui) na primeira vez que o software seja executado, até ser desabilitado pelo o usuário;

- Painel de mensagens que mostre passo-a-passo das construções, e que seja exibida perto de onde o usuário esteja executando o gesto;

- Oferecer sempre dicas de utilização ao entrar no software;

- Utilizar ícones que sejam padrões em outros softwares e que caso sejam semelhantes, possuir uma descrição textual;

- Criar gestos que sejam mais intuitivos e que são utilizados no cotidiano dos usuários;

- Oferecer manual de ajuda, contendo todas as funções que o software possui e os seus respectivos gestos. Este manual deve estar visivel e podendo ser consultado a qualquer momento.

\subsection{Ameaças à Validade}

A fim de garantir que a maioria dos problemas de usabilidade fossem encontrados, foram selecionados avaliadores com conhecimentos em engenharia de software, softwares de GI e avaliação heurística. Porém, não pode ser descartada a ameaça em relação a opiniões e experiências pessoais dos avaliadores, que podem avaliar os problemas de maneiras diferentes, atribuir um grau de severidade diferente dos demais e assim afetar nos resultados.

Outra possível ameaça identificada é a possibilidade dos avaliadores não conseguirem encontrar todos os problemas nos softwares, devido ao seu baixo número. Apesar de cinco avaliadores apresentarem um melhor custo-benefício para a avaliação de usabilidade, Nielsen e Molich (1990) mostra que um maior número de avaliadores ainda pode aumentar o número de problemas encontrados.

\subsection{Considerações finais}

No decorrer deste capítulo foi apresentada a análise heurística e o resultado de um questionário de três softwares (Geogebra, Geometry Pad e Sketchometry) de GI para o seu uso em tablets, realizada por cinco avaliadores.

De acordo com os resultados obtidos na avaliação heurística, quatro problemas encontrados foram classificados em nível grave, em que as atividades dos usuários podem ser comprometidas caso este problema persista. Estes quatro problemas encontrados são: correspondência entre o sistema e o mundo real, prevenção de erros, reconhecimento em vez de lembrança e ajuda e documentação. 
O problema relacionado a correspondência entre o sistema e o mundo real aborda principalmente a falta de padronização de alguns ícones, como o abrir e o novo. Devido a isto, os avaliadores sentiram dificuldades de localizarem estas duas funcionalidades no software. Este problema de padronização pode acarretar outros problemas, como a prevenção de erros. Caso o ícone não esteja legivel ou os forem visualmente ícones semelhantes, prejudica na prevenção de erros, como, por exemplo, no software Geogebra, em que o ícone com imagem de lupa refere-se a abrir arquivos, porém pode ser confundindo com a função de busca dentro do próprio software.

Um dos problemas de reconhecimento em vez de lembrança foi encontrado no software Geometry Pad e está relacionado com a exclusão dos objetos geométricos, em que é difícil para o usuário identificar como acessar esta opção na interface. Este problema e os outros encontrados poderiam ser amenizados com ajuda e documentação do software, mostrando quais gestos e funcionalidades estão disponíveis. No entanto, nenhum tipo de ajuda e documentação foram encontrados nos três softwares avaliados.

Além da avaliação heurística, os avaliadores também responderam um questionário, detalhado na Seção 4.2, que aborda sobre a utilização do dispositivo móveis nas atividades, o aspecto da interface e as suas interações. Os resultados mostraram que os avaliadores não consideraram que o tamanho do dispositivo prejudicou no desempenho das atividades e, que a interface do software Sketchometry atendeu melhor adequadamente aos aspectos dos dispositivos móveis se comparado com os demais, pois apresenta uma interação maior por meio dos gestos.

Também foi observado pelos avaliadores que a interface do software Sketchometry apresenta maior dificuldade aos usuários novatos, por não possuir manual e sua interação ser totalmente por meio de gestos. Porém, esta desvantagem diminui a longo prazo, fazendo que os usuários mais experientes possam executar mais rapidamente as suas ações. Além disso, os resultados apresentaram que os gestos podem ser afetados pelo conhecimento prévio em geometria pelo usuário, e que este conhecimento pode facilitar na execução das atividades.

Com os resultados deste capítulo foi possivel identificar os principais problemas nas interfaces dos softwares de GI atuais, que podem ser evitados e/ou resolvidos em versões futuras. Estes problemas podem ser evitados com um amplo manual de ajuda e documentação do sistema, abordando os gestos que devem ser feitos e as funcionalidades disponíveis, bem como a utilização de ícones que sejam padronizados e fáceis de identificar. É importante salientar também que um software de GI baseado em gestos deve possuir gestos mais próximos do cotidiano dos usuários, pois facilita o aprendizado reduzindo o uso da carga cognitiva. 
64CAPÍTULO 4. ANÁLISE DE USABILIDADE DOS SOFTWARES DE GI PARA TABLETS 


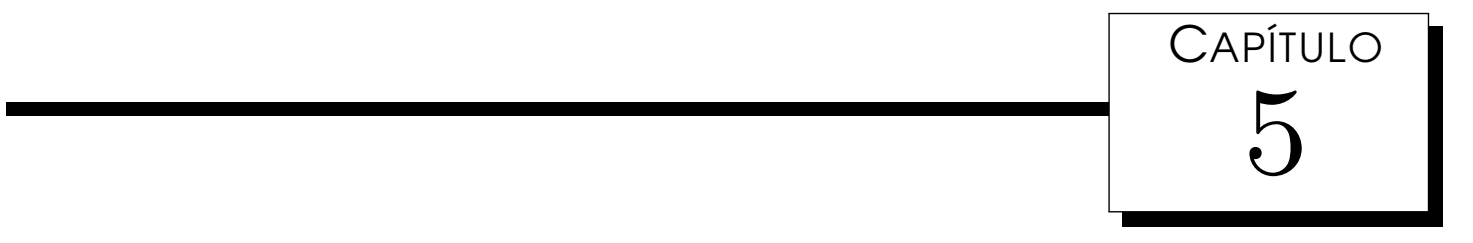

\section{Desenvolvimento de um Software de Gl com Interface Gestual}

Nos capítulos anteriores foram apresentados os conceitos sobre softwares de GI e a importância da interface no processo de ensino-aprendizagem. Também foram expostas lacunas de pesquisas relacionadas a interação e a interface de softwares de GI para dispositivos móveis com telas multitoque. Visto a importância deste tipo de interação/interface, realizou-se avaliações heurísticas em softwares de GI já existentes que possuem interação por meio de gestos e podem ser utilizados em tablets (vide Capítulo 4). Devido aos diversos problemas identificados, foram apresentadas sugestões que podem ser utilizadas como diretrizes para auxiliar no desenvolvimento de interfaces de software de GI para telas multitoque. Essas sugestões foram utilizadas neste capítulo para desenvolver um protótipo de software de GI, nomeado GeoTouch.

Nas Seções seguintes serão apresentadas a criação de um conjunto de gestos para construção de objetos geométricos, uma interface de software de GI utilizando os gestos definidos e a sua avaliação heurística. Na Seção 5.1 é apresentada a identificação dos requisitos para o desenvolvimento de um software de GI. Na Seção 5.2 é apresentado os gestos que podem ser desenvolvidos em softwares de GI utilizando os conceitos matemáticos. Na Seção 5.3 é apresentado um protótipo desenvolvido com interação por meio do toque, bem como suas funcionalidades, arquitetura e implementação, sendo a sua avaliação heurística detalhada na Seção 5.4. Por fim, as considerações finais são discutidas na Seção 5.5 . 


\subsection{Identificação dos Requisitos para um Software de GI}

Um estudo recente conduzido por Vitale et al. (2014) explorou a relação entre gestos e conceitos geométricos (e.g. circunferências, pontos, retas paralelas). Neste estudo, os autores investigaram diferentes gestos e tentaram relacioná-los com as propriedades do objeto geométrico a ser construído. Por exemplo, por meio de dois pontos, é possivel traçar uma reta; para isto o estudante deveria construir dois pontos de uma determinada distância entre eles e depois traçaria a reta por estes dois pontos já construídos. No estudo, gestos foram pré-definidos de forma a manter relações com as propriedades dos objetos geométricos. Os resultados obtidos mostraram que esta abordagem pode afetar positivamente o processo de ensino-aprendizagem. O estudo também indicou que os estudantes que possuíam conhecimentos mais sólidos sobre a geometria conseguiam realizar corretamente os gestos de acordo com os conceitos geométricos. Além disso, os estudantes que possuíam alguma dificuldade em geometria tiveram a oportunidade de demonstrar por meio de gestos como era um objeto geométrico de acordo com os conceitos já aprendidos, gerando um ambiente saudável para discussão sobre propriedades geométricas de objetos.

Ao observar o estudo de Vitale et al. (2014), este trabalho realizou entrevistas com especialistas da área de matemática, a fim de investigar como propor gestos para construção de objetos geométricos que podem auxiliar no entendimento da geometria. Foram entrevistadas quatro professoras do ICMC-USP com doutorado em Educação Matemática. As entrevistas foram realizadas individualmente e tiveram duração média de uma hora. Para conduzir a entrevista foram definidas um conjunto de perguntas-padrão. Além disso, foi dada a liberdade para o especialista expor seus anseios e necessidades sobre o uso da tecnologia, em particular, softwares de GI em dispositivos móveis no contexto escolar. Os dados das entrevistas foram tabulados para auxiliar na definição de requisitos para o sistema. Em particular, as entrevistas apontaram que o aprendizado dos conceitos geométricos pode ser dificultado se os gestos criados não tiverem relação com as propriedades geométricas dos objetos. Por exemplo, se uma circunferência for desenhada com o gesto de um círculo, o aluno não vai entender que o círculo possui um raio de tamanho x e que todos os pontos desta circunferência estão equidistante do centro, gerando problemas conceituais que afetam a aprendizagem. Para amenizar este problema, é importante que haja significado para cada gesto realizado, ou seja, que os conceitos matemáticos sejam utilizados para definir um gesto. Além dos benefícios pedagógicos que esta abordagem oferece, também existem vantagens relacionadas ao desenvolvimento de uma interface de GI, pois o estudante poderia aplicar o conhecimento prévio sobre geometria para interagir com o software e realizar suas ações.

Além da identificação das funcionalidades mais comumente utilizadas durante 
as atividades apontadas, pelas professoras entrevistadas, também foram levantados requisitos de acordo com as versões disponíveis de softwares de GI. Com estas informações, foi possível elaborar o Diagrama de Caso de Uso (Figura 5.1) e definir as funcionalidades principais do software. Este diagrama auxilia na proposta de um novo software, sendo possivel identificar os requisitos funcionais do sistema.

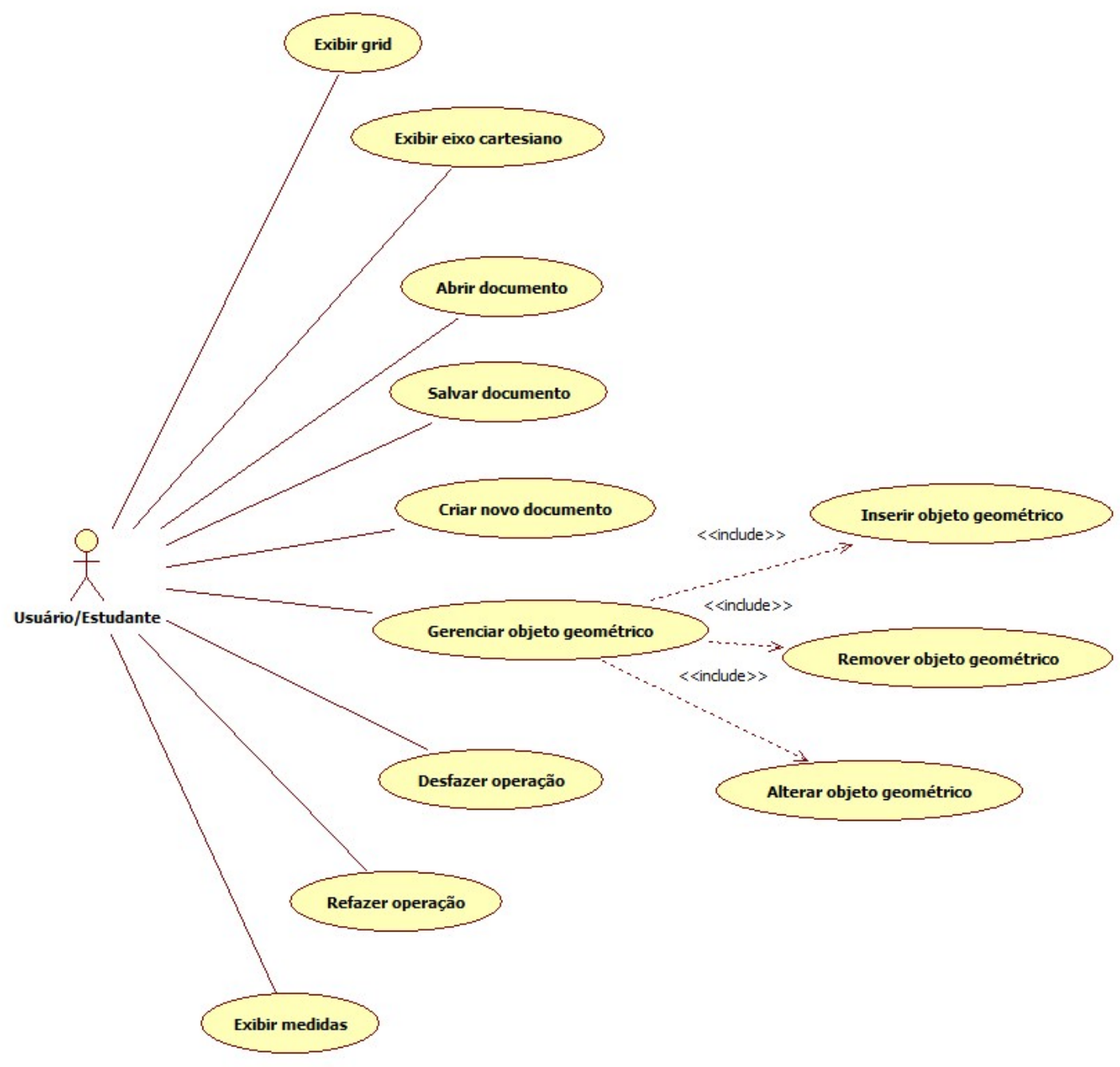

Figura 5.1: Caso de uso do software GeoTouch

A partir do caso de uso, foram identificadas as funcionalidades básicas e de edição, apresentadas nas Tabelas 5.2 e 5.1. Na Tabela 5.1 são apresentadas as funcionalidades de operação básica do software (i.e. construção de objetos geométricos), incluindo exibição de medidas e medir ângulo. Na Tabela 5.2 são apresentadas as funcionalidades de edição destes objetos geométricos. Os casos de uso da Figura 5.1, apresentados como "Inserir objeto geométrico", "Remover objeto geométrico"e "Alterar objeto geométrico", utilizam as funcionalidades apresentadas na Tabela 5.3 para 
construção básica de objetos geométricos.

Tabela 5.1: Funcionalidades para a operação do software.

\begin{tabular}{||l|}
\hline \hline Funcionalidades de operação \\
\hline \hline Novo \\
\hline Abrir \\
\hline Salvar \\
\hline Exibir medidas \\
\hline Medida ângulo \\
\hline
\end{tabular}

Tabela 5.2: Funcionalidades para a edição de objetos geométricos.

\begin{tabular}{||l|}
\hline \hline Funcionalidades de edição \\
\hline \hline Remover \\
\hline Desfazer \\
\hline Refazer \\
\hline Ajustar tamanho \\
\hline
\end{tabular}

Tabela 5.3: Funcionalidades básicas para a construção de objetos geométricos.

\begin{tabular}{||l||}
\hline \hline Funcionalidades de construção \\
\hline \hline Ponto \\
\hline Ponto médio \\
\hline Reta \\
\hline Segmento de reta \\
\hline Semi-reta \\
\hline Perpendicular \\
\hline Paralela \\
\hline Circunferência \\
\hline Intersecção \\
\hline
\end{tabular}

Além dos Requisitos Funcionais de construção, edição e operação, também foram identificados os Requisitos não funcionais, que estão relacionados a termos de desempenho, usabilidade, confiabilidade e tecnologias envolvidas. Estes requisitos são características adicionais para contribuir com a qualidade do software. Entretanto, o desenvolvedor pode optar por atender esses requisitos ou não. Os Requisitos não funcionais identificados foram:

- Requisitos de facilidade de uso: os gestos do software deverão ser de fácil compreensão pelos o usuários, sendo relacionado com os gestos do cotidiano ou com os conceitos do gesto; 
- Requisitos de portabilidade: o software poderá ser utilizado em dispositivos móveis que possuem diferentes tamanhos de tela (e.g. tablets ou smartphones);

- Requisitos de implementação: o software deverá ser desenvolvido na linguagem Java para Android.

\subsection{Definição dos Gestos de Construção}

Com a identificação das funcionalidades de construção apresentadas na seção anterior, foi elaborado um dicionário de gestos para realizar a construção de objetos geométricos. Todos os gestos foram criados de acordo com os conceitos geométricos dos objetos a serem construídos. O dicionário de gestos é composto pela descrição textual do objeto, sua relação com os conceitos geométricos (caso exista) e um conjunto de figuras ilustrativas que apresentam como realizar os gestos em uma interface baseada em tela multitoque, como ocorre no software proposto, GeoTouch. Estes gestos estão organizados em três categorias, a seguir:

- Gestos do Núcleo: gestos principais do software e que são a base para os gestos de outras categorias;

- Gestos de Navegação: gestos para a navegação no software;

- Gestos Básicos: gestos básicos da aplicação para a construção dos objetos geométricos.

\subsubsection{Gestos do Núcleo}

Os gestos da categoria "Gestos do Núcleo" são gestos básicos que fornecem suporte para a criação de gestos mais avançados do sistema. Nesta categoria, são encontrados os gestos toque breve, pressionar, pressionar mais toque, movimento, arrasto, rotação e ajustar, sendo detalhados a seguir:

Gesto: Toque Breve (Figura 5.2)

Descrição: Este gesto consiste em tocar brevemente um dedo na superfície da tela.

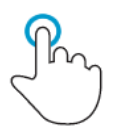

Figura 5.2: Gesto Toque Breve. 
Gesto: Pressionar (Figura 5.3)

Descrição: Consiste em tocar com um dedo na superfície da tela por um longo período

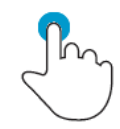

Figura 5.3: Gesto Pressionar.

Gesto: Arrasto (Figura 5.4)

Descrição: Este gesto consiste em arrastar rapidamente com a ponta do dedo na tela

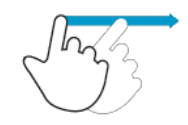

Figura 5.4: Gesto Arrasto.

Gesto: Movimento (Figura 5.5)

Descrição: Este gesto consiste em selecionar objetos e movimentá-los usando um dedo sem perder o contato com a tela.

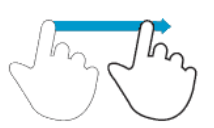

Figura 5.5: Gesto Movimento.

Gesto: Rotação (Figura 5.6)

Descrição: Este gesto consiste em tocar a tela com um dedo e movimentá-lo no sentido horário ou anti-horário, formando um círculo. 


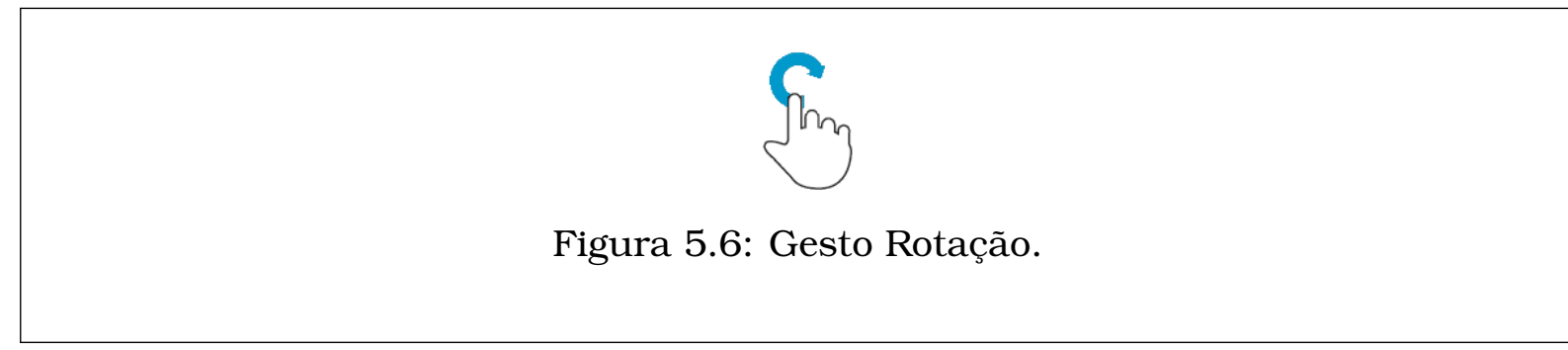

Gesto: Ajustar (Figura 5.7)

Descrição: Este gesto consiste em tocar a tela com dois dedos e movimentá-los em lados opostos.

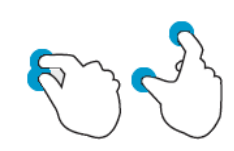

Figura 5.7: Gesto Ajustar.

\subsubsection{Gestos de Navegação}

A categoria "Gestos de Navegação" agrupa o gestos utilizados para realizar atividades de manipulação/edição e são baseados nos gestos definidos pela a categoria "Gestos de Núcleo”. Os gestos desta categoria são funcionalidades de desfazer, refazer, selecionar, movimentar e editar.

Gesto: Desfazer (Figura 5.8)

Gesto base: Arrasto

Descrição: O gesto consiste em arrastar dois dedos simultaneamente da esquerda para a direita.

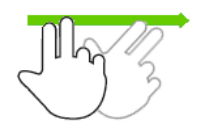

Figura 5.8: Gesto Desfazer. 
Gesto: Refazer (Figura 5.9)

Gesto base: Arrasto

Descrição: O gesto consiste em arrastar dois dedos simultaneamente da direta para a esquerda.

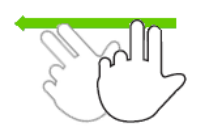

Figura 5.9: Gesto Refazer.

Gesto: Selecionar (Figura 5.10)

Gesto base: Pressionar

Descrição: O gesto consiste em tocar a superfície da tela, para selecionar um objeto, sem perder o contato.

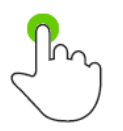

Figura 5.10: Gesto Selecionar.

Gesto: Movimentar (Figura 5.11)

Gesto base: Movimento

Descrição: O gesto consiste em movimentar um objeto selecionado.

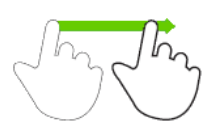

Figura 5.11: Gesto Movimentar. 
Gesto: Editar (Figura 5.12)

Gesto base: Ajustar

Descrição: O gesto consiste em tocar a tela com dois dedos e movimentá-los em direção oposta, com o objetivo de aumentar ou diminuir o tamanho de um objeto.

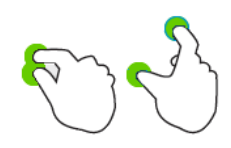

Figura 5.12: Gesto Editar.

\subsubsection{Gestos Básicos}

Os gestos da categoria "Gestos Básicos" correspondem aos gestos básicos para a criação dos objetos geométricos. Nesta categoria, são encontrados os gestos de criação de ponto, ponto médio, circunferência, circunferência definida por um segmento de reta, reta, segmento de reta, semi-reta, paralela e perpendicular. Todos os gestos são baseados em gestos da categoria "Gestos do Núcleo" e serão apresentados a seguir, o seu nome, seu gesto base (gesto de núcleo), sua definição conceitual na matemática, sua descrição de como realizar o gesto e a comparação com os gestos em outros softwares, como Sketchometry, Geometry Pad e Geogebra, explorados no Capítulo 4 deste trabalho.

Gesto: Ponto (Figura 5.13)

Gesto base: Toque Breve

Definição conceitual: O ponto é a especificação de um local, não tem comprimento, largura ou profundidade. O verdadeiro ponto tem dimensão 0, porém, para que possa ser visualizado, é colocado uma dimensão pequena (Bowman, 1985).

Descrição: O gesto consiste com um toque breve com um dedo na tela do dispositivo, criando assim um ponto, no local em que o estudante tocou.

Comparação: Em todos os softwares a construção é por meio do toque breve em tela. 


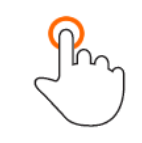

Figura 5.13: Gesto Ponto.

Gesto: Ponto Médio (Figura 5.14)

Gesto base: Pressionar e Toque Breve

Definição conceitual: O ponto compõe o ponto médio, que é o ponto central equidistante de ambos pontos finais de um segmento de uma reta (Coll e Teberosky, 2002).

Descrição: O gesto consiste em pressionar dois dedos na tela e depois pressionar o dedo do meio na tela para criar o ponto médio.

Comparação: No software Geogebra, o ponto médio é construído por meio da sua pré-seleção no menu. Posteriormente, o usuário deve criar o primeiro ponto e o segundo ponto, sendo construído automáticamente o ponto médio. Nos softwares Geometry Pad e Sketchometry esta funcionalidade não esta disponível.

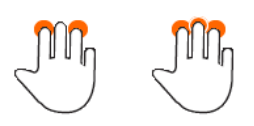

Figura 5.14: Gesto Ponto Médio.

Gesto: Circunferência (Figura 5.15)

Gesto base: Toque Breve e Rotação

Definição conceitual: A circunferência é o conjunto de pontos de um círculo (ou plano) que são equidistantes do seu centro (Carvalho, 1988).

Descrição: O gesto circunferência consiste em dois passos. Primeiro passo, devese tocar brevemente a tela, para criar o ponto central da circunferência. No 
segundo passo, deve-se realizar o gesto de rotação envolta do ponto central, fazendo com que os pontos desta circunferência sejam equidistante do centro.

Comparação: Nos softwares Geogebra e Geometry Pad a construção da circunferência é similar, sendo que a funcionalidade deve ser selecionada antes de realizar a construção. Posteriormente, o usuário deve tocar brevemente na tela duas vezes, a primeira para definir o centro da circunferência e a segunda vez para definir o raio. No software Sketchometry, a circunferência é realizada somente com movimento de rotação, sem definir qualquer ponto. Com a falta de um ponto central, os usuários não conseguem identificar que a circunferência é o conjunto de pontos que são equidistantes do seu centro.

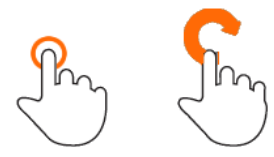

Figura 5.15: Gesto Circunferência.

Gesto: Circunferência definida por um segmento de reta (Figura 5.16)

Gesto base: Toque Breve, Movimento, Rotação

Definição Conceitual: A circunferência possui como raio o segmento de reta definido.

Descrição: A criação da circunferência definida por um segmento de reta consiste em três passos. Primeiro passo, deve-se criar um segmento de reta, por meio da construção de dois pontos, sendo o segundo passo, fazer o gesto de movimento e atravessar de um ponto ao outro, para construir o segmento de reta. No terceiro e último passo, deve-se realizar o movimento de rotação envolta do segmento de reta recentemente criado, para defini-lo como o raio da circunferência.

Comparação: No software Geogeobra e Geometry Pad, o usuário deve criar previamente um segmento de reta e posteriormente escolher no menu a opção para criar a circunferência. Durate a construção da circunferência, o usuário deve tocar brevemente os dois pontos do segmento de reta previamente criado. No software Sketchometry, o usuário deve criar um segmento de reta 
e posteriormente fazer meio arco, saindo de um ponto para o outro. Este movimento dificulta a identificação do raio da circunferência, que é definida pelo segmento de reta, pelo o usuário.

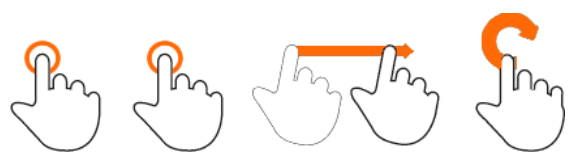

Figura 5.16: Gesto Circunferência definida por um segmento de reta.

Gesto: Reta (Figura 5.17)

Gesto base: Toque Breve, Movimento

Definição conceitual: A reta é um conjunto infinito de pontos geométricos, não tendo curvatura, princípio e fim (Iezzi et al., 1997).

Descrição: O gesto consiste em criar dois pontos com o gesto "Toque Breve" e realizar o gesto movimento fora do raio de proximidade dos pontos, ou seja, passar por cima dos dois pontos.

Comparação: Nos softwares Geogebra e Geometry Pad, o usuário deve escolher previamente a funcionalidade para a construção da reta. Para a construção, o usuário precisa tocar duas vezes brevemente na tela, em locais diferentes, para definir os dois pontos da reta. No software Sketchometry, o usuário faz o gesto de linha na tela do dispositivo, sendo que a reta criada não possui os pontos. Nos softwares Geogebra e Geometry Pad, não é possivel realizar a construção da reta sem ao menos um ponto, sendo diferente do software Sketchometry. Neste último software, o usuário não consegue identificar que a reta é um conjunto infinito de pontos geométricos.

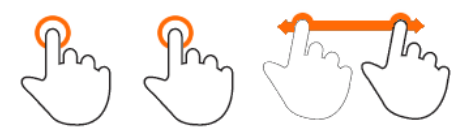

Figura 5.17: Gesto Reta. 
Gesto: Semi-reta (Figura 5.18)

Gesto Base: Toque Breve, Movimento

Definição conceitual: A semi-reta, que possui uma extremidade com limite e a outra extremidade para o infinito (Iemenes et al., 1997).

Descrição: O gesto consiste em criar dois pontos com o gesto "Toque Breve" e realizar o gesto movimento de forma que o usuário trace uma reta dentro do raio de um dos pontos e passar por cima de outro.

Comparação: A construção da semi-reta nos softwares Geogebra e Geometry Pad são de maneira similar e a construção deve ser pré-selecionada no menu. O usuário deve construir o primeiro ponto e o segundo em diferentes locais da tela, sendo que a construção do segundo ponto determina a direção da semi-reta. No software Sketchometry o usuário deve tocar brevemente a tela em locais diferentes para a construção dos pontos e posteriormente traçar uma reta que passe por cima de um ponto (para determinar a direção da semi-reta) e que o limite da reta termine no outro ponto. Durante a execução do gesto para a construção do objeto semi-reta no software Sketchometry é mostrado explicitamente a extremidade de um lado da semi-reta possui limite e a outra para o infinito, sendo diferente nos softwares Geogebra e Geometry Pad.

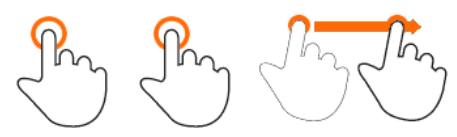

Figura 5.18: Gesto Semi-reta.

Gesto: Segmento de reta (Figura 5.19)

Gesto Base: Toque Breve, Movimento

Definição conceitual: O segmento de reta é o conjunto de todos os pontos entre dois pontos limites (Trotta et al., 1979).

Descrição: O gesto consiste em criar dois pontos com o gesto "Toque Breve" e realizar o gesto movimento dentro do raio de proximidade dos pontos. 
Comparação: Para criar o segmento de reta nos softwares Geogebra e Geometry Pad, esta funcionalidade deve ser selecionada no menu. Em ambos os softwares, o usuário deve criar dois pontos em lugare distintos da tela para construir o segmento de reta. No software Sketchometry o usuário deve criar dois pontos na tela em lugares diferentes e traçar uma reta em que os limites desta reta tenham uma curta distância dos pontos (os limites da reta devem passar por cima dos pontos). O gesto do Sketchometry deixa explícito que o segmento de reta é um conjunto de todos os pontos entre dois pontos limites, sendo que nos softwares Geogebra e Geometry Pad, o usuário consegue identificar este conceito somente após a construção do segmento de reta.

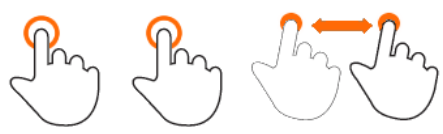

Figura 5.19: Gesto Segmento de reta.

Gesto: Perpendicular (Figura 5.20)

Gesto base: Pressionar, Rotação

Definição conceitual: As paralelas são compostas por duas retas e possuem um ângulo de 90 graus entre elas (Dolce et al., 2009).

Descrição: Deve-se selecionar os dois pontos de uma reta e utilizar o gesto de meia rotação para criar um ângulo de 90 o graus.

Comparação: No software Geometry Pad, a reta perpendicular deve ser selecionada previamente no menu. Posteriormente, deve-se tocar brevemente na reta que deseja que possua a perpendicular. No software Geogebra, o usuário deve selecionar a função para a criação da perpendicular no menu e posteriormente tocar brevemente um dos pontos da reta em que deseja seja criada a perpendicular. A construção deste objeto geométrico no Sketchometry é bastante diferente dos demais softwares: o usuário deve fazer o gesto de em formato de "L"na reta em que deseja fazer a perpendicular. No último software, apesar deste gesto não ser intuitivo, ele esta fortemente relacionado com o conceito de 90 graus entre duas retas. 

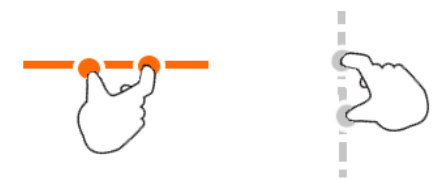

Figura 5.20: Gesto Perpendicular.

Gesto: Paralela (Figura 5.21)

Gesto base: Pressionar, Movimento

Definição conceitual: As retas paralelas são retas equidistantes entre si e que nunca se cruzam (Dolce e Pompeu, 2005).

Descrição: A paralela possui o movimento de pressionar para selecionar a reta que deseja formar paralela e depois o gesto movimento é usado para fixar onde a paralela vai estar localizada.

Comparação: Foi observado que o software Geometry Pad não possui esta funcionalidade. No software Geogebra, o usuário deve escolher a construção de reta paralela previamente no menu e posteriormente tocar na reta em que deseja ser construída a paralela, e finalmente tocar onde a paralela deseja que fique localizada. No software Sketchometry, o usuário deve fazer o gesto em formato em "Z"na horizontal, na reta em que deseja criar a paralela. Neste último software, o gesto não é intuitivo, difícil de ser executado e não está relacionado com os conceitos da reta paralela.

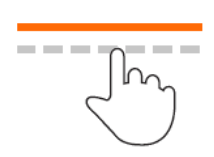

Figura 5.21: Gesto Paralela.

\subsection{Protótipo}

O protótipo foi desenvolvido na plataforma Android versão 4.0 e pode ser executado em dispositivos móveis, como tablets de 7 e 10 polegadas ou smpartphones. A interação com o software pode ser realizada por meio de um ou mais dedos, e as construções básicas dos objetos geométricos são feitas por meio dos gestos definidos nas seções 
anteriores. Isso permitiu uma sensível redução do número de ícones em tela. A Figura 5.22.a mostra a tela de apresentação do aplicativo, que foi nomeado GeoTouch. A Figura 5.22.b mostra a tela inicial do protótipo, na qual é possivel identificar que o lado direito é a área de desenho, em que os usuários podem construir os objetos geométricos, e o lado esquerdo, fica localizado o menu. Este menu é acessado por meio de um ícone localizado na parte superior esquerda e foi desenvolvido de modo que o usuário consiga escondê-lo quando desejar trabalhar na área de desenho e mostrá-lo quando precisar acessar alguma funcionalidade do menu.

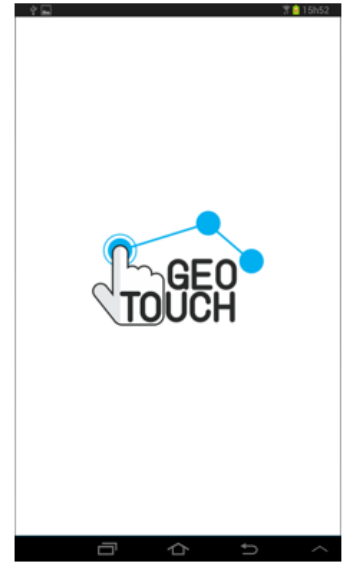

(a)

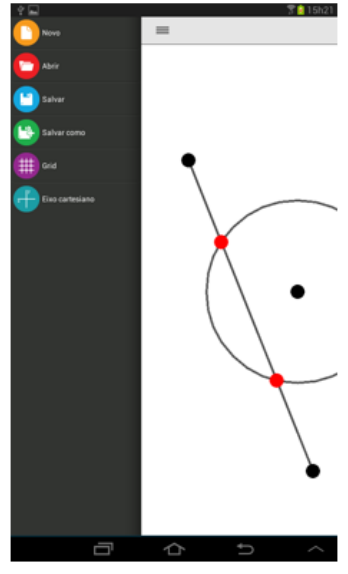

(b)

Figura 5.22: Tela de apresentação e inicial do software GeoTouch.

Ao acessar pela primeira vez o aplicativo, um conjunto de imagens sobre quais gestos e funcionalidades podem ser utilizadas, é exibido ao usuário antes de abrir o protótipo (Figura 5.23). Isto faz com que os estudantes sejam induzidos a conhecer o software de modo geral, antes de começar realizar as atividades. Estas telas de apresentação do software podem ser desabilitadas na tela configurações quando o estudante julgar que não precisa mais observá-las toda vez que entrar no software. Este mesmo manual também pode ser acessado a qualquer momento pelo ícone com imagem de interrogação localizado no lado superior esquerdo, na barra de título do sistema.

Além dos objetos geométricos serem construídos sem a necessidade de escolher previamente a função em algum ícone, estes objetos também podem ser construídos por meio de um menu suspenso (Figura 5.24.a). Para mostrar o menu suspenso, o usuário deve realizar duas construções iniciais, como pontos, selecioná-los utilizando dois dedos ao mesmo tempo e esperar por 3 segundos. Neste momento, o menu suspenso é apresentado com várias opções de construção, como traçar reta, traçar segmento, traçar semi-reta, criar ponto médio, criar circunferência e exibir distância. O mesmo menu suspenso também é mostrado para remover os objetos em tela, en- 

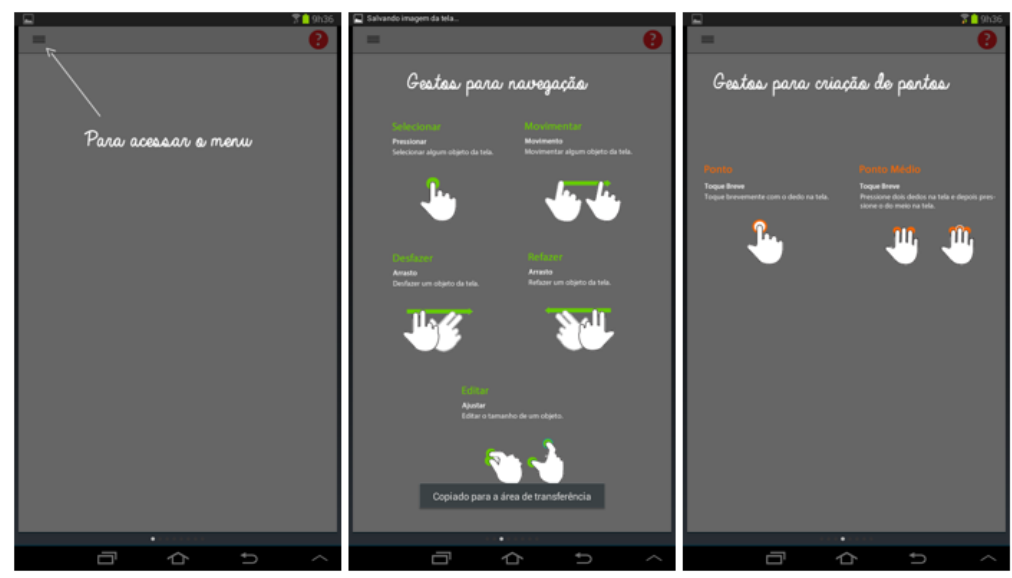

Figura 5.23: Telas de apresentação do software GeoTouch.

tretanto, ao invés de utilizar dois dedos, somente um dedo é requerido, e somente um objeto é excluído por meio deste movimento (Figura 5.24.b).

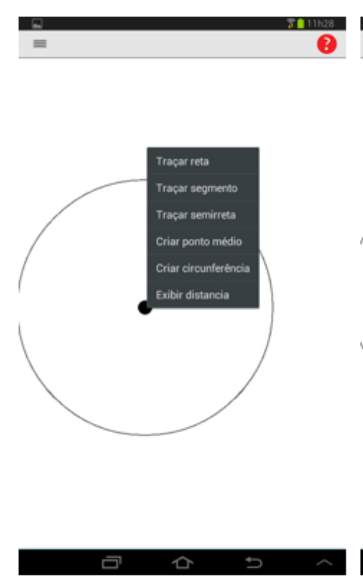

(a)

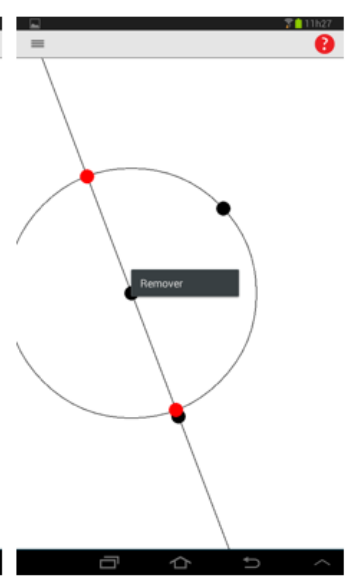

(b)

Figura 5.24: Menu suspenso para criar e remover objetos.

O protótipo também oferece a opção de "Grid", que é um tipo de quadriculado que ajuda na orientação do desenho pelo o usuário. Esta funcionalidade está localizada no menu lateral e o usuário pode escolher qual será o tamanho do grid. Na Figura 5.25 é possivel observar a caixa que mostra a preferencia do grid e o seu resultado final. Além da funcionalidade grid, o usuário também pode escolher a opção "Eixo Cartesiano". Esta funcionalidade é similar ao "Grid", porém é mostrado as coordenadas. Desta maneira, o usuário consegue ter uma ideia de qual é o tamanho das suas construções (Figura 5.26).

Ao sair do software, uma mensagem de confirmação é apresentada ao usuário (Figura 5.27), com o objetivo que o usuário saia do aplicativo de maneira indesejada. A mensagem pergunta ao usuário se deseja salvar as atividades e quais os procedi- 


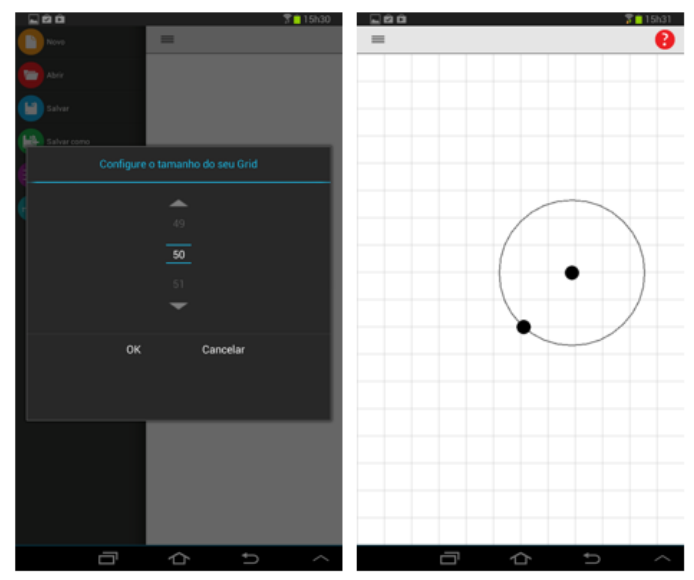

Figura 5.25: Funcionalidade de Grid.

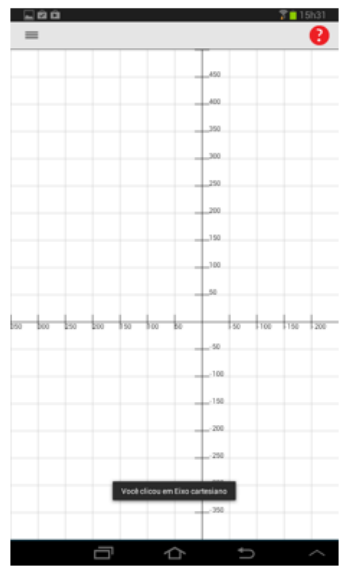

Figura 5.26: Funcionalidade de Eixo Cartesiano.

mentos que devem ser realizados para que isto aconteça. Nesta mensagem o usuário possui a opção de cancelar e permanecer na tela das atividades ou sair totalmente do software.

\subsubsection{Funcionalidades Disponíveis}

O protótipo já está disponível gratuitamente na loja virtual de aplicativos da Google, o Google Play, acessivel pelo endereço: https://play.google.com/store/apps/details?id=com.usp.icmc. Atualmente, o protótipo disponibiliza funcionalidades que envolvem construções básicas de objetos geométricos para o ensino da geometria (e.g. pontos, retas, circunferências e paralelas), manipulação destes objetos (e.g. movimentação de um objeto) e edição (e.g. aumentar o tamanho de uma reta ou circunferência). Além disso, outras funcionalidades básicas de um software também foram desenvolvidas, como abrir e salvar um documento, novo documento e; fazer e desfazer. Na Tabela 5.4 mostra as funcionalidades básicas de um software de GI. A Tabela 5.5 mostra todas as 


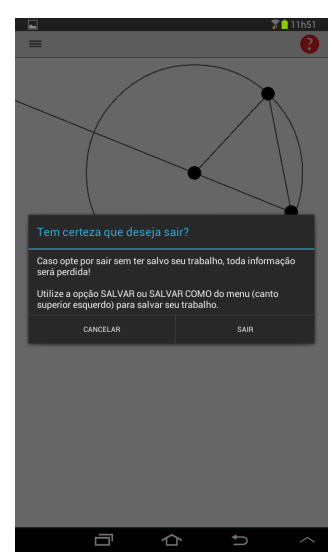

Figura 5.27: Mensagem de saída do software.

funcionalidades de construção básica, edição e manipulação que o GeoTouch oferece.

Tabela 5.4: Tabela de operações básicas do software.

\begin{tabular}{||l|}
\hline \hline Operações Básicas \\
\hline \hline Novo \\
\hline Abrir \\
\hline Salvar \\
\hline Exibir medidas \\
\hline Grid \\
\hline Eixo cartesiano \\
\hline Medir distância \\
\hline
\end{tabular}

\subsubsection{Arquitetura}

O software foi organizado em diferentes pacotes. Pacotes são diretórios (ou pastas) que são utilizados para agrupar classes semelhantes ou relacionadas. Foi desenvolvido dois principais pacotes no software (Figura 5.28). O principal pacote, chamado de "Pacote Básico", contém as classes para a criação dos objetos geométricos, como, ponto, ponto médio, circunferência, circunferência definida por segmento de reta, reta, semi-reta, segmento de reta, perpendicular, paralela e intersecção. Este mesmo pacote possui um espaço chamado Cache para armazenar todos os objetos geométricos construídos até o momento. Este espaço é importante, pois caso o estudante mude a orientação do dispositivo móvel (e.g. tela em paisagem ou em retrato), o software seja capaz de apresentar novamente os objetos nas posições corretas. Além disso, a cada momento que se cria um novo objeto, por padrão do Android, a tela é limpada. Para evitar que os objetos construídos sejam removidos, é utilizado o espaço de Cache para apresentar os objetos construídos em tela. O "Pacote de Ajuda", contém a classe que apresentam as figuras e as descrições dos gestos para utilizar 
Tabela 5.5: Tabela de funcionalidades do software.

\begin{tabular}{||l|l|l||}
\hline \multicolumn{1}{|c|}{ Construções Básicas } & \multicolumn{1}{|c||}{ Edição } & \multicolumn{1}{|c||}{ Manipulação } \\
\hline \hline Ponto & $\begin{array}{l}\text { Aumentar ou diminuir o } \\
\text { tamanho do objeto }\end{array}$ & $\begin{array}{l}\text { Mover o objeto de lu- } \\
\text { gar }\end{array}$ \\
\hline Ponto médio & & \\
\hline $\begin{array}{l}\text { Circunferência definida } \\
\text { porcunferência Seg. }\end{array}$ & & \\
\hline Reta & & \\
\hline $\begin{array}{l}\text { Semi-Reta } \\
\text { Segmento de Reta }\end{array}$ & & \\
\hline Paralela & & \\
\hline Perpendicular & & \\
\hline Intersecção & & \\
\hline
\end{tabular}

as funcionalidades do software. E, por fim, o "Pacote de Visualização", são as classes que possibilitam a visualização dos elementos em tela e que recebem a resposta de alguma ação realizada na tela do dispositivo móvel.

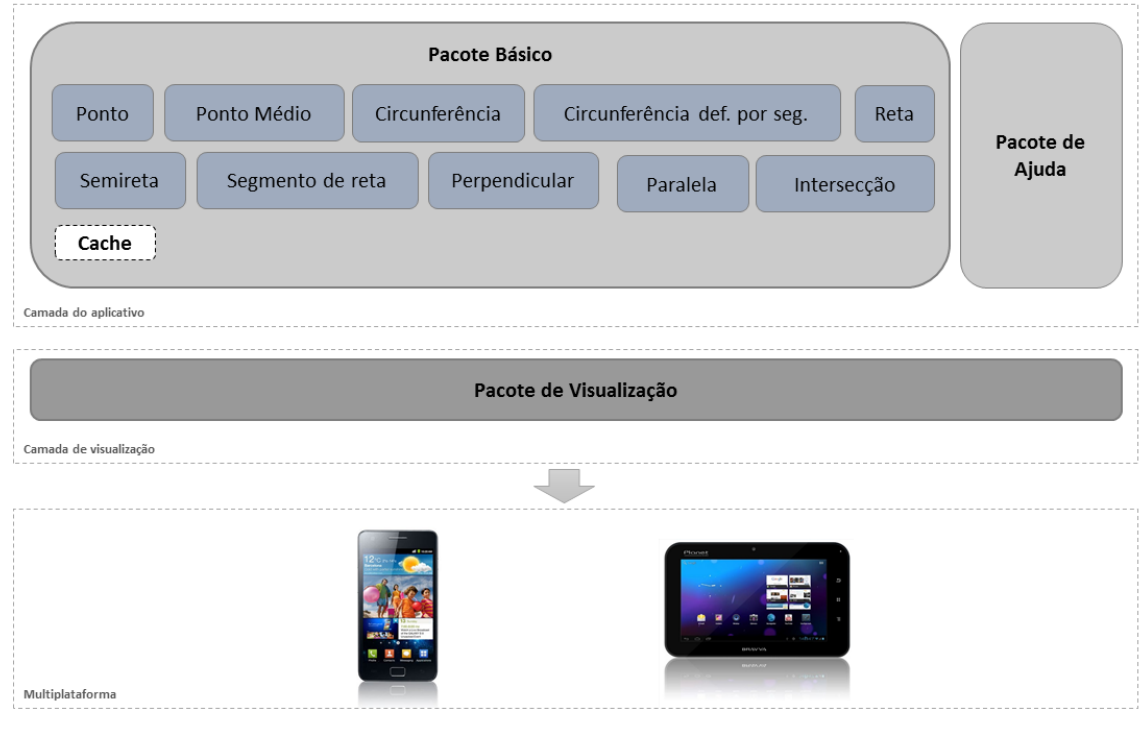

Figura 5.28: Arquitetura do software GeoTouch.

Durante a implementação do software, estes três pacotes foram chamados de com.usp.icmc.og, com.usp.icmc.gui e com.usp.icmc.help. Outros pacotes também foram desenvolvidos, como mostrado na Tabela 5.6, apresentando o nome do pacote e a sua descrição. Todos os pacotes começam com o termo "com.usp.icmc", para sinalizar onde está sendo desenvolvido o software, sendo o final do nome caracterizando qual é o pacote. 
Tabela 5.6: Pacotes do softare GeoTouch.

\begin{tabular}{||l|l||}
\hline \hline Pacote & \multicolumn{1}{|c|}{ Descrição } \\
\hline \hline com.usp.icmc.tgeo & Contém a classe principal, de desenho e a de abertura \\
\hline com.usp.icmc.bean & Contém classes de estrutura dos objetos geométricos \\
\hline com.usp.icmc.gui & $\begin{array}{l}\text { Contém as classes que compõem parte gráfica do soft- } \\
\text { ware }\end{array}$ \\
\hline com.usp.icmc.help & Contém as classes do manual de ajuda \\
\hline com.usp.icmc.listener & $\begin{array}{l}\text { Contém as classes que executam as ações dos botões } \\
\text { do menu }\end{array}$ \\
\hline com.usp.icmc.og & Contém as classes dos objetos geométricos \\
\hline
\end{tabular}

A Figura 5.29 apresenta as classes que estão localizadas no pacote com.usp.icmc.og. Neste pacote estão localizada as classes dos objetos geométricos, como, ponto, ponto médio, intersecção, reta, semi-reta, segmento de reta, paralela, perpendicular, circunferência e circunferência definida por segmento de reta.Todas estas classes são referenciadas dentro da classe Reconhecimento de Gestos, que é responsável em identificar qual gesto o usuário está realizando (e.g. ponto ou reta) e direcionar para a ação correta (e.g. criar ou mover ou remover). Além disso, as classes para a construção dos objetos geométricos são filhas da classe Objeto Dinâmico, que compartilha características em comum entre as classes, como id, rótulo, ponto, x e y. A classe Circunferência tem como filha a classe Circunferência def. Seg. e possui um atributo para informar o seu raio. A classe Reta tem como filha as classes Semi-reta, Paralela, Segmento de reta e Perpendicular. E, por fim, a classe Ponto tem como filha as classes Intersecção e Ponto Médio, tendo também um atributo para informar o seu raio. Esta classe Ponto é a base de todas as construções dos outros objetos geométricos.

\subsubsection{Implementação}

Os objetos geométricos do software são construídos e exibidos em uma classe que refere-se a área de desenho. Esta classe herda as características de sua classe pai RelativeLayout, que possibilita que um grupo de objetos sejam apresentados em sua posição relativa, ou seja, permite que o objeto seja apresentado em qualquer parte da tela. Por exemplo, o usuário consegue criar um ponto em qualquer lugar que desejar, sem a necessidade de estar alinhado a quaisquer outros objetos.

\section{Reconhecimento de Gestos}

Os objetos são criados a partir de toques na tela, sendo que um conjunto destes toques compõe os gestos para a execução das funcionalidades. Todo toque em tela é verificado pela classe Reconhecimento de Gestos, que é responsável por identificar o tipo de toque (e.g. toque breve, movimento ou pressionar) e decidir qual gesto será 


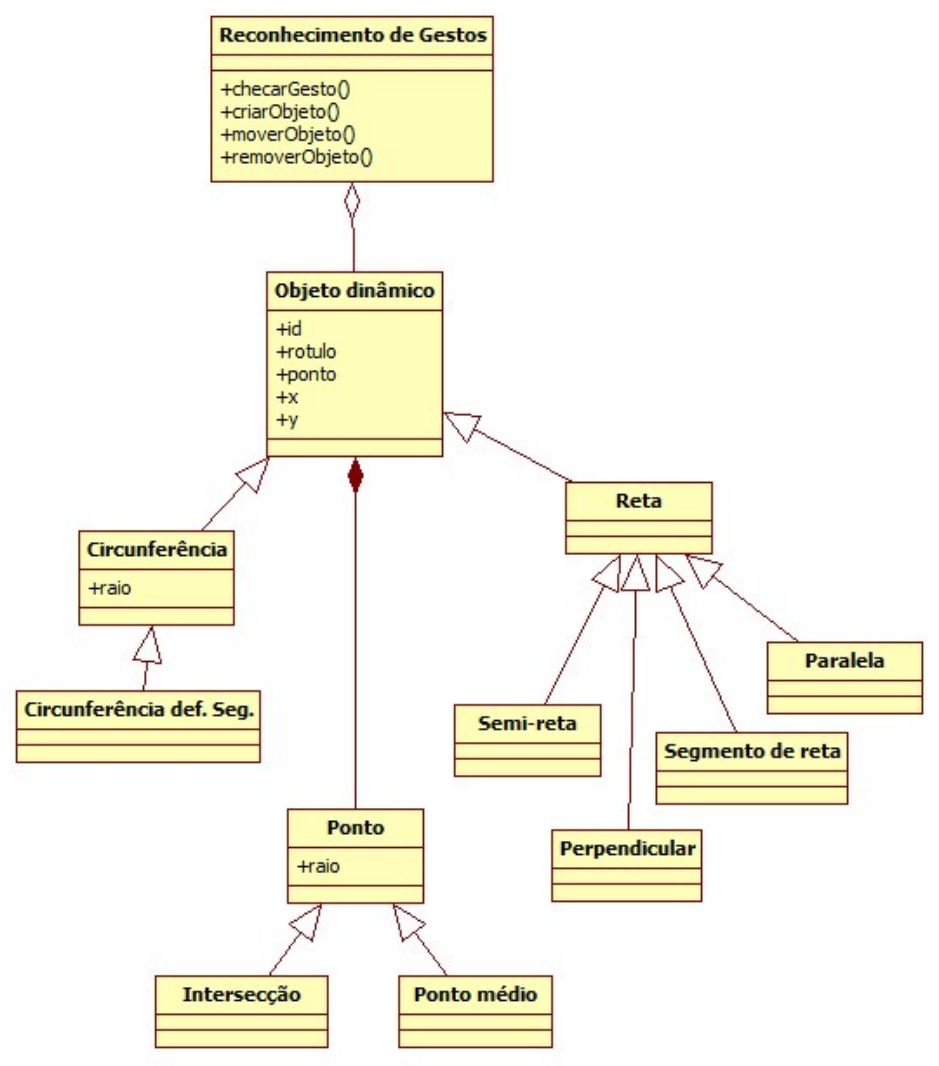

Figura 5.29: Arquitetura do software GeoTouch.

executado (e.g. seleção, movimentação ou criação). O código abaixo mostra resumidamente a implementação do método que é invocado sempre que ocorrer algum toque em tela. O toque é verificado em três tipos de ações: ACTION_DOWN (pressionamento), ACTION_MOVE (movimentação) e ACTION_UP (despressionamento). Na ação de pressionamento em tela pelo o usuário, é verificado se algum objeto já foi criado e se esta sendo selecionado; caso isto não ocorra, é armazenado em uma váriavel indicando que o usuário deseja criar um ponto. Caso o usuário esteja movimentando o(s) dedos(s), é verificado se há algum objeto que esteja selecionado para haver a movimentação do mesmo; caso contrario, é verificado se o usuário está realizando o gesto para a criação de circunferência, reta, segmento de reta, semi-reta, paralela, ponto médio ou perpendicular. E por fim, quando o usuário deixa de tocar a tela (despressionamento), é verificado se o usuário deseja criar algum objeto geométrico e é chamado o método para a criação de objetos geométricos.

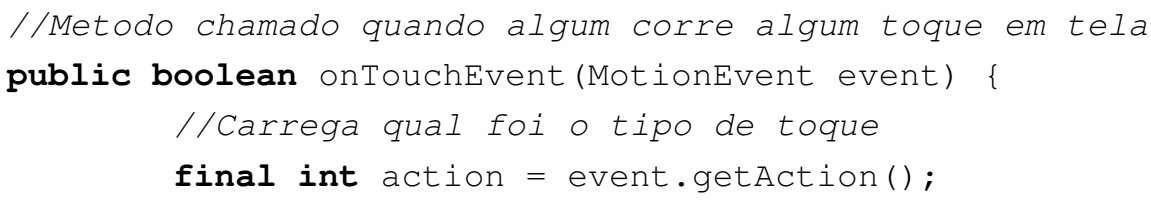




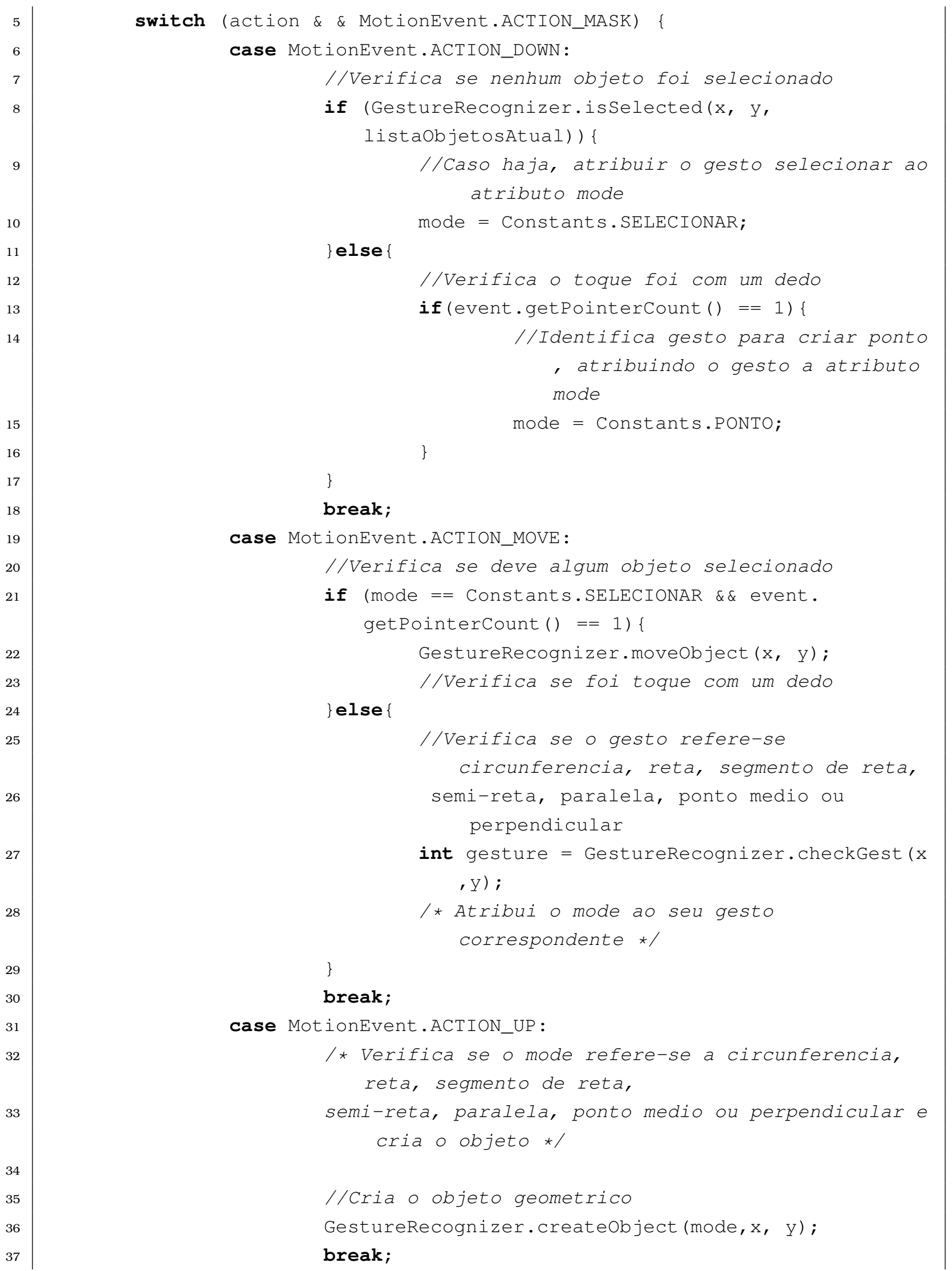




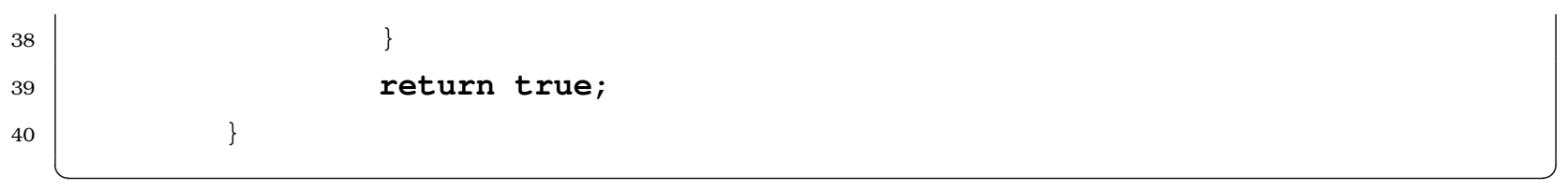

A Figura 5.30 e 5.31 mostra detalhadamente o fluxo do toque em tela. Este fluxo contêm os três tipos de ações em tela descritos anteriormente, sendo pressionamento (toque na tela), movimentação (moveu dedo na tela) e despressionamento (removou dedo da tela). A Figura 5.31 mostra detalhadamente a ação "O movimento utilizou algum ponto selecionado?", destacado em laranja na Figura 5.30.

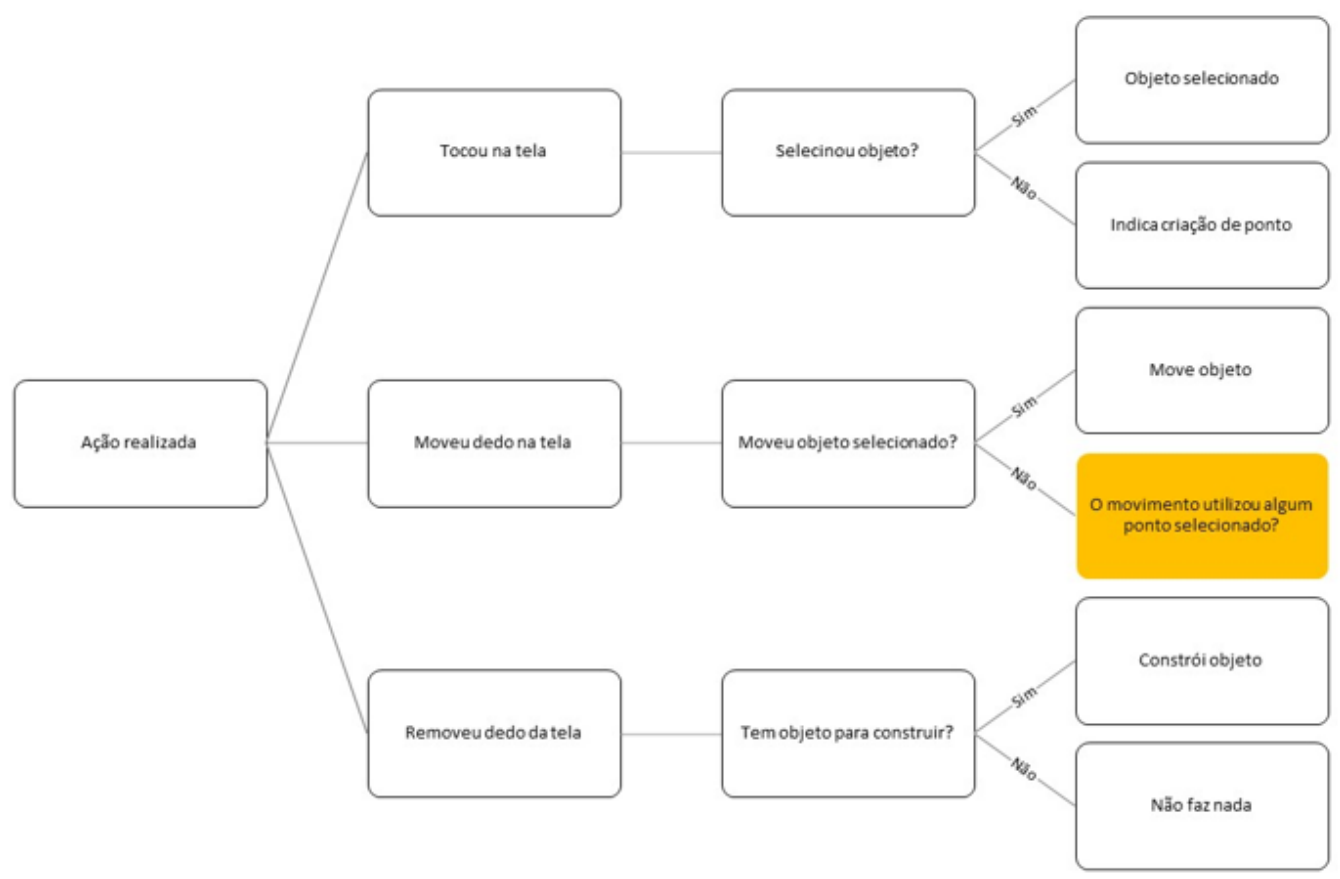

Figura 5.30: Fluxograma das ações ao tocar na tela.

\subsubsection{Pontos, Retas e Circunferências}

Todos os objetos geométricos devem possuir ao menos um ponto. Na geometria, o ponto é a especificação de um local, não possuindo largura e nem comprimento; entretanto, para facilitar a manipulação deste objeto pelo o usuário, o ponto no software é tratado como circunferência de raio pequeno e que possui preenchimento. Quando este ponto é selecionado ou movimentado, é checada uma distância de proximidade (Figura 5.32), que possibilita que o usuário consiga selecionar ou movimentar este ponto mesmo que não esteja tocando exatamente na sua localização do x e y.

A plataforma Android possui algumas funções prontas que possam ser utilizadas para desenho, como a construção de polignos, circunferências e retas. Entretanto, a função pronta para retas não abrange retas infinitas, sendo necessário implemen- 


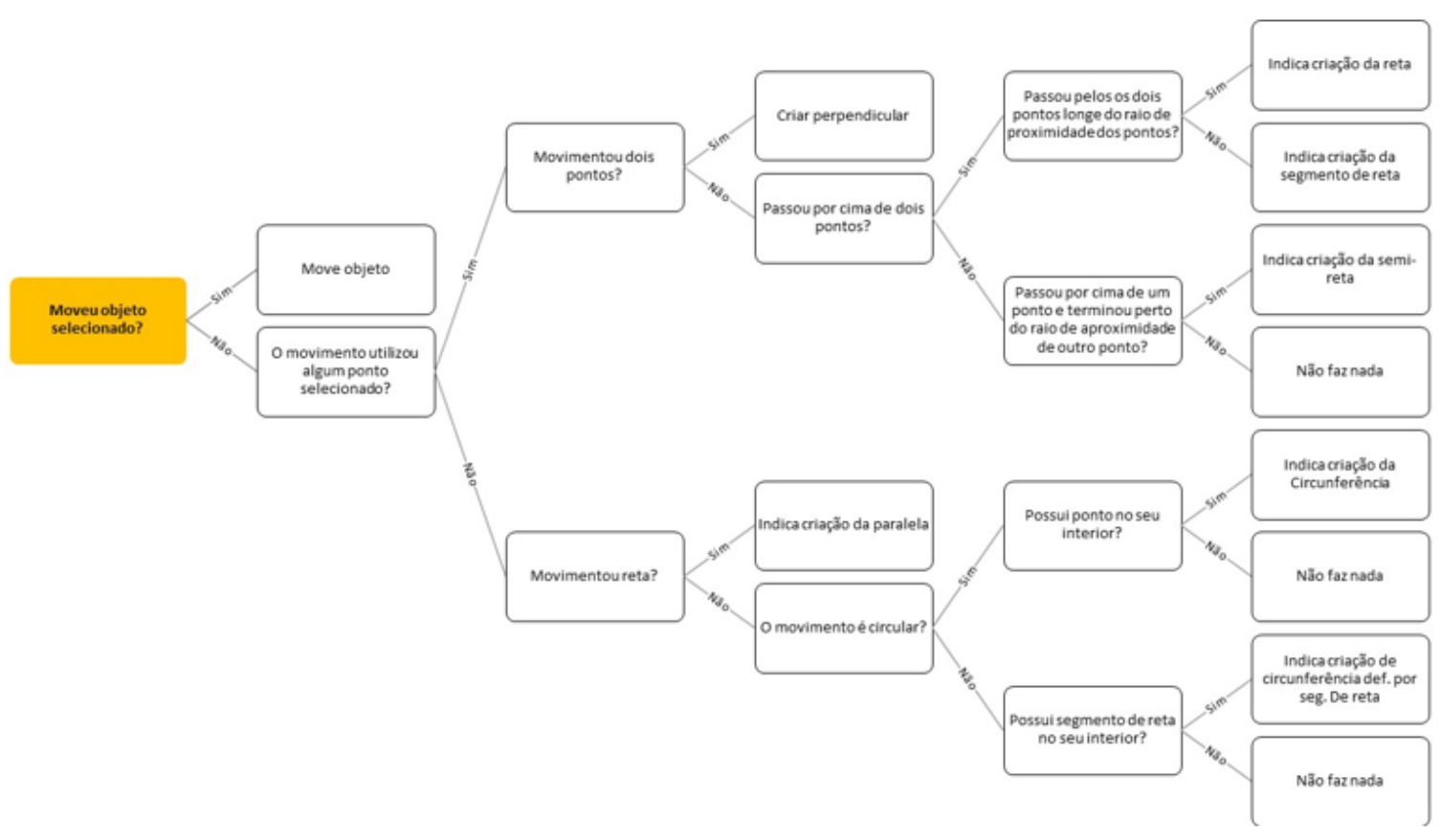

Figura 5.31: Detalhamento do fluxograma da ação de movimento que utiliza algum ponto selecionado.

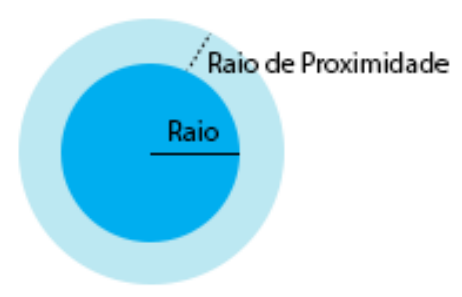

Figura 5.32: Espaço de proximidade para selecionar ou movimentar o ponto.

tar. Para contornar este problema, foi criado dois pontos adicionais na reta que o usuário esteja construindo, localizados fora da dimensão da tela (Figura 5.33). Desta maneira, o usuário possui a ilusão que a reta é infinita.

Para a criação da circunferência, é necessária a construção prévia de um ponto ou segmento de reta. O ponto ou o segmento de reta devem ser envolvidos pelo o gesto de rotação, sendo possível, desta maneira, a pesquisa destes dois objetos geométricos dentro da região da circunferência (Figura 5.34).

\subsection{Avaliação Heurística}

A fim de verificar a usabilidade do protótipo desenvolvido, foi realizado um teste de usabilidade seguindo os mesmos procedimentos definidos no Capítulo 4. No final deste teste, os problemas identificados foram comparados com o resultados obtidos 


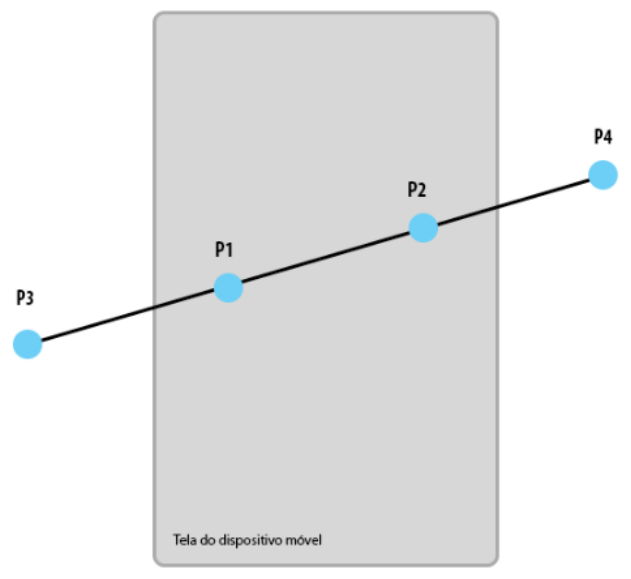

Figura 5.33: Implementação da reta infinita.

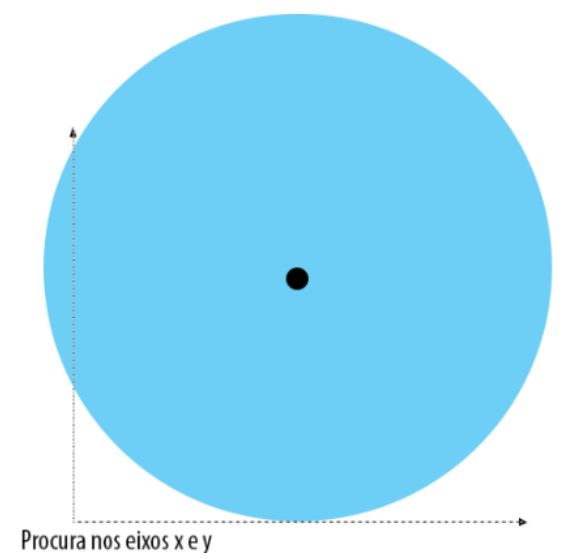

Figura 5.34: Procura de um ponto ou segmento de reta dentro da circunferência.

no teste de usabilidade realizado nos três softwares apresentados também no Capítulo 4. Esta comparação tem o objetivo de avaliar o desempenho do protótipo, que foi desenvolvido seguindo critérios pedagógicos para construção de objetos geométricos.

\subsubsection{Metodologia}

A metodologia utilizada para a avaliação do protótipo GeoTouch é a mesma metodologia utilizada para a avaliação dos softwares GeoGebra, Geometry Pad e Sketchometry, apresentada na Seção 4.1.1 do Capítulo 4. Participaram cinco avaliadores, sendo eles alunos de pós-graduação de Mestrado e Doutorado do Instituto de Ciências Matemáticas e de Computação da Universidade de São Paulo (USP) e são graduados em Ciência da Computação. Todos possuem conhecimentos intermediários em softwares de GI e conhecimento em avaliação de usabilidade utilizando heurísticas. A avaliação do software foi realizada em um Galaxy Tab de 7 polegadas e com versão Android 4.1. Também foi utilizado um computador, para que os avaliadores respondessem 
ao questionário e um guia impresso das atividades e heurísticas. O questionário de usabilidade e solução de exercícios foram os mesmos aplicados no Capítulo 4 deste trabalho.

\subsubsection{Resultados da Avaliação Heurística}

Após o protótipo ser avaliado, foi criada uma lista com os problemas identificados pelos os avaliadores. Um mesmo problema foi classificado em mais de uma heurística, podendo afetar a sua frequência. A Figura 5.35 apresenta a frequência que um problema foi encontrado em cada heurística . No eixo x, é mostrado a abreviação das heurísticas ${ }^{1}$, em que o seu significados podem ser encontrados na Tabela 4.1 do Capítulo 4. No eixo y, é mostrado a quantidade de vezes que o problema foi encontrado.

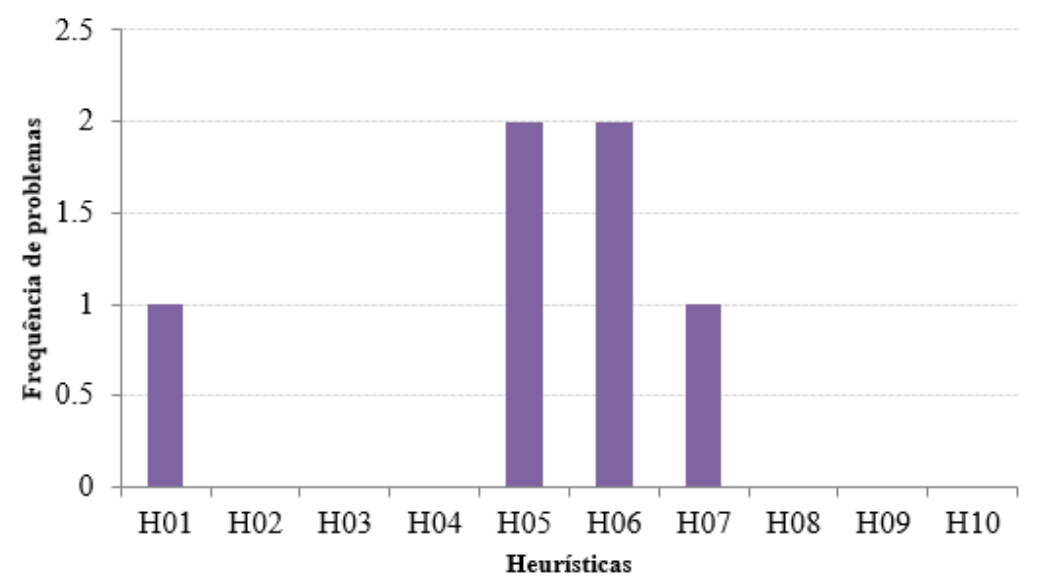

Figura 5.35: Frequência de problemas encontrados por heurística (vide Tabela 4.1).

Os avaliadores encontraram quatro problemas relacionados as heurísticas (HO1), (H05), (HO6) e (H07) no protótipo proposto. Estes problemas serão descritos a seguir.

Foi encontrado problemas relacionados a falta de mensagem de quais objetos estão sendo construído ao realizar os gestos (HO1), a falta de mensagens mostrando os passos para construir o objeto durante a sua construção (H05), dificuldade em relembrar dos gestos para fazer e refazer (H06), e falta de atalhos para as funções do menu lateral (H07). A Figura 5.36 apresenta uma comparação entre os softwares avaliados do Capítulo 4 com o protótipo GeoTouch. É possível observar que o protótipo apresenta uma menor ocorrência de problemas se comparado com os softwares

\footnotetext{
${ }^{1}$ As dez heurísticas propostas por Nielsen são: (HO1) Visibilidade do status do sistema; (H02) Correspondência entre o sistema e o mundo real; (HO3) Controle do usuário e liberdade; (H04) Consistência e padrões; (H05) Prevenção de erros; (H06) Reconhecimento em vez de lembrança; (H07) Flexibilidade e eficiência de uso; (H08) Estética e design minimalista; (H09) Ajuda para usuário identificar, diagnosticar e corrigir erros; (H10) Ajuda e documentação
} 
GeoGebra, Geometry Pad e Sketchometry. Além disso, o protótipo não apresentou erros relacionados a correspondência entre o sistema e o mundo real (H02), controle do usuário e liberdade (H03), consistência e padrões (HO4), estética e design minimalista (H08), ajuda para identificar e corrigir erros (H09) e, ajuda e documentação (H10).

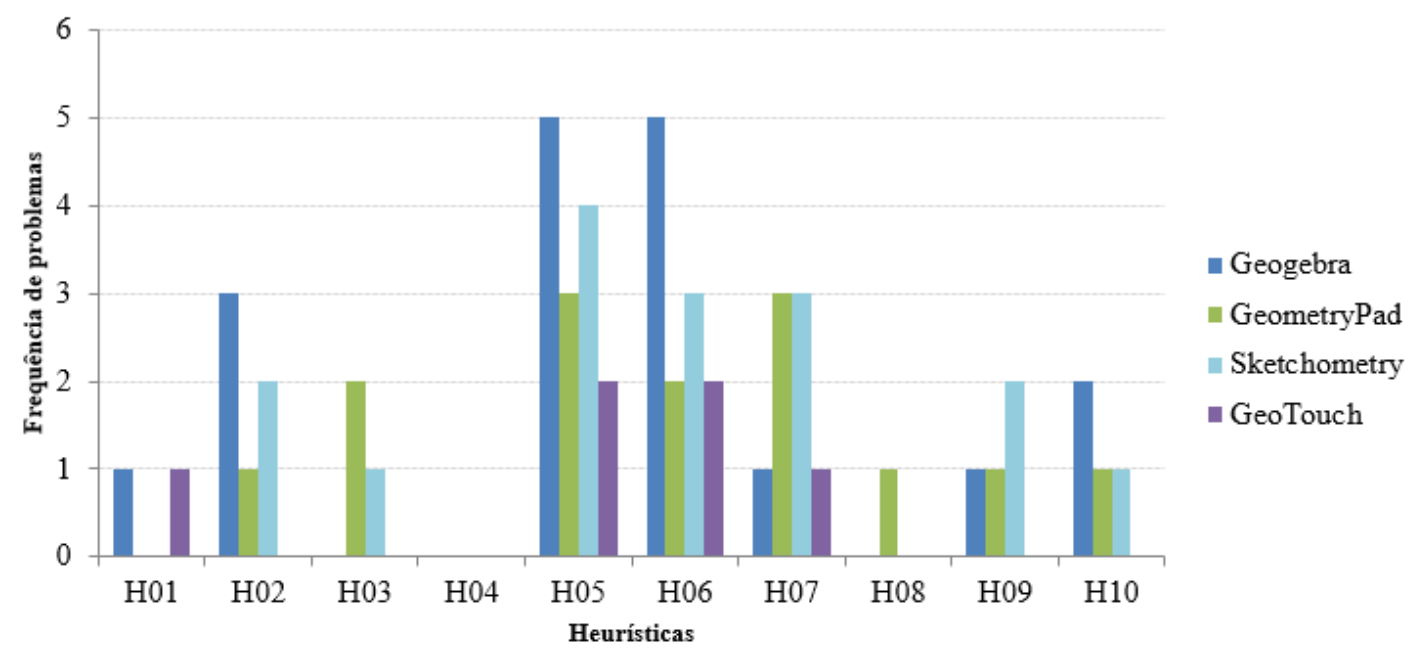

Figura 5.36: Frequência de problemas encontrados por heurística e por software avaliado.

\subsubsection{Análise dos Dados}

Foram encontrados três problemas (Tabela 5.7) no software GeoTouch e classificados de acordo com as heurísticas propostas por Nielsen (1993). O principal problema identificado foi a falta de mensagem mostrando quais são os objetos que estão criados no momento da sua construção. Por exemplo, o gesto para construir uma reta pode ser similar ao gesto para a construção dos gestos semi-reta e segmento de reta. Para os avaliadores, é interessante que haja uma mensagem na tela identificando qual objeto será construído com o gesto que está sendo executado no momento. Outro problema encontrado no protótipo foi a dificuldade de lembrar os gestos desfazer e refazer, fazendo com que o avaliador precisasse consultar várias vezes a documentação. Por fim, o último problema identificado pelos os avaliadores foi a carência de atalhos para algumas funções do menu lateral, como novo, salvar, salvar como, grid e eixo cartesiano.

A Figura 5.37 apresenta o grau de severidade em relação aos problemas encontrados e suas heurísticas. É possível observar que foram somente encontrados problemas relacionados a visibilidade do status do sistema (H01), prevenção de erros (H05), reconhecimento em vez de lembrança (HO6) e flexibilidade e eficiência de uso (HO7). Todos os problemas classificados nestas heurísticas tiveram grau de severidade clas- 
Tabela 5.7: Lista de problemas encontrados no software GeoTouch e a classificação de suas heurísticas.

\begin{tabular}{||l|c||}
\hline \hline Problema & Heurísticas \\
\hline \hline $\begin{array}{l}\text { Não possui mensagem sobre quais gestos estão sendo } \\
\text { construídos no sistema }\end{array}$ & $1,5,6$ \\
\hline Os gestos de desfazer e refazer não estão intuitivos & 5,6 \\
\hline O sistema não possui atalhos para as funçóes do menu & 7 \\
\hline
\end{tabular}

sificados entre $25 \%$ a $50 \%$ pelos os avaliadores.

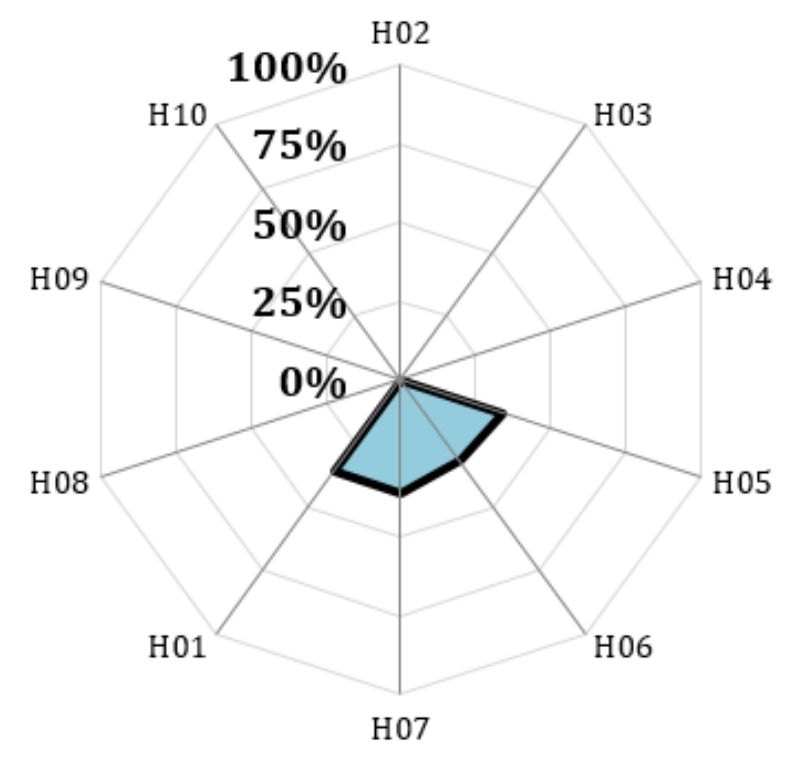

Figura 5.37: Grau de severidade entre as heurísticas no software GeoTouch.

\subsubsection{Questionários}

O mesmo questionário ${ }^{2}$ aplicado durante a avaliação dos três softwares avaliados no Capítulo 4 na Seção 4.2, foi aplicado no protótipo GeoTouch. A Figura 5.38 apresenta o a pontuação final de cada questão respondida pelos os avaliadores. Observa-se que a questão $\mathrm{B} 7$, correspondente a facilidade de aprendizagem da interface, possui menos pontuação que os demais. Isto ocorre devido a necessidade do estudante consultar o manual e ajuda para realizar os primeiros gestos. Todas as demais questões

\footnotetext{
${ }^{2}$ As perguntas do questionário foram: (Q1) O tamanho da tela é adequado para realizar as atividades?; (Q2) A interação por meio dos dedos foi fácil/intuitivo?; (Q3) Os gestos para construir os objetos geométricos são intuitivos/naturais?; (Q4) Os conhecimentos matemáticos previamente conhecidos afetou no modo de construir os objetos geométricos?; (Q5) As telas lhe parecem visualmente agradáveis?; (Q6) A interface está adequada para um dispositivo móvel (ou é semelhante a interface de um software de desktop)?; (Q7) A interface é fácil de aprender?; (Q8) A execução das atividades é mais rápida?.
} 
ficaram com média acima de 4 pontos, que significa uma pontuação dentro da classificação "Bom". Além disso, as questões relacionadas com a influência do conhecimento matemático prévio na execução dos gestos (Q4), visual da interface (Q5) e desenvolvimento da interface adequada para um dispositivo móvel (Q6) quase alcançaram a nota máxima do questionário (5).

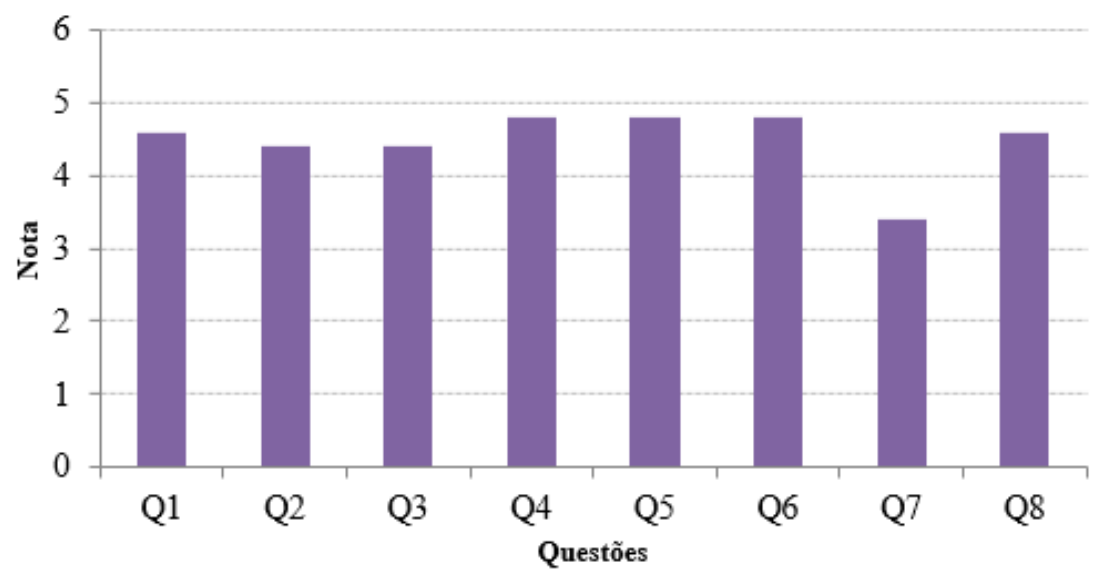

Figura 5.38: Pontuação final para cada questão do questionário no software GeoTouch.

A Figura 5.39 apresenta a comparação dos resultados do questionário do software GeoTouch com os softwares GeoGebra, Geometry Pad e Sketchometry. É possivel observar que o software GeoTouch apresentou resultados superiores aos outros softwares, exceto a $\mathrm{Q} 7$, representando maior satisfação dos avaliadores em relação ao uso do software.

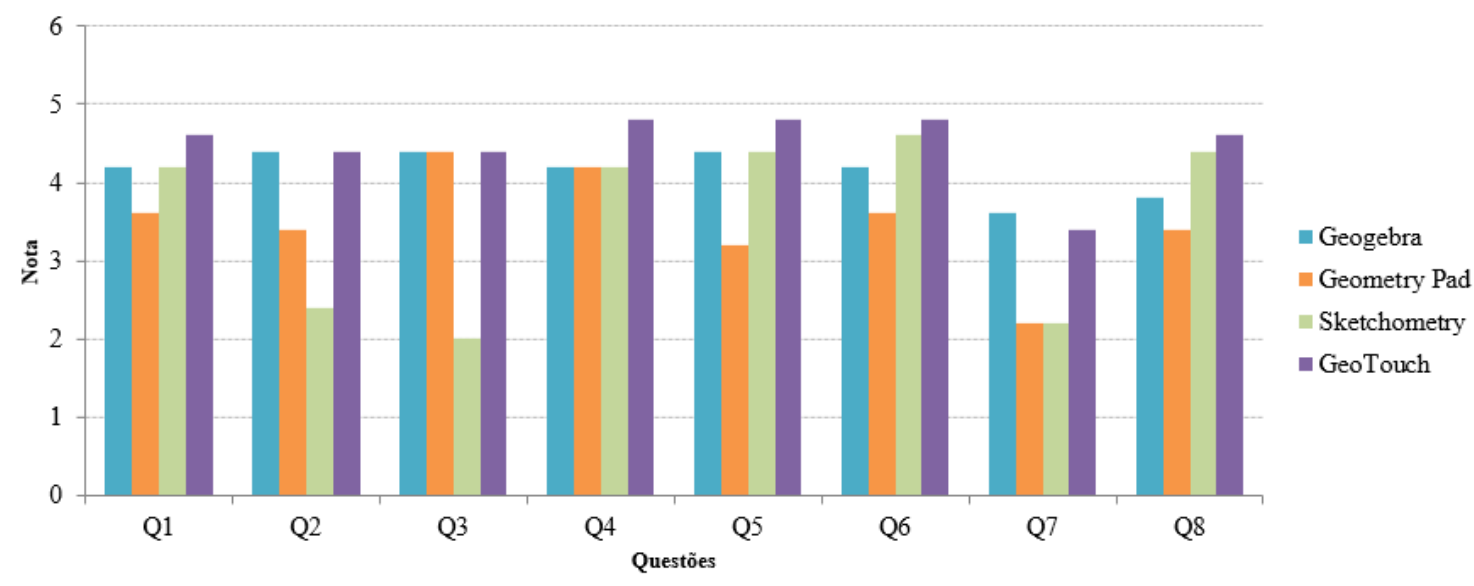

Figura 5.39: Comparação da pontuação final para cada questão do questionário entre os softwares avaliados neste trabalho. 


\subsubsection{Discussão}

Ao analisar os resultados da avaliação de heurísticas do protótipo GeoTouch, foi possível observar que o software proposto, GeoTouch, apresentou menos problemas que os softwares GeoGebra, Geometry Pad e Sketchometry, sendo reportado somente três problemas pelos avaliadores. Além disso, os três problemas possuíram severidade leve, o que indica que não afetam gravemente o uso do software pelos usuários. $O$ problema relacionado a visibilidade e status do sistema é representado pela falta de mensagens que mostram quais objetos são resultados dos gestos que o estudante está realizando naquele momento. Os outros problemas relacionados a prevenção de erros e reconhecimento em vez de lembrança estão relacionados a dificuldade de lembrar os gestos de desfazer e refazer. Por fim, o último problema encontrado é a falta atalhos das funções do menu lateral, que são: novo, abrir, salvar, salvar como, grid e eixo cartesiano.

$\mathrm{Na}$ avaliação dos questionários, o protótipo mostrou menos pontuação em relação à facilidade de aprendizado da interface. Os avaliadores consideraram o tempo gasto de leitura para o aprendizado de todos os gestos um fator de dificuldade. Para solucionar este problema, um avaliador sugeriu o uso de gifs animados ou vídeos, demonstrando os gestos que o GeoTouch possui, tornando a leitura do manual uma atividade dinâmica e mais rápida. Também foi observado que estes gestos eram construídos pelos avaliadores de acordo com os conhecimentos de geometria previamente adquiridos. As questões relacionadas a satisfação visual e desenvolvimento adequado ao dispositivo móvel também mostraram pontuações elevadas, quase atingindo a pontuação máxima.

Algumas das diretrizes propostas no Capítulo 4 deste trabalho, como, (i) guia de ajuda visual; (ii) dicas de utilização; (iii) ícones padrões; (iv) gestos intuitivos e relacionados com a geometria e; (iv) manual de ajuda de fácil acesso foram desenvolvidas neste protótipo. É possível observar que os resultados da avaliação heurística não mostraram problemas relacionados as heurísticas correspondentes a estas diretrizes, que seriam: correspondência entre o sistema e o mundo real, controle do usuário e liberdade, consistência e padrões, estética e design minimalista, ajuda para diagnosticar e corrigir erros e, ajuda e documentação. Os resultados sugerem que o desenvolvimento destas diretrizes sugeridas no Capítulo 4 nos softwares de GI para Interfaces Gestuais pode trazer benefícios de usabilidade.

\subsubsection{Ameaças à validade}

As ameaças à validade deste experimento são as mesmas listadas na Seção 4.4 do Capítulo 4 deste trabalho. 


\subsection{Considerações finais}

No decorrer deste capítulo foi apresentado as preocupações pedagógicas ao desenvolver um software de GI em Interfaces Gestuais. Além disso, foi apresentado um protótipo chamado GeoTouch para o ensino da geometria por meio de gestos, sendo detalhado o seu dicionário de gestos. O protótipo possui funcionalidades básicas para a construções de objetos geométricos para o ensino da geometria (e.g. pontos, retas, circunferências e paralelas), manipulação destes objetos (e.g. movimentação de um objeto) e edição (e.g. aumentar o tamanho de uma reta ou circunferência). Além de disponibilizar funcionalidades padrões, como, novo, abrir, salvar, salvar como, grid e eixo cartesiano. Após o seu desenvolvimento, o protótipo foi realizado a avaliação heurísticas por cinco avaliadores.

De acordo com os resultados obtidos na avaliação heurística do protótipo, foram encontrados somente três problemas, sendo eles classificados em um baixo grau de severidade, não afetando diretamente as atividades dos usuários no momento da utilização do software. Estes três problemas estão relacionados as heurísticas como visibilidade do status do sistema, prevenção de erros, reconhecimento em vez de lembrança e flexibilidade de e eficiência de uso. O problema associado a visibilidade do status do sistema, juntamente com prevenção de erros e reconhecimento em vez de lembrança está relacionado com a falta de mensagens mostrando quais objetos vão ser resultantes daquele determinado gesto. As mesmas heurísticas de prevenção de erros e conhecimento em vez de lembrança também foram classificadas para o problema de facilidade de aprendizagem dos gestos de desfazer e refazer. Os avaliadores precisaram consultar o material para poder lembrar destes gestos. Por fim, o problema associado a flexibilidade e eficiência de uso está relacionado a falta de atalhos para as funções do menu lateral, como novo, salvar, salvar como, grid e eixo cartesiano.

Além da avaliação heurística, os avaliadores também responderam um questionário a fim de investigar qual o desempenho do software proposto em dispositivos móveis, com relação aos aspectos da interface e as suas interações. Os resultados mostram que os avaliadores consideraram que a interface do software não é fácil de aprender. Isto ocorre porque os usuários precisam de maior tempo para ler o manual para aprender os gestos do software. Além disso, na primeira vez que o software é executado, o manual pode ser consultado várias vezes. Este tipo de dificuldade pode ser agravado caso o usuário não possua conhecimento prévio de geometria, já que os avaliadores consideraram que os conhecimentos prévio de geometria afetaram o modo com que eles executavam os gestos. Entretanto, é importante ressaltar que esta dificuldade era esperada, pois os gestos foram criados para fazer com que o usuário (i.e. aluno) possa utilizar seus conhecimentos de geometria para realizar as construções 
geométricas e, assim, auxiliá-lo na fixação dos conceitos de geometria envolvidos. Podemos considerar assim, que este objetivo tem grande potencial de ser alcançado com a proposta de gestos e interface definidos neste trabalho.

Com este capítulo é possível observar que um software de GI com interação por meio de gestos pode trazer benefícios nos aspectos de usabilidade, caso algumas diretrizes sejam seguidas, como um vasto material de ajuda, contendo descrições textuais e visuais. Além de materiais de ajuda ou manuais, para que haja maior usabilidade, deve-se considerar o desenvolvimento dos gestos utilizando os conceitos geométricos, facilitando assim o aprendizado da interface. 
98CAPÍTULO 5. DESENVOLVIMENTO DE UM SOFTWARE DE GI COM INTERFACE GESTUAL 


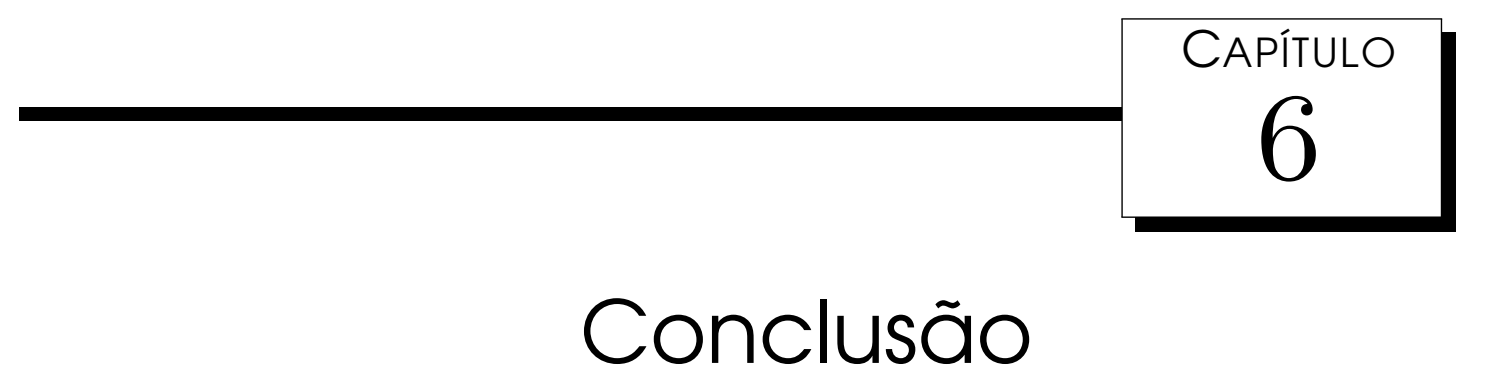

\subsection{Considerações Finais}

Este trabalho propôs um conjunto de gestos como meio de interação para construção de objetos geométricos que podem auxiliar na aprendizagem da geometria. Também foi desenvolvido e análisado um protótipo de software de GI utilizando os gestos propostos. Estes gestos foram desenvolvidos de acordo com os conceitos geométricos de cada objeto. Primeiramente, foi identificada a necessidade de investigar a interação por meio de toque nos softwares de GI, que é principalmente disponibilizada em dispositivos móveis com telas sensiveis ao toque, como tablets e smartphones. Posteriormente, três softwares de GI que permitem interação por meio de gestos foram avaliados heuristicamente por cinco especialistas em engenharia de software e usabilidade, resultando em uma lista de problemas e o seu grau de severidade. Com esta lista, foi possível o desenvolvimento do protótipo GeoTouch, com a elaboração dos gestos de acordo com as propriedades dos objetos geométricos. Durante a avaliação heurística pelos os especialistas, do protótipo GeouTouch e dos três softwares, foi observado que quando as construções dos gestos estão relacionadas as propriedades dos objetos geométricos construídos, a usabilidade do software aumenta, facilitando o aprendizado da interface.

Com este trabalho, espera-se que alunos e professores tenham ao seu dispor mais uma ferramenta que pode auxiliar na aprendizagem e ensino da geometria utilizando dispositivos móveis. Por ter sido desenvolvido para dispositivos móveis, o GeoTouch pode ser utilizado a qualquer momento e local, não limitando o seu uso somente em salas de aula ou em laboratórios. Além disso, espera-se que desenvolvedores 
de softwares de GI possam se beneficiar com algumas diretrizes aqui expostas neste trabalho, como alguns elementos de interface (e.g. manual ou painel de mensagens de passo-a-passo das construções) e os gestos para a construção e manipulação dos objetos geométricos.

\subsection{Contribuições}

A principal contribuição deste trabalho foi a elaboração dos gestos para a construção, edição e manipulação dos objetos geométricos em interfaces gestuais para dispositivos móveis. Estes gestos foram desenvolvidos de acordo com os conceitos geométricos de cada objeto, e implementados em um protótipo de software de GI na plataforma Android 4.1, tendo como principal foco o seu uso em tablets, porém podendo ser utilizado em dispositivos com telas menores, como smartphones. Este protótipo, denominado GeoTouch, já está disponível gratuitamente na loja virtual de aplicativos da Google (i.e. Google Play) ${ }^{1}$

Antes de realizar o desenvolvimento do protótipo, foi investigado por meio de um experimento, como a quantidade de ícones apresentados em tela poderia impactar no aprendizado dos alunos (Reis, Borges, et al., 2012). Nesta investigação, foi realizado um experimento com 69 estudantes de graduação em Engenharia da Computação da Universidade de São Paulo, sendo estes estudantes separados em dois grupos que deveriam avaliar dois tipos de interfaces: reduzida e completa. Resultados indicaram que os estudantes que trabalharam com a interface reduzida foram superficialmente mais produtivos se comparados com estudantes que trabalharam com a interface completa. Este mesmo experimento foi realizado com mais sete estudantes da pósgraduação em Ciência da Computação da Universidade de São Paulo, porém com o objetivo de investigar como a quantidade de ícones apresentados em tela poderia afetar no uso da carga cognitiva dos estudantes (Borges, Reis, et al., 2013). Os resultados sugeriram que a interface reduzida consome menos carga cognitiva persistente e melhora na produtividade de usuários experimentes, ou seja, a redução no número de ícones apresentados em tela poderia apresentar uma melhoria de usabilidade. Ao observar os benefícios da diminuição dos ícones na interface, um mapeamento sistemático foi realizado a fim de verificar se as interfaces dos softwares de GI existentes apresentam poucos ícones em tela, além de investigar quais os tipos de interação existentes nos softwares de GI, e quais dispositivos que são comumente executados (Reis, Borges, et al.; 2013). Este mapeamento mostrou que a maioria dos softwares de GI utilizam a interação por meio do clique do mouse e que são executados em computadores de mesa. Por meio deste mapeamento, foi possível observar a carência de estudos em relação a interação por meio de toque nos softwares de GI.

\footnotetext{
${ }^{1}$ https://play.google.com/store/apps/details?id=com.usp.icmc.tgeo
} 
Neste trabalho também foram sugeridos alguns critérios que os desenvolvedores do softwares de GI em Interfaces Gestuais deveriam seguir, como a disponibilização de um vasto manual de ajuda e mensagens do que está acontecendo na interface, sendo extraídos de avaliações heurísticas de três softwares de GI com interação por meio de gestos disponiveis. Além de seguir estes critérios, o protótipo GeoTouth teve os seus gestos desenvolvidos de acordo com as preocupações pedagógicas, em que o gesto está fortemente relacionado com as propriedades dos objetos geométricos.

Foram geradas três publicações relacionadas com esta pesquisa:

REIS, H. M.; BORGES, S. S.; DURELLI, V. H. S.; MORO, L. F. S.; BRANDAO, A. A. F.; BARBOSA, E. F.; BRANDAO, L. O.; MAILLARD, P. A. J.; BITTENCOURT, I. I.; ISOTANI, S. Towards Reducing Cognitive Load and Enhancing Usability Through a Reduced Graphical User Interface for a Dynamic Geometry System: An Experimental Study. In: Multimedia Technologies for E-Learning (MTEL), 2012, Irvine,CA. IEEE International Symposium on Multimedia (ISM), 2012, Irvine, CA, 2012.

REIS, H. M.; BORGES, S. S.; ISOTANI, S. Interação em Interfaces de Softwares de Geometria Interativa: Um Mapeamento Sistemático. In: Simpósio Brasileiro de Informática na Educação (SBIE), 2013, Campinas. In: Simpósio Brasileiro de Informática na Educação (SBIE), 2013, Campinas. Anais do 24ํㅗㄹ, 2013. p. $1-10$.

BORGES, S. S.; REIS, H. M.; MORO, L. F. S.; DURELLI, V. H. S.; ISOTANI, S. Agrupamento Balanceado de Sujeitos a fim de Testar a Interface Gráfica de um Software de Geometria Interativa. RENOTE. Revista Novas Tecnologias na Educação, v. 11, p. 1-10, 2013.

ISOTANI, S. ; PEDRO, L. Z. ; REIS, H. M. ; BORGES, S. S. ; LOPES, A. M. Z. ; SOUZA, J. P. T. ; BRANDÃO, A. A. F. ; BRANDÃO, L. O. . Interactive Geometry Goes Mobile with GeoTouch. In: IEEE International Conference on Advanced Learning Technologies, 2014, Athens. Proceedings of the IEEE International Conference on Advanced Learning Technologies, 2014 (in press).

E houve a contribuição em duas publicações relacionadas com o grupo de pesquisa:

BORGES, S. S.; REIS, H. M.; DURELli, V. H. S.; MAILlARD, P. A. J.; BITTENCOURT, I. I.; ISOTANI, S.Gamificação Aplicada à Educação: Um Mapeamento Sistemático. In: Simpósio Brasileiro de Informática na Educação (SBIE), 2013, Campinas. Anais do 24ํㅗㄴ, 2013. p. 1-10. 
BORGES, S. S.; DURELLI, V. H. S. ; REIS, H. M.; ISOTANI, S. Systematic Mapping on Gamification Applied to Education. In: ACM Symposium On Applied Computing (ACM SAC), 2013, Gyeongju (South Korea). Proceedings of the Intelligent and Interactive Learning Environments (IILE) at the 29th ACM Symposium On Applied Computing (ACM SAC), 2014. v. XXIX.

\subsection{Limitações do trabalho efetuado}

Embora a realização da avaliação heurística por cinco especialistas na área de engenharia de software e conhecimentos em usabilidade tenha permitido que o protótipo proposto fosse avaliado no aspecto de usabilidade, observa-se a necessidade que o protótipo seja avaliado no aspecto pedagógico. Esta avaliação deveria ocorrer em ambiente real de ensino, com atividades em que os estudantes executam diariamente em sala de aula. Com os resultados desta avaliação seria possivel identificar as vantagens e desvantagens que um software de GI em Interfaces Gestuais pode afetar no ensino da geometria.

Outra limitação encontrada é a impossibilidade de reutilizar o código desenvolvido para ser executado em outros sistemas operacionais dos dispositivos móveis, como, por exemplo, em dispositivos que utilizam iOS, da Apple. Entretanto, o código desenvolvido pode auxiliar no processo de portabilidade, dando conhecimento aos desenvolvedores sobre o sistemas e os seus requisitos. E por fim, algumas funcionalidades ainda não estão disponíveis no protótipo, como a possibilidade de utilização de equações algébricas.

\subsection{Sugestões para trabalhos futuros}

O resultado deste trabalho viabilizar a realização de diversos trabalhos futuros para estender e aplicar a tecnologia na aprendizagem de geometria. Entre alguns trabalhos que, podem ser vilumbrados no futuro estão:

Realização de experimentos controlados em ambientes reais de aprendizagem com alunos e professores.

Estender e disponibilizar o dicionário de gestos para construção de objetos geométricos de forma a padronizar a maneira de interagir com softwares de GI em telas multitoque.

Extensão das funcionalidades do protótipo como a criação de ponto sobre objetos, cálculo de ângulos, inclusão de rótulos, e avalição automática de exercícios. 
A viabilização de atividades colaborativas onde os alunos e professores possam compartilhar suas construções e trabalhar de maneira síncrona.

E finalmente, tornar o código do protótipo aberto para que a comunidade possa contribuir como novos módulos e funcionalidades para o sistema. 


\section{Referências Bibliográficas}

Usability testing of an academic library web site: a case study. The Journal of Academic Librarianship, vol. 27, n. 3, páginas 188 - 198, 2001.

Ardito, C.;Costabile, M. F. M. M. D. L. R. L. S. R. T. E. R. V. An approach to usability evaluation of e-learning applications. Universal Access in the Information Society, vol. 4, n. 3, páginas 270 - 283, 2006.

AtiYAh, M. What is geometry? In: PRITCHARD, C., ed. The Changing Shape of Geometry: Celebrating a Century of Geometry and Geometry Teaching, Capítulo: I, Cambridge University Press, páginas 24-30, 2003.

Bailey, J.; Budgen, D.; Turner, M.; Kitchenham, B.; Brereton, P.; Linkman, S. Evidence relating to object-oriented software design: A survey. In: Empirical Software Engineering and Measurement, 2007. ESEM 2007. First International Symposium on, páginas 482-484, 2007.

Baker, K.; Greenberg, S.; Gutwin, C. Heuristic Evaluation of Groupware Based on the Mechanics of Collaboration. In: EHCI 'O1 Proceedings of the 8th IFIP International Conference on Engineering for Human-Computer Interaction, páginas 123-140, 2001.

BANU, S. M. Augmented Reality system based on sketches for geometry education. 2012 International Conference on E-Learning and E-Technologies in Education (ICEEE), páginas 166-170, 2012.

Blagojevic, R.; Chen, X.; TAn, R. Using tangible drawing tools on a capacitive multi-touch display. Proceedings of the 26th, 2012.

Blanke, D.; Schneider, G. TOM: A Multi-touch System for Learning Math. hochschule-trier.net, 2011. 
Bonnard, Q.; Jermann, P.; Legge, A.; Kaplan, F.; Dillenbourg, P. Tangible paper interfaces: Interpreting pupils' manipulations. In: Proceedings of the 2012 ACM International Conference on Interactive Tabletops and Surfaces, ITS '12, New York, NY, USA: ACM, páginas 133-142, 2012 (ITS '12, ).

Botana, F.; VAlCARCE, J. L. A dynamic-symbolic interface for geometric theorem discovery. Computers and Education, vol. 38, n. 1-3, páginas 21-35, 2002.

Bowman, C. L. Individuals and points. Notre Dame J. Formal Logic, vol. 26, n. 1, páginas 61-75, 1985.

BRUnO, R. Distance learning: answering learners' needs through the human face of technology the example of the interactive e-learning system platform (ines). In: E-Learning in Industrial Electronics, 2006 1ST IEEE International Conference on, páginas 107-112, 2006.

Carvalho, B. Desenho Geométrico. 332 páginas, 1988.

CAstillo, S.; Ayala, G. Armoleo: An architecture for mobile learning objects. In: Electronics, Communications and Computers, 2008. CONIELECOMP 2008, 18th International Conference on, páginas 53-58, 2008.

Coll, C.; Teberosky, A. Aprendendo Matemática-Conteúdos Essensiais para o Ensino Fundamental. Ática edição. 256 páginas, 2002.

Dolce, O.; IezzI, G.; Machado, A. Geometria Plana: Conceitos Básicos - Volume único. 208 páginas, 2009.

Dolce, O.; Pompeu, J. N. Fundamentos de Matemática Elementar - Geometria Plana. 7 edição. 456 páginas, 2005.

DRINGUS, L. P. An iterative usability evaluation procedure for interactive online courses. Journal of Interactive Instruction Development, vol. 7, n. 4, páginas 10-14, 1995.

DybÅ, T.; Dingsø YR, T.; Hanssen, G. K. Applying Systematic Reviews to Diverse Study Types: An Experience Report. In: International Symposium on Empirical Software Engineering and Measurement, páginas 225-234, 2007.

ERbas, A. K.; Yenmez, A. A. The effect of inquiry-based explorations in a dynamic geometry environment on sixth grade students' achievements in polygons. Computers and Education, vol. 57, n. 4, páginas 2462-2475, 2011.

Erez, M. M.; Yerushalmy, M. "If You Can Turn a Rectangle into a Square, You Can Turn a Square into a Rectangle ..." Young Students Experience the Dragging 
Tool. International Journal of Computers for Mathematical Learning, vol. 11, n. 3, páginas 271-299, 2007.

Escribano, J.; Botana, F.; AbÁnades, M. A. Adding remote computational capabilities to dynamic geometry systems. Mathematics and Computers in Simulation, vol. 80, n. 6, páginas $1177-1184,2010$.

FAbre, A.; Sternberger, L. Constrained Gesture Interaction in 3D Geometric Constructions, páginas 324-334. 2006.

Grice, R. A.; Bennett, A. G.; Fernheimer, J. W.; Geisler, C.; Krull, R.; Lutzky, R. A.; RolPh, M. G.; SEARCH, P.; ZAPPEN, J. P. Heuristics for broader assessment of effectiveness and usability in technology-mediated technical communication. Technical Communication, vol. 60, n. 1, 2013.

Grothman, R. C.a.r. - compass and rules. [On-line], http://car. rene-grothmann.de/doc_en/overview.html.

GRUdin, J. Why CSCW Applications Fail: Problems in the Design and Evaluation of Organizational Interfaces. In: CSCW' 88 Proceedings of the 1988 ACM conference on Computer-supported cooperative work, páginas 85-93, 1988.

HANNE, K.-H. Multimodal Communication, Natural Language and Direct Manipulation (Gestures) in Human-Computer Interation. In: Edwards, A. D. N.; Holland, S., eds. Multimedia Interface Design in Education, Capítulo: 11, NATO ASI Series, página 223, 1994.

Hara, N.; Kling, R. Students' Distress with a Web-based Distance Education Course: An Ethnographic Study of Participants' Experiences. Information, Communication and Society, vol. 3, n. 4, páginas 557-579, 2000.

Hohenwarter, M. Geogebra. [On-line], http://www.geogebra.org/cms/pt_BR/ component/contact/11-developers/1-markus.

Hollebrands, K. The role of a dynamic software program for geometry in the strategies high school mathematics students employ. Journal for Research in Mathematics Education, vol. 38, n. 2, páginas 164-192, 2007.

Holzinger, A.; Nischelwitzer, A. Meisenberger, M. Mobile Phones as a Challenge for m-Learning: Examples for Mobile Interactive Learning Objects. In: Third IEEE International Conference on Pervasive Computing and Communications Workshops, páginas $307-311,2005$.

Iemenes, L. M. P.; Jakubovic, J.; Lellis, M. C. Para que serve a Matemática? Geometria (2o Grau). 48 páginas, 1997. 
Iezzi, G.; Dolce, O.; Degenszajn, D. M.; Perigo, R. Matemática: volume único. 651 páginas, 1997.

ISO, ed. ISO 9241-11: Ergonomic requirements for office work with visual display terminals (VDTs) - Part 9: Requirements for non-keyboard input devices. 2000.

Isotani, S. Desenvolvimento de ferramentas no iGeom : utilizando a geometria dinâmica no ensino presencial e a distância. Tese de doutorado, Universidade de São Paulo, 2005.

Isotani, S.; BRAndÃo, L. Como Usar a Geometria Dinâmica? O Papel do Professor e do Aluno Frente às Novas Tecnologias. In: Anais do Workshop de Informática na Escola, páginas 120-128, 2006.

Isotani, S.; BRANDÃo, L. Ferramenta de avaliação automática no iGeom. In: Anais do Simpósio Brasileiro de Informática na Educação (SBIE), páginas 328-337, 2004.

JACKIW, N. Sketchpad. [On-line], http://www.dynamicgeometry.com/General_ Resources/Recent_Talks.html.

JANIČIĆ, P.; QUARESMA, P. Automatic verification of regular constructions in dynamic geometry systems. In: Automated Deduction in Geometry, páginas 39-51, 2007.

Jeffries, R.; Desurvire, H. Usability Testing vs. Heuristic Evaluation: Was there a contest? ACM SIGCHI Bulletin, vol. 24, n. 4, páginas 39-41, 1992.

Jeffries, R.; Miller, J. R.; Wharton, C.; UyedA, K. User interface evaluation in the real world: a comparison of four techniques. In: CHI '91 Proceedings of the SIGCHI Conference on Human Factors in Computing Systems, páginas 119-124, 1991.

Kalloo, V.; Mohan, P. A Mobile Learning Study in High School Mathematics: Challenges, Lessons Learned and Recommendations. In: 2011 IEEE 11th International Conference on Advanced Learning Technologies, páginas 45-47, 2011.

Kitchenham, B.; Charters, S. Guidelines for performing Systematic Literature Reviews in Software Engineering. Relatório técnico EBSE 2007-001, Keele University and Durham University Joint Report, 2007.

KortenkAmp, U. Cinderella. [On-line], http://www.cinderella.de/tiki-index. php.

Kortenkamp, U.; Dohrmann, C. User interface design for dynamic geometry software. Acta Didactica Napocensia, vol. 3, n. 2, páginas 59-66, 2010. 
Kortenkamp, U.; MATERliK, D. Geometry teaching in wireless classroom environments using Java and J2ME. Science of Computer Programming, vol. 53, n. 1, páginas 71-85, 2004.

KovÁRovÁ, A.; SOKOLSKY, M. Using virtual reality for teaching solid geometry: A case study for a cube section. Interactive Collaborative Learning, , n. September, páginas 428-433, 2011.

Kurtenbach, G.; Hulteen, E. Gestures in Human-Computer Communication. In: The Art and Science of Interface Design., páginas 309-317, 1990.

LABORDE, C. The role and uses of technologies in mathematics classrooms: Between challenge and modus vivendi. Canadian Journal of Science, Mathematics and Technology Education, vol. 7, n. 1, páginas 68-92, 2007.

LaI, A.-F.; Lai, H.-Y.; Shen, V. R. L.; Tsai, I. C.; Chou, A. The Evaluation of TwoStage Mobile Learning Guidance of Math in an Elementary School. In: Seventh International Conference on Wireless, Mobile and Ubiquitous Technology in Education, páginas 282-286, 2012.

LAVY, I.; SHRIKI, A. Engaging in problem posing activities in a dynamic geometry setting and the development of prospective teachers' mathematical knowledge. The Journal of Mathematical Behavior, vol. 29, n. 1, páginas 11-24, 2010.

LiANG, W.; YU, S.; LONG, T. A study of the tablet computer's application in K-12 schools in China. In: 2011 International Conference on Advanced Intelligence and Awareness Internet, páginas 164 - 168, 2011.

LiU, Y.; Lin, Q.; DAI, G. Pigp: A pen-based intelligent dynamic lecture system for geometry teaching. In: HuI, K.-C.; PAN, Z.; Chung, R.-K.; Wang, C.; Jin, X.; GöBEL, S.; LI, E.-L., eds. Technologies for E-Learning and Digital Entertainment, vol. 4469 of Lecture Notes in Computer Science, Springer Berlin Heidelberg, páginas 381-390, 2007.

MACKRELl, K. Design decisions in interactive geometry software. $Z d m$, vol. 43, n. 3, páginas 373-387, 2011.

MARIOTTI, M. A. Introduction to proof: the mediation of a dynamic software environment. Educational Studies in Mathematics, vol. 44, n. 1-2, páginas 25-53, 2000 .

MASON, J. Asking mathematical questions mathematically. International Journal of Mathematical Education in Science and Technology, vol. 31, n. 1, páginas 97-111, 2010. 
Mathema, B. C. Multi-Touch All-Point Touchscreens : The Future of User Interface Design. In: Mobile Dev and Design, páginas 1-4, 2009.

Milrad, M. Challenges, Perspectives and Reality. In: NYIRI, K., ed. Mobile Learning: Essays on Philosophy, Psychology and Education, Passagen, páginas 151-164, 2003.

Nacenta, M. A.; Kamber, Y.; QIAng, Y.; Kristensson, P. O. Memorability of predesigned and user-defined gesture sets. In: Proceedings of the SIGCHI Conference on Human Factors in Computing Systems (CHI 2013), New York, New York, USA: ACM Press, páginas 1099-1108, 2013.

Naismith, L.; Lonsdale, P.; Vavoula, G.; Sharples, M. Literature Review in Mobile Technologies and Learning Literature Review in Mobile Technologies and Learning. Relatório técnico, 2004.

Nielsen, J. Finding Usability Problems Through Heuristic Evaluation. In: In Proceedings of CHI '92 (Monterey), páginas 373-380, 1992.

Nielsen, J. Usability Engineering. San Francisco, CA, 1993.

Nielsen, J. Scenarios in discount usability engineering. In: Scenario-based design, páginas $59-83,1995$.

Nielsen, J.; Molich, R. Heuristic evaluation of user interfaces. In: CHI '9O Proceedings of the SIGCHI Conference on Human Factors in Computing Systems, páginas 249-256, 1990.

O’Hara, K.; Harper, R.; Mentis, H.; Sellen, A.; Taylor, A. On the Naturalness of Touchless: Putting the "Interaction" Back into NUI. ACM Transactions on Computer-Human Interaction (TOCHI) - Special issue on the theory and practice of embodied interaction in HCI and interaction design, vol. 20, n. 1, página 25, 2013.

PaAs, F.; Renkl, A.; Sweller, J. Cognitive load theory and instructional design: Recent developments. Educational Psychologist, vol. 38, n. 1, páginas 1-4, 2003.

Pahwa, A.; Gruenbacher, D.; Starrett, S.; Morcos, M. Distance learning for power professionals: virtual classrooms allow students flexibility in location and time. Power and Energy Magazine, vol. 3, n. 1, páginas 53 - 58, 2005.

Parsons, D.; Ryu, H.; Cranshaw, M. A Study of Design Requirements for Mobile Learning Environments. In: International Conference on Advanced Learning Technologies, páginas 96-100, 2006. 
Petersen, K.; Feldt, R.; Mujtaba, S.; Mattsson, M. Systematic mapping studies in software engineering. In: Proceedings of the 12th international conference on Evaluation and Assessment in Software Engineering, páginas 68-77, 2008.

Plass, J. L.; Chun, D. M.; Mayer, R. E.; Leutner, D. Cognitive load in reading a foreign language text with multimedia aids and the influence of verbal and spatial abilities. Computers in Human Behavior, vol. 19, n. 2, páginas 221-243, 2003.

Pretorius, R.; Budgen, D. A Mapping Study on Empirical Evidence Related to the Models and Forms used in the UML. In: In 2nd ACM-IEEE International Symposium on Empirical Software Engineering and Measurement (ESEM), páginas 342344, 2008.

REIS, H. M., B. S. I. S. Interaćão em interfaces de softwares de geometria interativa: Um mapeamento sistemático. In: Simpósio Brasileiro de Informática na Educação (SBIE), páginas 1-10, 2013.

Reis, H. M.; Borges, S. S.; Durelli, V. H. S.; Moro, L. F. S.; et Al. Isotani, S. Towards Reducing Cognitive Load and Enhancing Usability through a Reduced Graphical User Interface for a Dynamic Geometry System: An Experimental Study. In: IEEE International Symposium on Multimedia (ISM), páginas 445-450, 2012.

Roanes-Lozano, E.; Roanes-Macías, E.; Villar-Mena, M. A bridge between dynamic geometry and computer algebra. Mathematical and Computer Modelling, vol. 37, n. 9-10, páginas 1005-1028, 2003.

Rubin, J.; Chisnell, D. Handbook of Usability Testing. 21-25 páginas, 2008.

SAFFER, D. Designing Gestural Interfaces. O’Reilly, 235 páginas, 2009.

Scharf, F.; Gunther, S.; Winkler, T.; Herczeg, M. Spellit: Development of a Multi-Touch Application to Foster Literacy Skills at Elementary Schools. In: Frontiers in Education Conference (FIE), 2010 IEEE, páginas T4D-1 - T4D-6, 2010.

Schimpf, F.; SPANNAGEL, C. Reducing the graphical user interface of a dynamic geometry system. ZDM, vol. 43, n. 3, páginas 389-397, 2011.

Shimomura, Y.; Hvannberg, E. T.; Hafsteinsson, H. Haptic cues as a utility to perceive and recognise geometry. Universal Access in the Information Society, vol. 12, n. 2, páginas 125-142, 2013.

Silva Filho, J. L. F.; Klein JR., V. H.; Lins, O.; Costa, T. Ergonomia cognitiva em ambientes virtuais de aprendizagem: uma análise da interface humano 
- computador (IHC) do Sistema Polvo. In: Anais do Encontro Nacional de Engenharia de Produção, www. abepro.org.br/biblioteca/enegep2008_tn_stp_069_ 490_11885.pdf, páginas 1-13, 2008.

Sivaji, A.; Abdullah, A.; Downe, A. Usability testing methodology: Effectiveness of heuristic evaluation in e-government website development. In: Modelling Symposium (AMS), 2011 Fifth Asia, páginas 68-72, 2011.

SNELler, J. The Tablet PC classroom: Erasing borders, stimulating activity, enhancing communication. In: Frontiers In Education Conference - Global Engineering: Knowledge Without Borders, Opportunities Without Passports, Ieee, páginas S3J-5 S3J-10, 2007.

SonG, X.; ZHU, X. A Sketch Recognition Scheme for Primary Geometry Education. In: Biomedical Engineering and Computer Science (ICBECS), 2010 International Conference on, páginas 1-5, 2010.

Starcic, A. I.; Cotic, M.; ZaJC, M. Design-based research on the use of a tangible user interface for geometry teaching in an inclusive classroom. British Journal of Educational Technology, vol. 44, n. 5, páginas 729-744, 2013.

Sung, E.; MAYER, R. E. Online multimedia learning with mobile devices and desktop computers: An experimental test of clark's methods-not-media hypothesis. Computers in Human Behavior, vol. 29, n. 3, páginas 639-647, 2013.

TANBellini, M. J. G. S.; Brandẽo, L. O uso da Geometria Interativa como Facilitador no Ensino e Aprendizagem de Matemática: estudo com duas turmas de sexta série do ensino fundamental. In: XVI Workshop de Informática na Educação, 2010.

Tootell, H.; Plumb, M.; Hadfield, C.; Dawson, L. Gestural Interface Technology in Early Childhood Education: A Framework for Fully Engaged Communication. In: 2013 46th Hawaii International Conference on System Sciences, Ieee, páginas 13-20, 2013.

Trotta, F.; Imenes, L. M. P.; Jakubovic, J. Matemática Aplicada-Segundo Grau. 172 páginas, 1979.

Vitale, J. M.; Swart, M. I.; Black, J. B. Integrating intuitive and novel grounded concepts in a dynamic geometry learning environment. Computers and Education, vol. 72, n. 0, páginas 231-248, 2014. 


\section{Tabelas dos estudos primários classificados e sem classificação}

Tabela A.1: Estudos primário selecionados, o tipo do estudo e o tipo de contribuição.

\begin{tabular}{|l|l|l|l|}
\hline \multicolumn{1}{|c|}{ Autor } & \multicolumn{1}{|c|}{ Artigo } & Tipo do artigo & Contribuição \\
\hline $\begin{array}{l}\text { Kaufmann } \\
\text { e }\end{array}$ & $\begin{array}{l}\text { Designing Immersive Vir- } \\
\text { tual Reality for Geometry } \\
\text { Education }\end{array}$ & Evaluation Research & tool \\
\hline Narboux & $\begin{array}{l}\text { A Graphical User Interface } \\
\text { for Formal Proofs in Geo- } \\
\text { metry }\end{array}$ & Evaluation Research & tool \\
\hline Iordan et al. & $\begin{array}{l}\text { Visual interactive environ- } \\
\text { ment for doing geometrical } \\
\text { constructions }\end{array}$ & Evaluation Research & tool \\
\hline Liu et al. & $\begin{array}{l}\text { PIGP: a pen-based intelli- } \\
\text { gent dynamic lecture sys- } \\
\text { tem for geometry teaching }\end{array}$ & Evaluation Research & tool \\
\hline Bonnard et al. & $\begin{array}{l}\text { Paper interfaces for lear- } \\
\text { ning geometry }\end{array}$ & Evaluation Research & tool \\
\hline
\end{tabular}


Tabela A.1 - continua na página anterior

\begin{tabular}{|c|c|c|c|}
\hline Autor & Artigo & Tipo do artigo & Contribuição \\
\hline Blagojevic et al. & $\begin{array}{l}\text { Using tangible drawing to- } \\
\text { ols on a capacitive multi- } \\
\text { touch display }\end{array}$ & Evaluation Research & tool \\
\hline Reis et al. & $\begin{array}{l}\text { Towards Reducing Cogni- } \\
\text { tive Load and Enhancing } \\
\text { Usability through a Redu- } \\
\text { ced Graphical User Inter- } \\
\text { face for a Dynamic Geo- } \\
\text { metry System: An Experi- } \\
\text { mental Study }\end{array}$ & Validation Research & method \\
\hline $\begin{array}{l}\text { Chuan Cai, } \\
\text { Xun Lai }\end{array}$ & $\begin{array}{l}\text { A Web-Based Mathemati- } \\
\text { cal User Interface for E- } \\
\text { Science System }\end{array}$ & Solution Proposal & process \\
\hline Fabre et al. & $\begin{array}{l}\text { Constrained gesture inte- } \\
\text { raction in } 3 \mathrm{~d} \text { geometric } \\
\text { constructions }\end{array}$ & Evaluation Research & tool \\
\hline Banu & $\begin{array}{l}\text { Augmented reality system } \\
\text { based on sketches for geo- } \\
\text { metry education }\end{array}$ & Evaluation Research & tool \\
\hline Starcic et al. & $\begin{array}{l}\text { Design-based research on } \\
\text { the use of a tangible user } \\
\text { interface for geometry tea- } \\
\text { ching in an inclusive clas- } \\
\text { sroom }\end{array}$ & Validation Research & method \\
\hline $\begin{array}{l}\text { Schimpf } \quad \text { e } \\
\text { Spannagel }\end{array}$ & $\begin{array}{l}\text { Reducing the graphi- } \\
\text { cal user interface of a } \\
\text { dynamic geometry system }\end{array}$ & Validation Research & tool \\
\hline $\begin{array}{l}\text { Kovárová e So- } \\
\text { kolský }\end{array}$ & $\begin{array}{l}\text { Using virtual reality for te- } \\
\text { aching solid geometry: A } \\
\text { case study for a cube sec- } \\
\text { tion }\end{array}$ & Solution Proposal & tool \\
\hline $\begin{array}{l}\text { Blanke e Sch- } \\
\text { neider }\end{array}$ & $\begin{array}{l}\text { TOM: A multi-touch sys- } \\
\text { tem for learning math }\end{array}$ & Evaluation Research & tool \\
\hline
\end{tabular}


Tabela A.1 - continua na página anterior

\begin{tabular}{|ll|l|l|l|}
\hline \multicolumn{1}{|c|}{ Autor } & \multicolumn{1}{|c|}{ Artigo } & Tipo do artigo \\
Xiao-juan & e & $\begin{array}{l}\text { A sketch recognition } \\
\text { Xcheme for primary geo- } \\
\text { metry education }\end{array}$ & Evaluation Research & tool \\
\hline $\begin{array}{l}\text { Kortenkamp e } \\
\text { Materlik }\end{array}$ & $\begin{array}{l}\text { Geometry teaching in wi- } \\
\text { reless classroom environ- } \\
\text { ments using Java and } \\
\text { J2ME }\end{array}$ & Evaluation Research & tool \\
\hline $\begin{array}{l}\text { Shimomura } \\
\text { al. }\end{array}$ & $\begin{array}{l}\text { Haptic cues as a utility to } \\
\text { perceive and recognise ge- } \\
\text { ometry }\end{array}$ & Solution Proposal & tool \\
\hline Cuixia et al. & $\begin{array}{l}\text { An adaptive sketching } \\
\text { user interface for edu- } \\
\text { cation system in virtual } \\
\text { reality }\end{array}$ & Validation Research & tool \\
\hline
\end{tabular}

Tabela A.2: Estudos primário selecionados, o tipo do estudo e o tipo de contribuição.Estudos primário selecionados sem categoria, o tipo do estudo e o tipo de contribuição.

\begin{tabular}{|c|c|c|c|}
\hline Autor & Artigo & Tipo do artigo & Contribuição \\
\hline $\begin{array}{l}\text { Erez e Ye- } \\
\text { rushalmy }\end{array}$ & $\begin{array}{l}\text { If you can turn a rec- } \\
\text { tangle into a square, you } \\
\text { can turn a square into a } \\
\text { rectangle ... Young stu- } \\
\text { dents experience the drag- } \\
\text { ging tool }\end{array}$ & Opinion Paper & model \\
\hline Mackrell & $\begin{array}{l}\text { Design decisions in inte- } \\
\text { ractive geometry software }\end{array}$ & Philosophical Papers & tool \\
\hline
\end{tabular}


116APÊNDICE A. TABELAS DOS ESTUDOS PRIMÁRIOS CLASSIFICADOS E SEM CLASSIFICAÇÃO 


\section{Formulário: Análise de usabilidade em softwares de GI para Tablets}

O objetivo desta análise é o auxiliar no desenvolvimento de um Software de Geometria Interativa para Tablets. Todos os resultados obtidos neste experimento serão utilizados para a melhoria de interfaces de Geometria Interativa em interfaces gestuais e os seus dados permanecerão em sigilo.

Instrução: Por favor leia e realize as instruções abaixo.

Tarefa 1: Preencha o formulário com as informações pessoais.

Tarefa 2: Leia atentamente as Heurísticas de Usabilidade (Anexo A).

Tarefa 3: Realize as tarefas do Anexo B para conhecer o sistema.

Tarefa 4: Resolva os exercícios do Anexo C.

Tarefa 5: Responda o "Formulário de Usabilidade" de acordo com as heurísticas de usabilidade (Anexo D).

Tarefa 6: Responda o "Questionário” (Anexo E).

Tarefa 7: Caso há alguma consideração, preencher o campo de sugestões e submeta as informações.

\section{Obrigada pela participação!.}

\section{Anexo A - Heuristicas de Usabilidade}


1 - Visibilidade do status do sistema: O sistema deve sempre manter os usuários informados sobre o que está acontece, através de feedback apropriado em tempo razoável

2 - Correspondência entre o sistema e o mundo real: O sistema deve falar a linguagem dos usuários, com palavras, frases e conceitos familiares ao usuário, ao invés de termos técnicos e linguagem do sistema. Siga as convenções do mundo real, fazendo com que as informações apareçam em uma ordem natural e lógica.

3 - Controle do usuário e liberdade: É necessário uma saída de emergência claramente marcada para sair do estado indesejado sem ter que passar por um extenso diálogo. As opções "desfazer"e "refazer"são recomendáveis e importantes.

4 - Consistência e padrões: Os usuários não devem ter que pensar se palavras diferentes, ícones, situações ou ações significam a mesma coisa. Fale a mesma língua, e nunca identifique uma mesma ação com ícones ou palavras diferentes. Trate coisas similares da mesma maneira, facilitando a identificação pelo usuário.

5 - Prevenção de erros: Primeiro, um design cuidadoso antecipa a experiência do usuário e prevê um problema evitando que este ocorra, é melhor do que mensagens de erro. É importante eliminar as condições propensas a erros, bem como utilizar opção de confirmação antes de comprometer a ação.

6 - Reconhecimento em vez de lembrança: Evite acionar a memória do usuário o tempo inteiro, fazendo com que cada ação precise ser revista mentalmente antes de ser executada. Permita que a interface ofereça ajuda contextual, e informações capazes de orientar as ações do usuário, ou seja, que o sistema dialogue com o usuário.

7 - Flexibilidade e eficiência de uso: O sistema precisa ser fácil para usuários leigos, mas flexível o bastante para se tornar ágil à usuários avançados. Por exemplo, essa flexibilidade pode ser conseguida com a permissão de teclas de atalhos.

8 - Estética e design minimalista: Evite que os textos e o design fale mais do que o usuário necessita saber. Os "diálogos"do sistema precisam ser simples, diretos e naturais, presentes nos momento em que são necessários.

9 - Ajuda para usuário identificar, diagnosticar e corrigir erros: As mensagens de erro devem ser expressas em linguagem simples (sem códigos), indicar com precisão o problema e sugerir uma solução construtiva. 
10 - Ajuda e documentação: Um bom design deve evitar ao máximo à necessidade de ajuda na utilização do sistema. Ainda sim, um bom conjunto de documentação e ajuda deve ser utilizado para orientar o usuário em caso de dúvida. Deve ser visível, facilmente acessada, e oferecer uma ferramenta de busca na ajuda.

\section{Anexo B - Tarefas}

1. Criar um ponto

2. Mover o ponto

3. Modificar o tamanho do ponto

4. Criar ponto médio forma livre

5. Criar ponto médio por dois pontos

6. Mover ponto médio

7. Criar uma reta por meio de dois pontos

8. Criar uma reta de forma livre

9. Mover reta

10. Mover um dos pontos da reta

11. Criar segmento de reta por meio de dois pontos

12. Criar segmento de reta de forma livre

13. Mover segmento

14. Mover um dos pontos do segmento

15. Criar semi-reta por meio de dois pontos

16. Criar semi-reta de forma livre

17. Modificar o tamanho da semi-reta

18. Mover semi-reta

19. Mover um dos pontos da semi-reta

20. Criar perpendicular

21. Mover perpendicular

22. Criar paralela 
23. Mover paralela

24. Criar uma circunferência de forma livre

25. Criar uma circunferência por meio da distância entre dois pontos

26. Criar medida de ângulo

27. Criar medida de distância entre dois pontos

28. Desfazer ação

29. Refazer ação

30. Inserir Intersecção entre dois objetos

31. Mover Intersecção

32. Inserir ponto sobre um objeto

33. Excluir objeto geométrico

34. Limpar tela inteira

35. Excluir mais de um objeto ao mesmo tempo

36. Modificar nome do documento

37. Salvar documento

38. Abrir documento

\section{Anexo C - Exercícios}

1. Conforme a figura abaixo, crie um ângulo reto. Tutorial: Ângulo reto é o ângulo formado quando uma semi-reta, tocando em um ponto de uma outra reta, cria dois ângulos iguais de 90 graus.

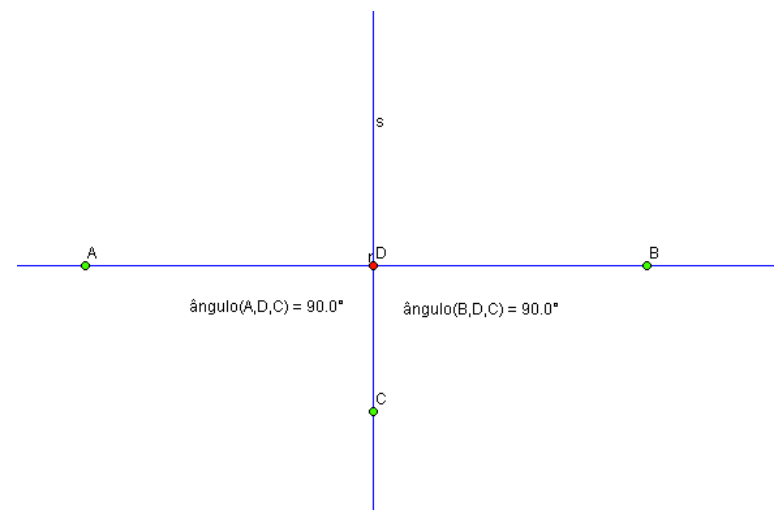


2. Conforme a figura abaixo, crie os pontos A e B e encontre a mediatriz entre os pontos. Tutorial: Mediana é o lugar geométrico dos pontos que equidistam de dois pontos A e B distintos. Com o traçado da mediatriz a determinação do ponto médio do segmento $\mathrm{AB}$ é uma consequência.

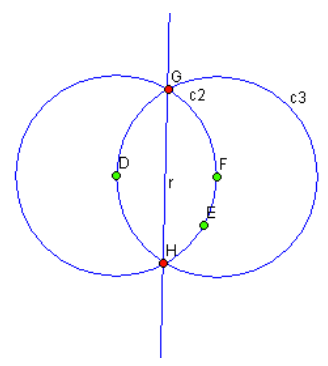

3. Conforme a figura abaixo, crie os pontos A e B, e faça uma circunferência que tenha como centro o ponto $A$ e que passe por $B$. Trace uma reta e calcule o raio da circunferências. Tutorial: $O$ raio de uma circunferência ou círculo é definido com a distância do centro a um ponto qualquer da circunferência. Analogamente se define o raio de uma esfera.

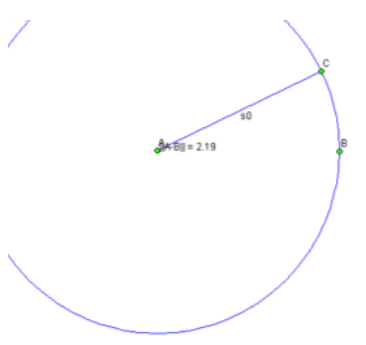

\section{Anexo D - Formulário de Usabilidade - Formulário eletrônico}

Reporte os problemas de usabilidade da Heurística do número 1 ao 10, classificandoos de acordo com o grau de usabilidade da tabela a seguir:

Tabela B.1: Grau de Severidade das heurísticas (Adaptado de Nielsen (1993)).

\begin{tabular}{||c|l||}
\hline \hline Grau de Severidade & \multicolumn{1}{c|}{ Descrição } \\
\hline \hline 0 & Não concordo que seja um problema de usabilidade \\
\hline 1 & $\begin{array}{l}\text { Cosmético: problema superficial, que precisa ser somente } \\
\text { quando houver tempo e dinheiro }\end{array}$ \\
\hline 2 & $\begin{array}{l}\text { Leve: problema de usabilidade pequeno, que possui baixa } \\
\text { prioridade para ser solucionado }\end{array}$ \\
\hline 3 & $\begin{array}{l}\text { Sério: problema de usabilidade severo, que possui priori- } \\
\text { dade e deve ser corrigido assim que possivel }\end{array}$ \\
\hline 4 & $\begin{array}{l}\text { Crítico: possui prioridade máxima e precisa de intervenção } \\
\text { imediata por impedir que os usuários utilizem apropriada- } \\
\text { mente a interface }\end{array}$ \\
\hline
\end{tabular}




\section{Heurística 1 - Visibilidade do status do Sistema}

- O sistema possui feedback rápido indicando o que está fazendo na interface no momento?

- O sistema possui feedback rápido indicando como você pode prosseguir na navegação do sistema?

- Descreva algum problema de usabilidade encontrado para esta heurística, classificando de acordo com o seu grau de usabilidade.

\section{Heurística 2 - Compatibilidade do sistema com o mundo real.}

- O sistema utiliza palavras, termos, expressões e conceitos familiares ao usuário?

- As informações aparecem em uma ordem lógica e natural como se fossem representações do mundo real?

- Descreva algum problema de usabilidade encontrado para esta heurística, classificando de acordo com o seu grau de usabilidade.

\section{Heurística 3 - Controle e liberdade do usuário.}

- O sistema possui alguma saída de emergência?

- O sistema possui funções "Desfazer" e "Refazer" facilmente disponíveis?

- Descreva algum problema de usabilidade encontrado para esta heurística, classificando de acordo com o seu grau de usabilidade.

\section{Heurística 4 - Consistência e padrões.}

- O sistema possui padrões e estilos consistentes?

- O sistema possui palavras, situações ou ações que geram dúvidas de entendimento ou interpretação?

- Descreva algum problema de usabilidade encontrado para esta heurística, classificando de acordo com o seu grau de usabilidade.

\section{Heurística 5 - Prevenção de erros.}

- O sistema possui ícones que ajudam a impedir a ocorrência de erros?

- Descreva algum problema de usabilidade encontrado para esta heurística, classificando de acordo com o seu grau de usabilidade.

\section{Heurística 6 - Reconhecimento ao invés de lembrança.}


- O sistema possui instruções, ações e opções visíveis ou facilmente recuperáveis sempre que apropriado para o uso?

- O Sistema possui ícones que ajudam a impedir a ocorrência de erros?

- Descreva algum problema de usabilidade encontrado para esta heurística, classificando de acordo com o seu grau de usabilidade.

\section{Heuristica 7 - Flexibilidade e eficiência de uso.}

- O sistema possui características de personalização de ações que podem ser feitos pelo próprio usuário?

- O sistema possui teclas para aumentar a eficiência de usuários novatos ou experientes?

- Descreva algum problema de usabilidade encontrado para esta heurística, classificando de acordo com o seu grau de usabilidade.

\section{Heurística 8 - Estética e design minimalista.}

- O sistema possui diálogo com informações irrelevantes ou raramente necessárias?

- O sistema possui links que disponibilizam informações extras raramente necessárias?

- Descreva algum problema de usabilidade encontrado para esta heurística, classificando de acordo com o seu grau de usabilidade.

\section{Heurística 9 - Ajuda para usuário identificar, diagnosticar e corrigir erros.}

- O sistema possui mensagens de erros que indicam precisamente o problema?

- O sistema possui mensagens de erros com linguagem simples?

- O sistema possui mensagens de erros com sugestão de soluções construtivas?

- Descreva algum problema de usabilidade encontrado para esta heurística, classificando de acordo com o seu grau de usabilidade.

\section{Heurística 10 - Ajudas e documentação.}

- O sistema possui opção de ajuda?

- O sistema possui opção de ajuda de fácil acesso ou localização?

- Descreva algum problema de usabilidade encontrado para esta heurística, classificando de acordo com o seu grau de usabilidade. 


\section{Anexo E - Questionário - Questionário eletrônico}

Q01: O tamanho da tela é adequado para realizar as atividades?

Q02: A utilização dos dedos para interagir com o software foi fácil?

Q03: Os gestos para construir os objetos geométricos são intuitivos/naturais?

Q04: Os conhecimentos matemáticos previamente conhecidos afetou no modo de construir os objetos geométricos?

Q05: As telas lhe parecem visualmente agradáveis?

Q06: A interface está adequada para um dispositivo móvel (ou é semelhante a interface de um software de desktop)?

Q07: A interface é fácil de aprender?

Q08: A execução das atividades é mais rápida? 


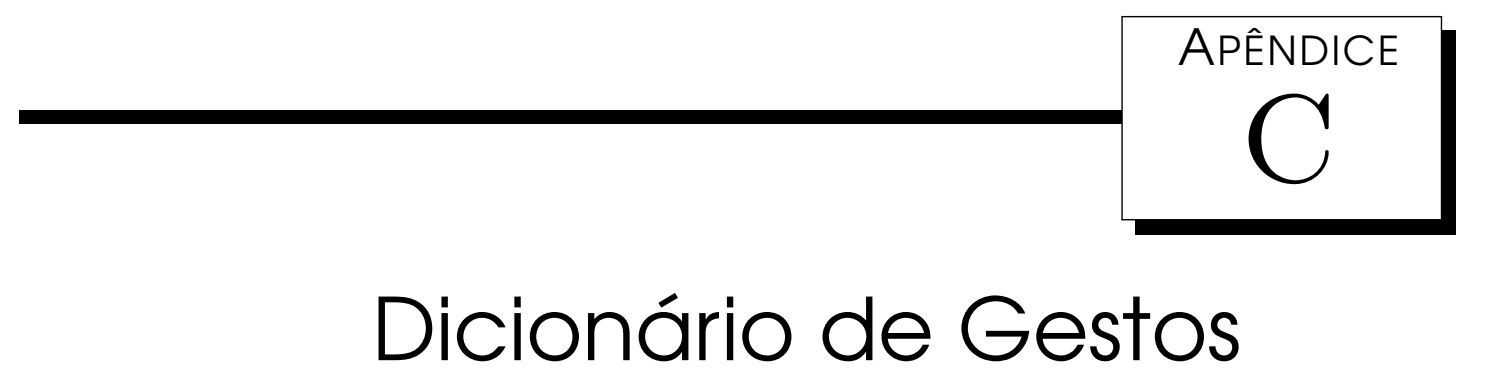

\section{Dicionário de Gestos}

Este dicionário de gestos apresenta todos os gestos que podem ser utilizado no sistema GeoTouch. Estes gestos são divididos nas seguintes categorias:

- Gestos do núcleo: Gestos principais do sistema e que são base para os outros gestos.

- Gestos básicos: Gestos básicos para a construção dos objetos geométricos.

- Gestos de navegação: Gestos para a navegação no sistema. 


\section{Gestos de Núcleo}
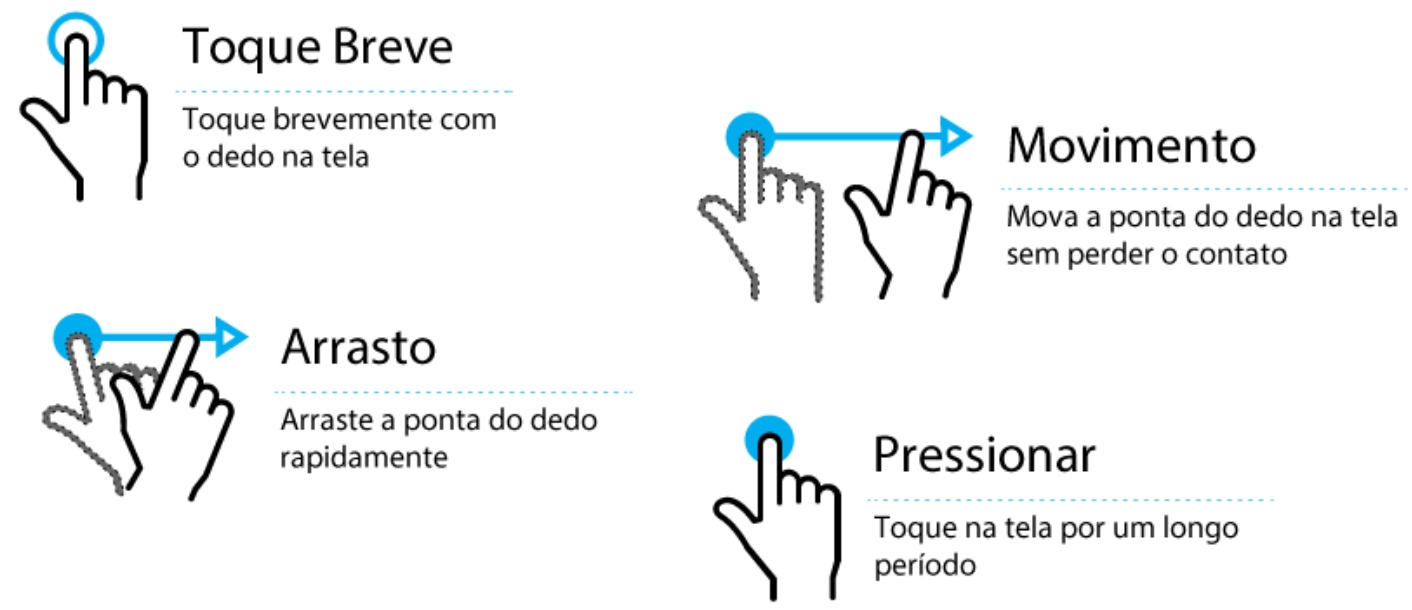

$\left\{\begin{array}{l}\text { Pressionar + Toque Breve } \\ \begin{array}{l}\text { Pressione a tela com um dedo e depois } \\ \text { toque rapidamente a tela com o segundo dedo }\end{array}\end{array}\right.$
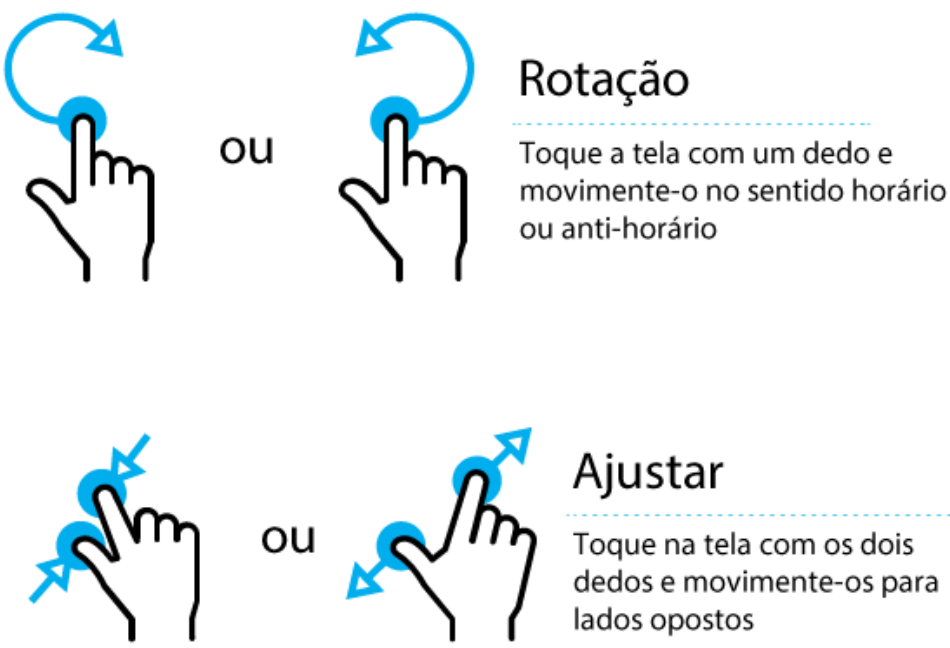

ou

\section{Ajustar}

Toque na tela com os dois dedos e movimente-os para lados opostos 


\section{Gestos Básicos}
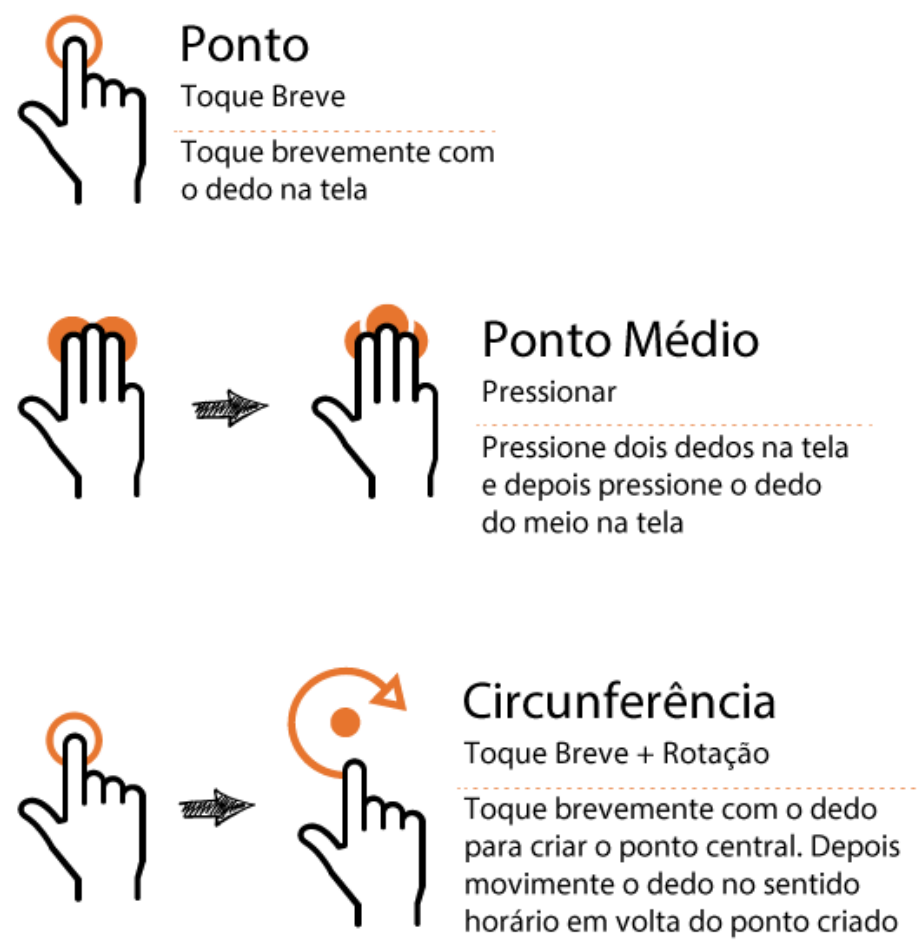

\section{Reta}

Toque Breve + Movimento

Crie dois pontos e trace uma reta passando por cima desses dois pontos. (Inicie a reta fora do raio de proximidade do primeiro ponto)

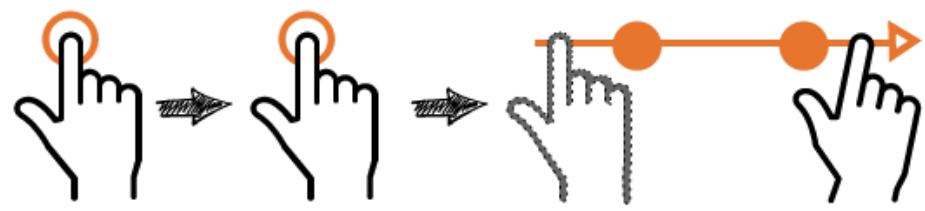




\section{Gestos Básicos}

\section{Semi-Reta}

Toque Breve + Movimento

Crie dois pontos e trace uma reta passando por cima desses dois pontos. (Inicie a reta dentro do raio de proximidade do primeiro ponto)

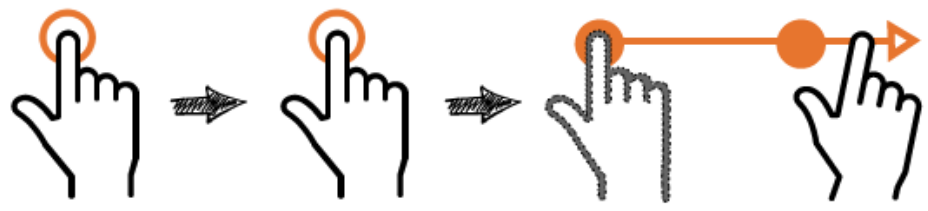

\section{Segmento de Reta}

Toque Breve + Movimento

Crie dois pontos e trace uma reta dentro do raio de proximidade desses dois pontos
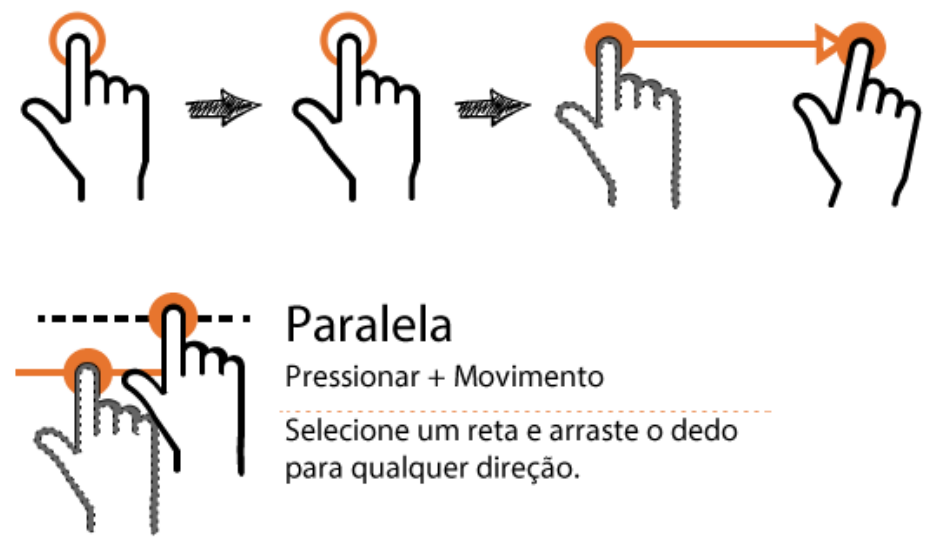

\section{Perpendicular}

Pressionar + Rotação

Segure dois pontos de uma reta e faça o movimento de rotação de 90 graus.
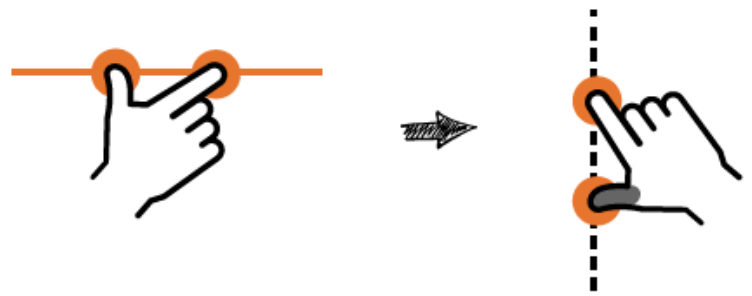


\section{Gestos de Navegação}

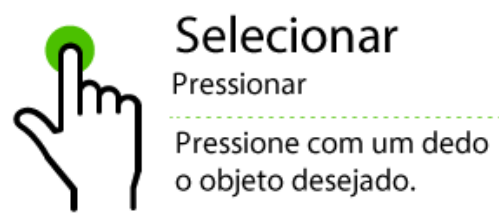
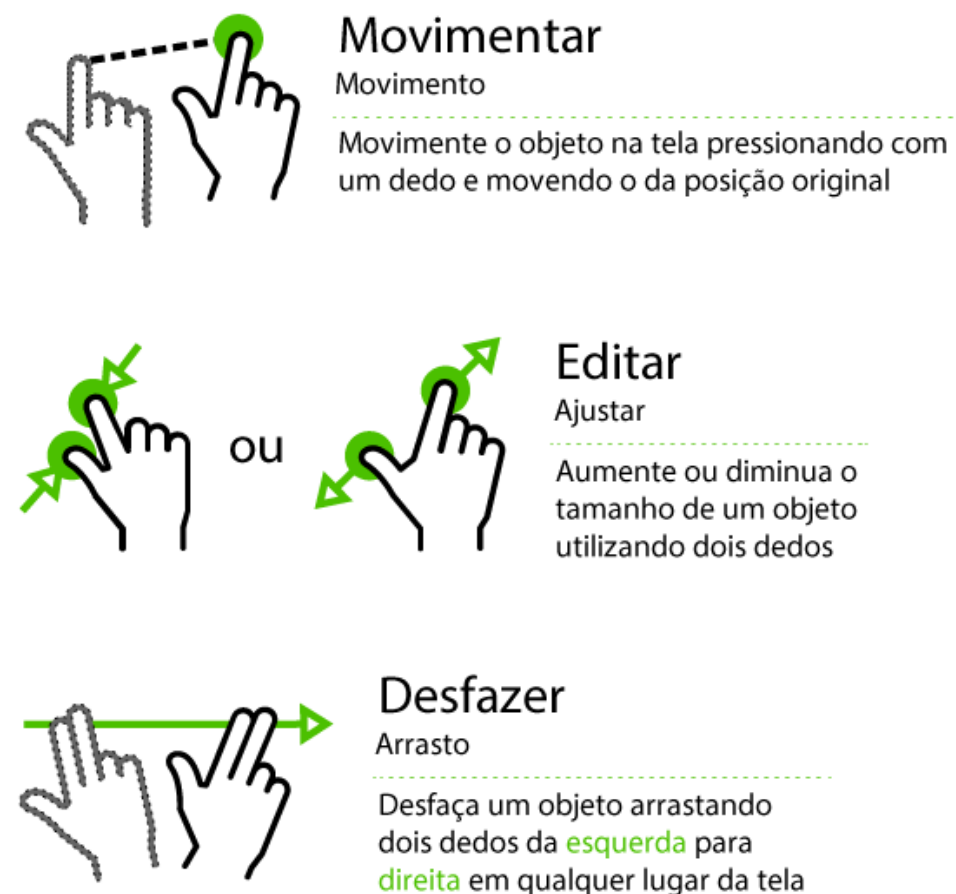

Desfazer

Arrasto

Desfaça um objeto arrastando

dois dedos da esquerda para

direita em qualquer lugar da tela

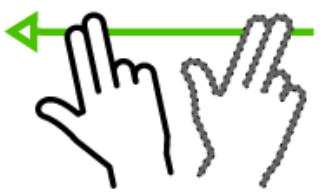

Refazer

Arrasto

Refaça um objeto arrastando dois dedos da direita para esquerda em qualquer lugar da tela 